\title{
Primary vascular access for hemodialysis treatment : a comparative study of autogenous radial-cephalic and prosthetic graft arteriovenous fistulas
}

Citation for published version (APA):

Rooijens, P. P. G. M. (2012). Primary vascular access for hemodialysis treatment : a comparative study of autogenous radial-cephalic and prosthetic graft arteriovenous fistulas. [Doctoral Thesis, Maastricht University]. Maastricht University. https://doi.org/10.26481/dis.20120913pr

Document status and date:

Published: 01/01/2012

DOI:

10.26481/dis.20120913pr

Document Version:

Publisher's PDF, also known as Version of record

Please check the document version of this publication:

- A submitted manuscript is the version of the article upon submission and before peer-review. There can be important differences between the submitted version and the official published version of record.

People interested in the research are advised to contact the author for the final version of the publication, or visit the DOI to the publisher's website.

- The final author version and the galley proof are versions of the publication after peer review.

- The final published version features the final layout of the paper including the volume, issue and page numbers.

Link to publication

\footnotetext{
General rights rights.

- You may freely distribute the URL identifying the publication in the public portal. please follow below link for the End User Agreement:

www.umlib.nl/taverne-license

Take down policy

If you believe that this document breaches copyright please contact us at:

repository@maastrichtuniversity.nl

providing details and we will investigate your claim.
}

Copyright and moral rights for the publications made accessible in the public portal are retained by the authors and/or other copyright owners and it is a condition of accessing publications that users recognise and abide by the legal requirements associated with these

- Users may download and print one copy of any publication from the public portal for the purpose of private study or research.

- You may not further distribute the material or use it for any profit-making activity or commercial gain

If the publication is distributed under the terms of Article $25 \mathrm{fa}$ of the Dutch Copyright Act, indicated by the "Taverne" license above, 


\section{Primary vascular access for hemodialysis treatment}

A comparative study of autogenous radial-cephalic and prosthetic graft arteriovenous fistulas

P.P.G.M. Rooijens 
ISBN/EAN: 978-94-6108-337-1

Lay-out and printed by: Gildeprint Drukkerijen, Enschede, the Netherlands

(C) 2012 P.P.G.M. Rooijens

This thesis was financially supported by:

W.L. Gore \& Associates, Johnson \& Johnson, Allergan, Bloomedical, Pfizer, Surgical Concepts, MediMast 


\title{
Primary vascular access for hemodialysis treatment
}

\author{
A comparative study of autogenous radial-cephalic and \\ prosthetic graft arteriovenous fistulas
}

Proefschrift

Ter verkrijging van de graad van doctor aan de Universiteit Maastricht op gezag van de Rector Magnificus, Prof. dr. L.L.G. Soete volgens het besluit van het College van Decanen, in het openbaar te verdedigen op donderdag 13 september 2012 om 16.00 uur

door

Patrick Petrus Gijsbertus Maria Rooijens

Geboren op 27 mei 1975 te Goirle 
Promotor:

Prof. dr. P.J.E.H.M. Kitslaar

Copromotores:

Dr. J.H.M. Tordoir

Dr. T.I. Yo (Maasstad Ziekenhuis, Rotterdam)

\section{Beoordelingscommissie :}

Prof. dr. M.W. de Haan (voorzitter)

Prof. dr. M. Post

Dr. F.M. van der Sande

Dr. A.A.E.A. de Smet (Maasstad Ziekenhuis, Rotterdam) 
Aan Marieke, Pepijn, Pieter en Fientje

Aan mijn ouders 
Paranimfen:

Elian J. Uitterlinden

Sander J.A. Beekmans 


\section{Contents}

Chapter 1 General introduction and outline of the thesis

Chapter 2 Radial-cephalic wrist arteriovenous fistula for hemodialysis:

meta-analysis indicates a high primary failure rate

Chapter 3 Prospective evaluation of failure modes in autogenous

radial-cephalic wrist access for hemodialysis

Chapter 4 Autogenous radial-cephalic or prosthetic brachial-antecubital forearm loop AVF in patients with compromised vessels? A randomized, multicenter study of the patency of primary hemodialysis access

Chapter 5 Current imaging techiques for stenosis detection in hemodialysis vascular access

Chapter 6 Multi-slice computed tomographic angiography for stenosis detection in forearm hemodialysis arteriovenous fistulas

Chapter 7 General discussion, conclusions and future perspectives

Chapter 8 Summary

Chapter 9 Nederlandse samenvatting

Appendices Dankwoord

Curriculum vitae

List of publications 

General introduction and outline of the thesis
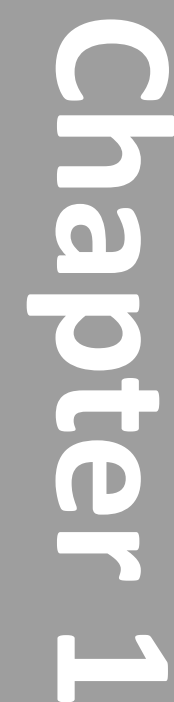
Chapter 1 


\section{End-stage renal disease}

Chronic renal disease (CRD) is increasingly recognized as a major public health problem. CRD is defined as the presence of structural abnormalities of the kidney that can lead to decreased kidney function (as measured by glomerular filtration rate). It is usually diagnosed when these abnormalities persist for more than 3 months. Markers of CRD include pathological or imaging abnormalities, frequently associated with the presence of proteinuria, arterial hypertension or renal tubular dysfunction. CRD has multiple etiologies including arteriosclerosis, diabetes, hypertension, glomerulonephritis and cystic disease, resulting in the loss of nephron number and function, leading to end-stage renal disease (ESRD). Delays in the diagnosis and prevention of progression of CRD have a key influence upon the increasing prevalence and global burden of ESRD. ${ }^{1}$

Grassmann et al. described data that showed that 1.9 million people were being treated for ESRD in 2005. Of these, 1.5 million were receiving dialysis, indicating that the proportion of patients with ESRD has an annual growth of $6-7 \% .^{2}$

Crude population data from the Dialysis Outcomes and Practice Patterns Study (DOPPS) I, II and III show that the growth rates in Europe are lower than the global average. The DOPPS reported a mean annual increase in the prevalence of ESRD of $3.66 \%$ and a mean annual increase in the incidence of ESRD of $3.01 \%{ }^{3}$ The main factors contributing to this rate of growth in ESRD also include the changing structure of population in terms of increasing age and expanding multiple comorbidities.

In the Netherlands in 2010, the prevalence of ESRD patients was 14.690 of which $43 \%$ receives dialysis therapy. ${ }^{4}$ Particularly the number of patients in the older age group of above 65 years increased dramatically from 1981 in 1999 to 5548 in 2010.

\section{Renal replacement therapy}

Patients with ESRD are permanently depending upon renal replacement therapy in order to avoid life treating uremia. ${ }^{5}$ This renal replacement therapy consists of either renal transplantation or some form of dialysis (peritoneal dialysis or hemodialysis). In peritoneal dialysis the peritoneum acts as a dialysis membrane, to remove waste products from the blood. In hemodialysis blood is withdrawn from the body through an arterial tube and transferred to the artificial kidney. After blood purification, it is returned to the body through a venous tube. For this purpose a well functioning vascular access is mandatory. 


\section{Hemodialysis vascular access}

Hemodialysis started in 1943 when William Kolff constructed an artificial kidney. He used venipuncture needles to obtain blood from the femoral artery and to reinfuse it via a cannulated vein. ${ }^{6}$ However the treatment stopped after no suitable veins were longer available.

It took 17 years before Quinton and Scribner introduced the first permanent vascular access: the Scribner shunt. This device consisted of 2 Teflon tubes connecting the patient to the dialyser; one tube was inserted near the wrist into the radial artery and one into a suitable adjacent vein. ${ }^{7}$ After hemodialysis, the circulatory access was kept open by connecting the two tubes outside the body using a small U-shaped Silastic device over a stainless steel plate. The major disadvantage of this shunt was the high risk for thrombosis and infection. In this same period Stanley Shaldon experimented with catheters which he introduced into the femoral artery and vein for immediate vascular access. ${ }^{8}$ Nowadays central vein catheters are mainly used for temporary dialysis treatment.

In 1966, Brescia, Cimino and Appel described the first internal, surgically created, arteriovenous fistula (AVF). ${ }^{9}$ They created a side-to-side anastomosis between the radial artery and the cephalic vein at the wrist (radial-cephalic arteriovenous fistula RCAVF). Other commonly used autogenous vascular accesses are brachial-cephalic, brachial-basilic and perforating vein AVFs in the elbow and upper arm. ${ }^{10-13}$

In the seventies, the arteriovenous graft (AVG) was introduced in order to create an artificial conduit for vascular access. Saphenous vein grafts, bovine heterografts, homologous vein grafts and human umbilical vein grafts have all been used for hemodialysis access. ${ }^{14-19}$ In 1976, the expanded polytetrafluorethylene (ePTFE) graft was introduced..$^{20}$ Until now it is the most used prosthetic graft for hemodialysis access. More recently, the grafts were produced from other materials such as plasma tetrafluorethylene or polyurethane. However these grafts have not proven to be superior to ePTFE. ${ }^{21-24}$

\section{Complications of arteriovenous fistulas}

Non-maturation, thrombosis, stenosis and steal syndrome are the most common complications of AVFs. Non-maturation is defined as the inability to use the AVF for hemodialysis after 6 weeks of creation. In RCAVF up to 31,5\% thrombose directly

after operation or do not function adequately due to failure of maturation. ${ }^{25-26}$ This results in delay of initiation of dialysis treatment with the need for placement of 
central venous catheters with the risk of catheter thrombosis (24-40\%), ${ }^{27-29}$ infection and sepsis $(2-18 \%)^{28-30}$ and central vein obstruction (30\%). ${ }^{31}$ Prosthetic AVGs are prone to develop arterial and/or venous stenoses, leading to flow decrease and thrombosis. However prosthetic AVGs have shorter and better maturation time and can be instantaneously used for cannulation. ${ }^{32}$

Access-related infection accounts for access failure in $20 \%$ of arteriovenous grafts, as well as a much smaller proportion of autogenous fistulas. ${ }^{33}$ Early postoperative wound infection after RCAVF and prosthetic AVF construction poses a high risk of wound dehiscense and secondary hemorrhage.

The incidence of steal syndrome, in which a considerable proportion of the arterial flow is shunted away from the distal upper extremity, resulting in peripheral ischemia, is low in distal AVFs ranging from $0.7 \%$ to $1.8 \%$ for RCAVFs and from $0.9 \%$ up to $3.5 \%$ for prosthetic forearm AVFs. ${ }^{34-35}$

\section{Imaging of access complications}

In current clinical practice, vascular access stenosis detection and grading are usually performed using duplex ultrasonography (DUS) and digital subtraction angiography (DSA). Analysis of the DSA images can be difficult due to vessel overlap, in particular at the level of the anastomoses, where multiple vessels may cross.

Relatively new minimal invasive technique for stenosis detection in hemodialysis access are magnetic resonance angiography (MRA) and multi-slice computed tomographic angiography (MS-CTA). Both techniques have three-dimensional (3D) capability to offer freely rotated projection angiograms to show vascular lesions from the appropriate perspective.

\section{Treatment of access complications}

An aggressive approach to evaluating immature fistulas for evidence of correctable abnormalities, with appropriate interventions, can improve maturation rate. ${ }^{36}$ Early detection and correction of hemodynamically significant stenosis in both autogenous and prosthetic AVFs reduces thrombosis rates. In addition, intervention with percutaneous transluminal angioplasty (PTA) or surgical revision to correct stenosis reduces the rate of AVF thrombosis. ${ }^{37-41}$ This pre-emptive correction of AVF at risk for thrombosis should have the additional economic impact of reducing emergency admissions due to access thrombosis, reducing the need for temporary central vein catheters with their attendant complications, and preventing underdialysis with its associated morbidity and mortality rates. 
Early postoperative wound infection requires treatment with intravenous antibiotics and drainage of pus collections. Late-onset infections of prosthetic AVFs often occur at cannulation sites and may resolve with simple antibiotic therapy, eventually combined with segmental graft replacement through a new subcutaneous route. ${ }^{42-43}$ In case of severe infection and risk of sepsis, graft explantation is required.

In a proportion of patients with steal syndrome symptoms improve without treatment but if they persist treatment options include flow-reducing operations with banding or plication of the AVF, with intraoperative flow monitoring to assess the required degree of luminal narrowing. In addition, distal arterial ligation and jump graft insertion to bypass the AV anastomosis are good options with acceptable results. If such interventions are unsuccessful, ligation of the fistula is required.

\section{Current guidelines}

European and American guidelines recommend the RCAVF at the wrist and the brachial-cephalic arteriovenous fistula at the elbow as the primary and secondary access options for hemodialysis treatment. ${ }^{44-46}$ The brachial-basilic arteriovenous fistula is the tertiary option, when the above options are not possible or have failed. As last resort the implantation of a prosthetic PTFE arteriovenous graft can be considered.

In case of tiny or diseased arteries and/or veins, the risk on access failure is probably higher and an alternative vascular access may be considered. However, there are only few data on the outcome of RCAVFs in patients with poor or doubtfull vessels and also information on the performance of prosthetic accesses in these patients is lacking. In addition, upper arm access has a considerably higher incidence of peripheral limb ischemia and cardiac failure due to high access flow. ${ }^{47-52}$ Therefore one may consider to primarily implant a prosthetic graft. Also, no specific recommendations are found in American or European guidelines for elderly patients with ESRD. ${ }^{46-53}$ By following these guidelines, selection of a RCAVF in elderly patients will be associated with an increased primary failure rate, necessitating a subsequent access procedure. That will, in particular, adversely affect the late referrals who have already started dialysis because a prolonged period with temporary central vein catheters and their associated complications will be required. ${ }^{54} \mathrm{~A}$ meta-analysis performed by Lazarides et al., confirmed the higher rate of RCAVF failure in elderly patients compared with non-elderly adults at 12 and 24 months. ${ }^{55}$ 


\section{The current thesis}

This thesis studies the outcome of forearm autogenous RCAVF versus forearm prosthetic AVG for hemodialysis access. As the primary failure chance of RCAVFs is high, as alternative a prosthetic vascular access was used in patients with poor vessels. Therefore, the results and long-term patency of both access modalities are assessed.

\section{Aims of this thesis}

1. To systematic review the literature to improve the precision of the estimates of primary failure rates and primary and secondary 1 year patency of RCAVFs for hemodialysis

2. To search for failure modes of autogenous RCAVFs and the impact of interventions on early fistula function.

3. To prospectively determine in a randomised study if patients with poor forearm vessels do benefit from implantation of a forearm prosthetic AVG for vascular access.

4. To review the current imaging techniques for stenosis detection in RCAVF and prosthetic AVG.

5. To assess the accuracy of MS-CTA for the detection and grading of stenoses in AVF in comparison with DSA.

\section{Outline of the thesis}

The RCAVF is still considered as the optimal first choice for an autogenous hemodialysis access. ${ }^{44-46}$ However, the RCAVF suffers from a high incidence of primary failure, due to early thrombosis or failure to mature. ${ }^{25-26}$ Estimates of primary failure, primary patency and secondary patency vary considerably. An important source of that variability is the lack of precision in individual studies. Therefore, we report in Chapter $\mathbf{2}$ the result of a systematic review, which improves the precision of the estimates of primary failure rates and primary and secondary 1 year patency of RCAVFs for hemodialysis. Chapter 3 provides insight into the early failure modes of autogenous RCAVFs and the impact of interventions on fistula salvage. Chapter 4 addresses a randomised multicenter study comparing autogenous RCAVFs and prosthetic brachial-antecubital forearm loop in patients with compromised vessels, focusing on patency rates, complications and interventions. 
Chapter 5 reviews the current imaging modalities for stenosis detection in hemodialysis vascular access. DSA and DUS investigation are the most accepted and employed techniques for assessment of vascular access. On lesser scale MRA en MSCTA has been used. In Chapter 6 the results of an alternative method of diagnosing the extent and severity of AVF stenoses with MS-CTA is described. MS-CTA offers the ability to acquire 3D data sets, which may potentially solve the problem of vessel overlap and increase the diagnostic accuracy. We conducted a prospective study to assess the accuracy of MS-CTA for detection and grading of stenoses in RCAVF and AVG in comparison to DSA, which was used as the gold standard of reference. Chapter 7 includes a general discussion of the findings of this thesis and those reported in the recent literature, future perspectives, and conclusions. Chapter $\mathbf{8}$ summarizes this thesis. 


\section{References}

1. Meguid El Nahas A, Bello AK. Chronic kidney disease: the global challenge. Lancet 2005;365:331-340.

2. Grassmann A, Gioberge S, Moeller S, Brown G. End-stage renal disease: global demographics in 2005 and observed trends. Artif Organs 2006;30:895-897.

3. Dor A, Pauly MV, Eichleay MA, Held PJ. End-stage renal disease and economic incentives: the International Study of Health Care Organization and Financing (ISHCOF). Int J Health Care Finance Econ 2007;7:73-111.

4. Stichting Renine, Rotterdam. Available at www.renine.nl. Accessed September 21, 2011.

5. Harrison TR, Braunwald E, eds. Harrison's principles of internal medicine. $15^{\text {th }}$ ed. New York: McGraw-Hill;2001.

6. Kolff WJ. First Clinical Experience with the Artificial Kidney. Ann Intern Med 1965;62:608619.

7. Quinton W, Dillard D, Scribner BH. Cannulation of blood vessels for prolonged hemodialysis. Trans Am Soc Artif Intern Organs 1960;6:104-113.

8. Shaldon S. Chiandussi L, Higgs B. Haemodialysis by percutaneous catheterisation of the femoral artery and vein with regional heparinisation. The Lancet 1961;2:857-859.

9. Brescia MJ, Cimino JE, Appel K, Hurwich BJ. Chronic hemodialysis using venipuncture and a surgically created arteriovenous fistula. N Eng J Med 1966;275:1089-1092.

10. Dagher F, Gelber R, Ramos E, Sadler J. The use of basilica vein and brachial artery as an A-V fistula for long term hemodialysis. J Surg Res 1976;20:373-376.

11. Cantelmo NL, LoGerfo FW, Menzoian JO. Brachiobasilic and brachiocephalic fistulas for secondary angioaccess routes. Surg Gynecol Obstet 1982;155:545-548.

12. Dunlop MG, Mackinlay JY, Jenkins AM. Vascular access: experience with the brachiocephalic fistula. Ann R Coll Surg Engl 1986;68:203-206.

13. Gracz KC, Ing TS, Soung LS, Armbuster KF, Seim SK, Merkel FK. Proximal forearm fistula for maintenance hemodialysis. Kidney Int 1977;11:71-75.

14. May J, Tiller D, Johnson J, Stewart J, Sheil AG. Saphenous-vein arteriovenous fistula in regular dialysis treatment. N Eng J Med 1969;280:770.

15. Yokoyama T, Bower R, Chinitz J, Schwartz A, Swartz C. Experience with 100 bovine arteriografts for maintenance hemodialysis. Trans Am Soc Artif Intern Organs 1974;20:328-333.

16. Butler HG $3^{\text {rd }}$, Baker LD Jr, Johnson JM. Vascular access for chronic hemodialysis; polytetrafluorethylene (PTFE) versus bovine heterograft. Am J Surg 1977;134:791-793.

17. Bonnaud P, Messier D, Man NK. Manufactured homologous vein graft for creation of arterio-venous fistula. Proc Eur Dial Transplant Assoc 1980;17:303-305.

18. Rubio PA, Farrell EM. Modified human umbilical vein arteriovenous fistula for maintenance hemodialysis: a 31/2-year experience. Arch Surg 1982;117:943-945.

19. Zuhlke HV, Anders A, Haring R. Arterio-venous fistulas constructed with formalin-fixed human umbilical grafts. Proc Eur Dial Transplant Assoc 1980;17:297-302.

20. Baker LD Jr., Johnson JM, Goldfarb D. Expanded polytetraflourethylene (PTFE) subcutaneous arteriovenous conduit: an improved vascular access for chronic hemodialysis. Trans Am Soc Artif Intern Organs 1976;22:382-387.

21. Helling TS, Nelson PW, Shelton L. A prospective evaluation of plasma-TFE and expanded PTFE grafts for routine and early use as vascular access during hemodialysis. Ann Surg 1992;216:596-599. 
22. Barron PT, Wellington JL, Lorimer JW, Cole CW, Moher D. A comparison between expanded polutetrafluorethylene and plasma tetrafluorethylene grafts for hemodialysis access. Can J Surg 1993;36:184-186.

23. Nakagawa Y, Ota K, Sato Y, Teraoka S, Agishi T. Clinical trial of new polyurethane vascular grafts for hemodialysis: compared with expanded polytetrafluorethylene grafts. Artif Organs 1995;19:1227-1232.

24. Kiyama H, Imazeki T, Kurihara S, Yoneshima H. Long-term follow-up of polyurethane vascular grafts for hemoaccess bridge fistulas. Ann Vasc Surg 2003;17:516-521.

25. Dixon BS, Novak L, Fangman J. Hemodialysis vascular access survival: upper-arm native arteriovenous fistula. Am J Kidney Dis 2002;39:92-101.

26. Zeebregts C, van den Dungen J, Bolt A, Franssen C, Verhoeven E, van Schilfgaarde R. Factors predictive of failure of Brescia-Cimino arteriovenous fistulas. Eur J Surg 2002;168:29-36.

27. McLaughlin K, Jones B, Mactier R, Porteus C. Long-term vascular access for hemodialysis using silicon dual-lumen catheters with guidewire replacement of catheters for technique salvage. Am J Kidney Dis 1997;29:553-559.

28. McDowell DE, Moss AH, Vasilakis C, Bell R, Pillai L. Percutaneously placed dual-lumen silicone catheters for long-term hemodialysis. Am Surg 1993;59:569-573.

29. Moss AH, McLaughlin MM, Lempert KD, Holley JL. Use of a silicone catheter with a Dacron cuff for dialysis short-term vascular access. Am J Kidney Dis 1988;12:492-498.

30. Dryden MS, Samson A, Ludlam HA, Wing AJ, Phillips I. Infective complications associated with the use of the Quinton 'Permacath' for long-term central vascular access in haemodialysis. J Hosp Infect 1991;19:257-262.

31. Grote J, Lufft V, Nikutta P, van der Lieth H, Bahlmann J, Daniel WG. Transesophageal echocardiographic assessmant of superior vena cava thrombosis in patients with longterm central venous hemodialysis catheters. Clin Nephrol 1994;42:183-188.

32. Fitzgerald JT, Schanzer A, McVicar JP, Chin AL, Perez RV, Troppmann C. Upper arm arteriovenous fistula versus forearm looped arteriovenous graft for hemodialysis access: a comparative analysis. Ann Vasc Surg 2005;19:843-850.

33. Berkoben M, Schwab SJ. Maintenance of permanent hemodialysis vascular access patency. J Am Nephrol Nurses Assoc 1995;22:17-24.

34. Zibari GB, Rohr MS, Landreneau MD, Bridges RM, DeVault GA, Petty FH, et al. Complications form permanent hemodialysis vascular access. Surgery 1988;104:681686.

35. Winsett OE, Wolma FJ. Complications of vascular access for hemodialysis. South Med J 1985;78:513-517.

36. Beathard GA, Settle SM, Shields MW. Salvage of the nonfunctioning arteriovenous fistula. Am J Kdiney Dis 1999;33:910-916.

37. Safa AA, Valji K, Roberts AC, Ziegeler TW, Hye RJ, Oglevie SB. Detection and treatment of dysfunctional hemodailysis access grafts: effect of a surveillance program on graft patency and the incidence of thrombosis. Radiology 1996;199:653-657.

38. Burger H, Zijlstra JJ, Kluchert SA, Scholten AP, Kootstra G. Percutaneous transluminal angioplasty improves longevity in fistulae and shunts for haemodialysis. Nephrol Dial Transplant 1990;5:608-611. 
39. Schwab SJ, Raymond JR, Saeed M, Newman DE, Dennis PA, Bollinger RR. Prevention of haemodialysis fistula thrombosis. Early detection of fistula stenoses. Kidney Int 1989; 36:707-711.

40. Turmel-Rodriques L, Pengloan J, Blanchier D, Abaza M, Birmele B, Haillot O, et al. Insufficient dialysis shunts: improved long-term patency rates with close hemodynamic monitoring, repeated percutaneous balloon angioplasty, and stent placement. Radiology 1993;187:273-278.

41. GlanzS, Gordon DH, Butt KMH, Hong J, Lipkowitz GS. The role of percutaneous angioplasty in the management of chronic hemodialysis fistulas. Ann Surg 1987;206:777-781.

42. Raju S. PTFE graft for hemodialysis access. Techniques for insertion and management of complications. Ann Surg 1987;206:666-673.

43. Fillinger MF, Reinitz ER, Schwartz RA, Resetarits DE, Paskanik AM, Bruch D, et al. Graft geometry and venous intimal-hyperplasia in arteriovenous loop grafts. J Vasc Surg 1990;11:556-566.

44. Tordoir J, Canaud B, Haage P, Konner K, Basci A, Fouque D et al. EBPG on Vascular Access. Nephrol Dial Transplant 2007;22:88-117.

45. Tordoir JH, Mickley V. European guidelines for vascular access: clinical algorithms on vascular access for hemodialysis. Edtna Erca J 2003;29:131-136.

46. Besarab A, Work J, Brouwer D, Bundman TE, Dinwiddie LC, Goldstein SL. Clinical Practice Guidelines for Hemodialysis Adequacy, Update 2006. Am J Kidney Dis 2006;48:S176247.

47. Anderson CB, Codd JR, Graff RA, Grace MA, Harter HR, Newton WT. Cardiac failure and upper extremity arteriovenous dialysis fistulas. Case reports and a review of the literature. Arch Intern Med 1976;136:292-297.

48. MacRea JM, Pandeya S, Humen DP, Krivitski N, Lindsay RM. Arteriovenous fistulaassociated high output cardiac failure: a review of mechanisms. Am J Kidney Dis 2004;43:e17-22.

49. Levine MP. The hemodialysis patient a hand amputation. Am J Nephrol 2001;21:498501.

50. Morsy AH, Kulbaski $M$, Chen $\mathrm{C}$, Isiklar $\mathrm{H}$, Lumsden AB. Incidence and characteristics of patients with hand ischemia after a hemodialysis access procedure. J Surg Res 1998;74:8-10.

51. Tordoir JH, Dammers R, van der Sande FM. Upper extremity ischemia and hemodialysis vascular access. Eur J Vasc Endovasc Surg 2004;27:1-5.

52. NKF-DOQI clinical practice guidelines for vascular access. National Kidney FoundationDialysis Outcomes Quality Initiative. Am J Kidney Dis 1997;30:S150-S191.

53. Vascular Access Society. Clinical algorithms on vascular access for hemodialysis. Available at www.vascularaccesssociety.com. Accessed September 21, 2011.

54. Xue JL, Dahl D, Ebben JP, Collins AJ. The association of initial hemodialysis access type with mortality outcome in elderly Medicare ESRD patients. Am J Kidney Dis 2003;42:1013-1019.

55. Lazarides MK, Georgiadis GS, Antoniou GA, Staramos DM. A meta-analysis of dialysis access outcome in elderly patients. J Vasc Surg 2007;45:420-426. 



\section{Radial-cephalic wrist arteriovenous}

fistula for hemodialysis: meta-analysis indicates a high primary failure rate 


\begin{abstract}
Objective: To improve the precision of the estimates of primary failure rates and primary and secondary 1 year patency of radial-cephalic arteriovenous fistulas (RCAVF) for hemodialysis.
\end{abstract}

Design: Meta-analysis.

Materials and Methods: A Medline search was performed of the English language medical literature between January 1970 and October 2002. Key words that were searched included radial-cephalic fistula, arteriovenous shunt, Brescia-Cimino fistula and patency. Primary failure, primary and secondary patency rates were analysed using the standard mixed effects model, which allows variability between the different studies.

Results: Eight prospective and 30 retrospective studies were included. The analysis showed a pooled estimated primary failure rate of $15.3 \%$ (95\% Cl:12.7\%-18.3\%). In addition, the pooled estimated primary and secondary patency rates of $62.5 \%$ (95\% $\mathrm{Cl}: 54.0 \%-70.3 \%)$ and $66.0 \%$ (95\% Cl:58.2\%-73.0\%) respectively were calculated. Subgroup analysis concerning various study characteristics, including study year, gender and age, did not reveal statistically significant differences.

Conclusion: Although, the autogenous RCAVF is considered to be the primary choice for vascular access, this meta-analysis indicates a high primary failure rate and only moderate patency rates at 1 year of follow-up. 


\section{Introduction}

Use of the radial-cephalic arteriovenous fistula (RCAVF) as an autologous vascular access for hemodialysis dates back to the mid $1960 \mathrm{~s}^{1}$. Once established, it has the advantage of good long-term survival, and a low complication rate. Therefore the RCAVF is considered the optimal first choice for an autologous hemodialysis fistula. However, the RCAVF suffers from a high incidence of primary failure, due to early thrombosis or failure to mature.

Estimates of primary failure, primary patency and secondary patency vary considerably. An important source of that variability is a lack of precision in individual studies.

In the present study, we aggregate primary failure rates and primary and secondary patency data at 1 year of follow up from various publications considering RCAVFs for hemodialysis, with the primary objective to improve the precision of the estimates of these parameters. The analysis provides important pieces of information that in the future will be incorporated in a decision model we are developing to compare effects of various treatment strategies for patients who need a vascular access for hemodialysis. In addition to improving the precision, a meta-analysis offers the opportunity to explore questions that could not be answered by the original studies by determining the effect of particular study characteristics on the overall results. In the present analysis we examined the effect of various study characteristics, including study year, gender and age.

\section{Methods}

\section{Data sources and data extraction}

A Medline search was performed of the English language medical literature between January 1970 and October 2002. Key words that were searched included radialcephalic fistula, arteriovenous shunt, Brescia-Cimino fistula and patency. This electronic database search was supplemented by manual search of bibliographic reference lists in review articles and original articles.

Studies that reported patency or primary failure data of RCAVFs were included if: (1) the patient and study characteristics were reported in sufficient detail to allow for adjustment for the case mix and the reporting methods in the analysis and (2) if the RCAVF was created at the wrist. In instances in which more than one publication from the same institution was available, we included only the most recent publication 
from that institution, unless evidence was available that the patient population did not overlap. Because there are only a few prospective studies ${ }^{2-9}$, we also included retrospective studies in this meta-analysis. ${ }^{10-39}$ Studies with insufficient information on the location of the constructed autogenous arteriovenous fistula were excluded. Also publications were excluded if the arteriovenous fistula was created in the anatomical snuff box, upper arm or in the antecubital fossa.

In many of the studies that were included, the results of the RCAVFs were reported together with those of other types of autogenous arteriovenous fistulas. Only when it was possible to separate the results of the RCAVFs from those of the other types these studies were included.

The methodologic quality of included trials was assessed independently by two reviewers, which resolved any discrepancies by discussion and consensus.

Nine prospective studies and 37 retrospective studies were identified as possible candidates for this meta-analysis. One prospective study and seven retrospective sudies were excluded, so that eight prospective and 30 retrospective studies were included in this meta-analysis.

A standard form was used to extract the data from the articles, including characteristics of study design, reporting methods, study population, patency data.

We repeated the analysis for subgroups defined by characteristics that might be of additional influence on the primary failure and patency rates. For example, we examined whether patency rates reported in studies which were performed before 1981, differ from studies reported from 1981 up to 1991 or differ from studies started after 1991. Other characteristics that were examined in subgroup analyses include the average age of the study population ( $\leq 50$ years vs $>50$ years) and the percentage of women in the study ( $\leq 40 \%$ vs $>40 \%$ ). Both cutoff points are median values of all studies together.

\section{Outcome measures}

The primary outcome measures were primary failure, primary patency and secondary patency at one year of follow up. For the purpose of this analysis, primary patency was defined as the interval from the time of RCAVF creation until any intervention designed to maintain or reestablish patency, access thrombosis, or the time of measurement of patency. Secondary patency was defined as the interval from the time of RCAVF creation until access abandonment, thrombosis, or the time of patency measurement including intervening manipulations (surgical or endovascular interventions) designed to reestablish functionality in thrombosed access. ${ }^{40}$ Primary failure was defined as fistula thrombosis, or failure to mature which results in inadequate functioning for hemodialysis after 6 weeks of creation. 


\section{Data analysis}

Primary failure, primary and secondary patency rates were analysed using the standard mixed effects model, which allows variability in the true study specifics rates. ${ }^{41}$ The estimated percentages and standard errors were transformed to the logit scale, then the analysis was carried out using SAS Proc Mixed. ${ }^{42}$ Next the results were transformed back. The method allowed the specification of covariates (metaregression) in order to search for the effect of possible explanatory variables.

To assess publication bias, funnel plots were made accompanied by the linear regression test on symmetry. ${ }^{43}$

Throughout this report, two sided $P$-values are reported, except for between study variances. A $P$-value of $<0.05$ was considered to be statistically significant.

\section{Results}

Nine prospective studies and 37 retrospective studies were identified as possible candidates for this meta-analysis. In many studies, the results of RCAVFs were reported together with other types of AVFs, such as AVFs created in the anatomical snuff-box. Wherever possible, we separated the results of the different AVFs. However when this was not possible, these studies were excluded. Therefore, eight prospective and 30 retrospective studies met the inclusion criteria. Table 1 lists patient characteristics of the included prospective studies, ordered by calender years in which the study started and finished.

\begin{tabular}{|c|c|c|c|c|c|c|}
\hline Author & Study years & $\begin{array}{l}\text { Number of } \\
\text { patients }\end{array}$ & $\begin{array}{l}\text { Number of } \\
\text { RCAVFs }\end{array}$ & $\begin{array}{c}\text { Male } \\
\%\end{array}$ & $\begin{array}{c}\text { Mean age } \\
\text { (years) }\end{array}$ & $\begin{array}{l}\text { Age range } \\
\text { (years) }\end{array}$ \\
\hline Reilly et. al. ${ }^{2}$ & $1976-1981$ & 145 & 145 & - & - & - \\
\hline Wetzig et. al. ${ }^{3}$ & $1979-1983$ & 85 & 100 & 48 & 50.5 & $16-69$ \\
\hline Wedgwood et. al. ${ }^{4}$ & $1981-1983$ & 71 & 71 & 68 & - & - \\
\hline Dixon et. al. ${ }^{5}$ & 1992-1998 & 73 & 73 & 82 & 51.6 & - \\
\hline Golledge et. al. ${ }^{6}$ & 1993-1996 & 107 & 107 & 68 & 63 & - \\
\hline Malovrh ${ }^{7}$ & 1993-1997 & 116 & 116 & 47 & 51.4 & $15-81$ \\
\hline Lin et. al. ${ }^{8}$ & 1994-1995 & 176 & 176 & 45 & 57.8 & $20-86$ \\
\hline Wong et. al. ${ }^{9}$ & 1996 & 60 & 60 & 62 & 58.4 & $17-77$ \\
\hline
\end{tabular}

Table 1. Prospective studies regarding the outcome of RCAVFs for hemodialysis. 
During the search for candidate studies for this meta-analysis, we noticed that most studies, which report on patency rates of RCAVFs, were in a retrospective setting. Therefore these studies were separately included in the analysis, and in a subgroup analysis we carefully examined whether their results differed from the prospective group. Table 2 lists patient characteristics of the retrospective studies, ordered by calender years in which the study started and finished.

In table 3 the primary failure rates and the primary and secondary patency rates at one year as reported in the prospective studies are presented. In all prospective studies a primary failure rate is reported. Only one study reported a secondary patency rate at 1 year, and another study reported also a primary patency rate at one year. Two studies reported both primary and secondary patency rates. Primary failure rates differ significantly among these studies. On one hand Wetzig et al. reported a low primary failure rate of $9.4 \%,{ }^{3}$ on the other hand Dixon et al. reported a very high primary failure rate of $31.5 \% .^{5}$

Table 4 lists the primary failure rates and the primary and secondary patency rates at one year as reported in the various retrospective studies. In all retrospective studies, except for six, primary failure rate was reported. Four studies reported also primary patency at one year and 11 studies reported also secondary patency at one year. Only in two studies, both primary and secondary patency at one year were reported. 


\begin{tabular}{|c|c|c|c|c|c|c|}
\hline Author & Study years & $\begin{array}{l}\text { Number of } \\
\text { patients }\end{array}$ & $\begin{array}{l}\text { Number of } \\
\text { RCAVFs }\end{array}$ & $\begin{array}{c}\text { Male } \\
\%\end{array}$ & $\begin{array}{l}\text { Mean age } \\
\text { (years) }\end{array}$ & $\begin{array}{l}\text { Age range } \\
\text { (years) }\end{array}$ \\
\hline Cohen et. al. ${ }^{10}$ & $1966-1967$ & 19 & 22 & 59 & - & $18-58$ \\
\hline Röhl et. al. ${ }^{11}$ & $1966-1967$ & 30 & 30 & - & - & - \\
\hline Kinnaert et. al. ${ }^{12}$ & $1966-1975$ & 202 & 202 & 62 & - & $16-69 *$ \\
\hline Tellis et. al. ${ }^{13}$ & $1968-1971$ & 59 & 59 & 59 & - & $14-55$ \\
\hline Zerbino et. al. ${ }^{14}$ & $1968-1974$ & 160 & 160 & $99 *$ & - & $19-77^{*}$ \\
\hline Thompson et. al. ${ }^{15}$ & $1970-1972$ & 77 & 77 & - & - & - \\
\hline Cheek et. al. ${ }^{16}$ & 1970-1973 & 84 & 84 & - & - & - \\
\hline Lindfors et. al. ${ }^{17}$ & $1970-1973$ & 45 & 45 & 67 & 42 & $18-67$ \\
\hline Paruk et. al. ${ }^{18}$ & 1971-1974 & 108 & 108 & - & - & - \\
\hline Tordoir et. al. ${ }^{19}$ & 1971-1981 & 114 & 129 & 47 & 48.5 & $16-75$ \\
\hline Burger et. al. ${ }^{20}$ & 1971-1991 & 208 & 208 & $56^{*}$ & $46^{*}$ & $7-80 *$ \\
\hline Thomsen et. al. ${ }^{21}$ & $1972-1978$ & 191 & 191 & 56 & 49.1 & $7-74$ \\
\hline Alm et. al. ${ }^{22}$ & $1972-1974$ & 67 & 67 & 48 & 48 & $12-67$ \\
\hline Rohr et. al. ${ }^{23}$ & 1973-1976 & 126 & 126 & - & $49 *$ & $14-82$ \\
\hline Fernström et. al. ${ }^{24}$ & $1975-1985$ & 71 & 83 & 73 & 50 & $22-73$ \\
\hline Kherlakian et. al. ${ }^{25}$ & $1977-1983$ & 106 & 106 & 61 & 50 & $17-80$ \\
\hline Simoni et. al. ${ }^{26}$ & 1979-1989 & 248 & 248 & 54 & 53 & $19-83$ \\
\hline Enzler et. al. ${ }^{27}$ & 1980-1992 & 412 & 412 & $55^{*}$ & $43.9 *$ & $7-81^{*}$ \\
\hline Cassioumis et. al. ${ }^{28}$ & 1981-1992 & 173 & 173 & - & $55^{*}$ & $13-85^{*}$ \\
\hline Al-Mohoya et. al. ${ }^{29}$ & $1983-1988$ & 112 & 112 & 60 & - & $13-75$ \\
\hline Sparks et. al. ${ }^{30}$ & $1983-1993$ & 147 & 147 & $58^{*}$ & $53.8^{*}$ & $18-79 *$ \\
\hline Nazzal et. al. ${ }^{31}$ & 1988-1989 & 85 & 85 & $61^{*}$ & $37^{*}$ & $7-70^{*}$ \\
\hline Leapman et. al. ${ }^{32}$ & 1989-1994 & 144 & 150 & 73 & 50.1 & $19.2-87.5$ \\
\hline Prischl et. al. ${ }^{33}$ & 1989-1994 & 123 & 123 & $63^{*}$ & $54.2^{*}$ & $17-85^{*}$ \\
\hline Miller et. al. ${ }^{34}$ & 1990-1994 & 41 & 41 & $45^{*}$ & $64.4^{*}$ & $33-90 *$ \\
\hline Bender et. al. ${ }^{35}$ & 1993 & 56 & 56 & $56^{*}$ & $62^{*}$ & $7-83^{*}$ \\
\hline Lin et. al. ${ }^{36}$ & 1994-1995 & 126 & 126 & 44 & - & $20-83$ \\
\hline Zeebregts et. al. ${ }^{37}$ & 1995-1999 & 150 & 153 & 63 & 56 & $17-80$ \\
\hline Ascher et. al. ${ }^{38}$ & 1996-1999 & 47 & 47 & $54 *$ & $69 *$ & $28-95^{*}$ \\
\hline Hingorani et. al. ${ }^{39}$ & $1997-2001$ & 206 & 206 & - & $68^{*}$ & 29-94* \\
\hline
\end{tabular}

Table 2. Retrospective studies regarding the outcome of RCAVFs for hemodialysis. * Based on all patients reported in the study, including patients with other procedures. 


\begin{tabular}{|c|c|c|c|}
\hline Author & $\begin{array}{c}\text { primary failure } \\
\text { rate (\%) }\end{array}$ & $\begin{array}{l}\text { primary patency } \\
\text { rate at } 1 \text { year }(\%)\end{array}$ & $\begin{array}{c}\text { secondary patency } \\
\text { rate at } 1 \text { year }(\%)\end{array}$ \\
\hline Reilly et. al. ${ }^{2}$ & 11 & - & 80 \\
\hline Wetzig et. al. ${ }^{3}$ & 9.4 & 78 & - \\
\hline Wedgwood et. al. ${ }^{4}$ & 9.9 & - & - \\
\hline Dixon et. al. ${ }^{5}$ & 31.5 & 44 & 52 \\
\hline Golledge et. al. ${ }^{6}$ & 18 & 69 & 70 \\
\hline Malovrh ${ }^{7}$ & 19.8 & - & - \\
\hline Lin et. al. ${ }^{8}$ & 13.6 & - & - \\
\hline Wong et. al. ${ }^{9}$ & 29.6 & - & - \\
\hline
\end{tabular}

Table 3. Primary failure rates and primary and secondary patency rates at 1 year as reported in the prospective studies

In all 8 prospective studies and in 30 retrospective studies a primary failure rate was reported. The estimated mean primary failure rate, based on the data from the prospective studies, does not statistically differ from that based on the retrospective studies ( $16.9 \%$ vs $14.7 \% ; P=0.51$ ). Therefore we pooled the data of the 38 studies, and the overall mean primary failure rate was estimated as $15.3 \%$ (95\% Cl:12.7\%$18.3 \%)$. There was very significant $(P<0.0001)$ heterogeneity between the study specific primary failure rates. The range covering $95 \%$ of the study specific primary failure rates was estimated as $6 \%$ to $34 \%$. In addition the estimated primary patency rate at one year, based on the retrospective studies does not statistically significantly differ from that based on the data from the retrospective studies $(64.6 \%$ vs $61.5 \%$; $P=0.73)$. The pooled primary patency rate at one year based on the retrospective studies together with the prospective studies is $62.5 \%(95 \% \mathrm{Cl}: 54.0 \%-70.3 \%)$. Again the between studies heterogeneity was very significant $(P<0.0001)$, resulting in an estimated $95 \%$ range for the study specific primary failure running from $39 \%$ to $82 \%$. Also no statistically significant difference was found between the estimated secondary patency at one year based on the prospective studies and that based on the retrospective studies $(68.5 \%$ vs $65.5 \% ; P=0.75)$. The pooled estimated secondary patency at one year is $66.0 \%$ (95\% $\mathrm{Cl}: 58.2 \%-73.0 \%)$. The between studies heterogeneity was very significant $(P<0.0001)$, resulting in an estimated $95 \%$ range for the study specific primary failure running from $36 \%$ to $87 \%$.

Several subgroup analyses were performed. The pooled results from the studies that included $40 \%$ or less women were in close agreement with those of studies with more than $40 \%$ women. The estimated primary failure rate was $16.3 \%$ vs. $15.9 \%$ $(P=0.09)$. Also the estimated primary patency rate at one year $(53.1 \%$ vs. $69.1 \%$; $P=0.07)$ and the estimated secondary patency rate at one year $(60.9 \%$ vs. $64.8 \%$; $P=0.66)$ did not differ significantly between these two groups. 


\begin{tabular}{|c|c|c|c|}
\hline Author & $\begin{array}{l}\text { primary failure } \\
\text { rate (\%) }\end{array}$ & $\begin{array}{l}\text { primary patency } \\
\text { rate at } 1 \text { year }(\%)\end{array}$ & $\begin{array}{l}\text { secondary patency } \\
\text { rate at } 1 \text { year (\%) }\end{array}$ \\
\hline Cohen et. al. ${ }^{10}$ & 13.6 & - & - \\
\hline Röhl et. al. ${ }^{11}$ & 10 & - & - \\
\hline Kinnaert et. al. ${ }^{12}$ & 8.6 & - & - \\
\hline Tellis et. al. ${ }^{13}$ & 23.7 & - & 32.2 \\
\hline Zerbino et. al. ${ }^{14}$ & 8.8 & - & - \\
\hline Thompsonet. al. ${ }^{15}$ & 13.0 & - & - \\
\hline Cheek et. al. ${ }^{16}$ & 3.6 & - & - \\
\hline Lindfors et. al. ${ }^{17}$ & 15.6 & - & - \\
\hline Paruk et. al. ${ }^{18}$ & 15.7 & - & 75.9 \\
\hline Tordoir et. al. ${ }^{19}$ & 10 & - & $80^{+}$ \\
\hline Burger et. al. ${ }^{20}$ & 6.3 & 53 & 79 \\
\hline Thomsen et. al. ${ }^{21}$ & 26 & - & 37 \\
\hline Alm et. al. ${ }^{22}$ & 29.9 & - & - \\
\hline Rohr et. al. ${ }^{23}$ & - & $60^{+}$ & - \\
\hline Fernström et. al. ${ }^{24}$ & 29 & $45^{+}$ & $55^{+}$ \\
\hline Kherlakianet. al. ${ }^{25}$ & 12 & - & 71 \\
\hline Simoni et. al. ${ }^{26}$ & - & 75.5 & - \\
\hline Enzler et. al. ${ }^{27}$ & - & - & 74 \\
\hline Cassioumiset. al. ${ }^{28}$ & - & - & 79.1 \\
\hline Al-Mohaya et. al. ${ }^{29}$ & 2.7 & - & - \\
\hline Sparks et. al. ${ }^{30}$ & 12.2 & - & - \\
\hline Nazzal et. al. ${ }^{31}$ & - & - & 72 \\
\hline Leapman et. al. ${ }^{32}$ & 13 & - & 56 \\
\hline Prischl et. al..$^{33}$ & 22.8 & - & 48 \\
\hline Miller et. al. ${ }^{34}$ & 12.2 & - & - \\
\hline Bender et. al. ${ }^{35}$ & 9 & - & 76 \\
\hline Lin et. al. ${ }^{36}$ & 23.8 & - & - \\
\hline Zeebregts et. al. ${ }^{37}$ & 27.5 & $55^{+}$ & - \\
\hline Ascher et. al. ${ }^{38}$ & 25 & - & - \\
\hline Hingorani et. al. ${ }^{39}$ & - & 75 & - \\
\hline
\end{tabular}

Table 4. Primary failure rates and primary and secondary patency rates at 1 year as reported in the retrospective studies

${ }^{+}$Data taken from figure 
In addition a subgroup analysis was performed concerning age. The median age of all studies together was 50 years. Therefore we investigated in a subgroup analysis if there was a difference in primary failure rate and in patency rates between the studies with a mean age of the population $\leq 50$ years and the studies with a mean age of the population $>50$ years. As what might be expected, the estimated primary failure rate among studies with a mean age above 50 years is higher than in studies with a mean age of 50 or lower. However this difference is not significant $15.5 \%$ vs. $19.7 \% ; P=0.25)$. Also the estimated primary patency rate at one year $(59.4 \% \mathrm{vs}$. $64.9 \% ; P=0.50)$ and the estimated secondary patency rate at one year $(66.4 \%$ vs. $65.8 \% ; P=0.94)$ did not differ significantly between these two groups.

Finally a subgroup analysis was performed concerning publication period. We divided the studies in three different groups; studies performed before 1981, between 1981 and 1991, and performed after 1991. Remarkable is the higher estimated primary failure rate for studies performed after 1991, however this difference is not significant (13.5\% vs. $13.0 \%$ vs. $18.0 \% ; P=0.14)$. The estimated primary patency rate at one year $(60.0 \%$ vs. $62.7 \%$ vs. $62.9 \% ; P=0.85)$ and the estimated secondary patency rate at one year (55.7\% vs. $66.8 \%$ vs. $67.7 \%$; $P=0.62$ ) did not differ significantly between these two groups.

No indication for publication bias in the primary and secondary patency rates was found. However there was a clear indication of publication bias for the primary failure rates $(P=0.001)$ (Figure 1$)$. Points in the lower region of the plot have low precision and correspond to small studies, and the variability between studies is therefore larger than in the upper region where the spread is smaller. If there is no publication bias, the scatter should be symmetric around the vertical line, independent of the precision. It is obvious that symmetry is violated. There should be more small studies with large primary failure rates. Therefore small studies with worse primary failure rates are underrepresented. 


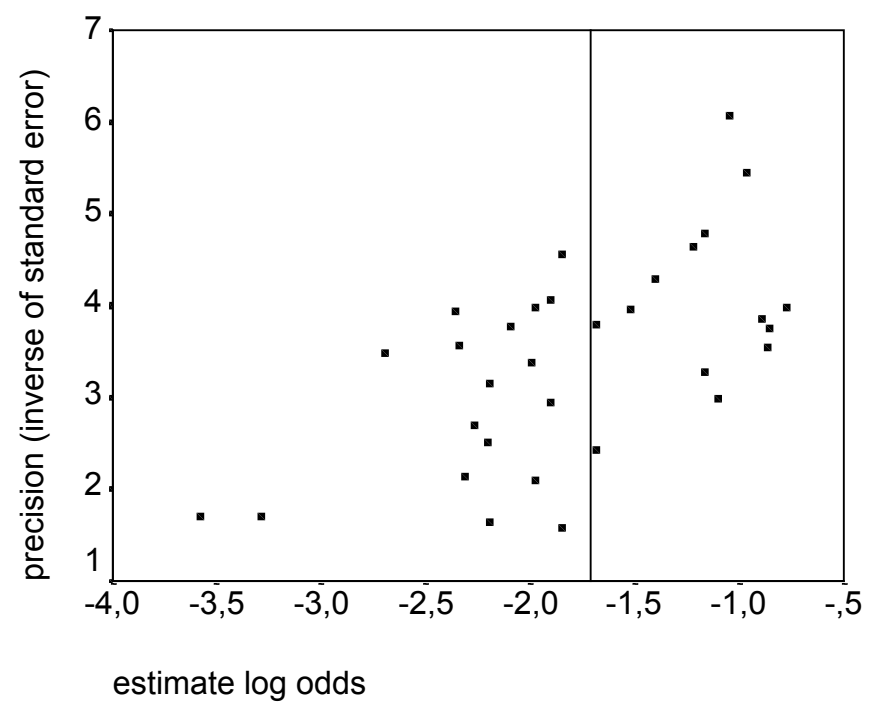

Figure 1. Funnel plot indicating publication bias for primary failure rates. The vertical reference line denotes the estimated overall log odds.

\section{Discussion}

The aim of this study was to aggregate primary patency, secondary patency and primary failure data from multiple sources, representing more than three decades of experience with the use of RCAVFs for hemodialysis across the world. The metaanalysis technique that we used allowed quantification of the variability between studies. A huge heterogeneity between studies was found in primary failure rates, primary patency and secondary patency. There are many potential causes of heterogeneity. An important (partly) explanation might be the heterogeneity between studies in the definitions of primary failure and primary/secondary patency. Only a few authors provided an explicit definition of the patency criterion they have used. When criteria were specified, many different definitions were used. A very minor part of the heterogeneity might be related to the fact that in some studies the patency data were not outlined in the text but presented in patency curves in figures. In some instances, this allowed subjective interpretations of these data, which may have resulted in larger variability. However it should be noticed that the patency data were independently derived by two different investigators, and did not reveal relevant differences. 
The meta-analytical technique we used for aggregating patency data allows the incorporation of covariates, which makes it possible to search for other possible sources of the differences between studies.

The effect of sex on primary patency, secondary patency and primary failure rates has been examined in many studies. ${ }^{6,33,44}$ For example, Allon et al. found that female sex was the only independent predictor of decreased likelihood of fistula maturation. ${ }^{44}$ Colledge et al. reported results from 107 patients (73 men, 43 women) with a first RCAVF; they found that fistula failure was more common in women and primary and secondary patency were better in men. ${ }^{6}$ In contrast, Prischl et al. found no significant differences in access survival between 80 men and 43 women on hemodialysis with a first RCAVF. ${ }^{33}$ The different outcome of these studies, can be explained by the small sample sizes and the fact that the populations were derived from single centers. In the present study no significant relation was found between the percentage men or women, and primary patency, secondary patency or primary failure rates. With regard to age and access patency several reports failed to find any association between age and access complications, ${ }^{45-47}$ although others reported a significant effect of age appearing after 6 months of follow-up. In this meta-analysis we found no relation between age and primary or, secondary patency and primary failure rates.

Finally our subgroup analysis showed a tendency towards a higher primary failure rate of fistulas constructed after 1991, however this difference was not significant. Possible explanations are the fact that the mean age of this subgroup is higher than in the other two groups, and the more liberal selection criteria for creation of a RCAVF, in recent years. In addition, the chronic dialysis population is more likely to have diabetes with various co-morbidities, including peripheral arterial obstructive disease and coronary artery sclerosis. Many of these patients appear to have poor vessels for construction of autogenous fistulas. In addition the Dialysis Outcome Quality Initiative (DOQI) published by the National Kidney Foundation in 1997 advocated intensive efforts to increase the use of RCAVF among these difficult dialysis patients. There are two possible explanations for the fact that there is no decrease in RCAVF patency over the years. The first explanation is that co-morbidity, like diabetes, has no significant influence on fistula patency. This explanation is supported by several studies, in which no difference in fistula maturation rates among diabetic and nondiabetic patients were found. ${ }^{44,45,48}$ The other possible explanation is the increased recognition of adequate preoperative vessel mapping and the value of fistula surveillance and elective intervention with percutaneous angioplasty of stenosed AVFs. However, as a result of this preoperative vessel mapping, one might even expect a decrease of primary failure rates and an increase of RCAVF patency rates. 
This study showed that differences in primary failure, primary patency and secondary patency can not be declared by patient demographics, such as sex and age. Therefore other factors must be taking into account, such as vessel diameter and quality. In a report of surgically created AVFs, Reilly et al. found that vein size was a significant predictor of subsequent fistula survival, while sex was not. ${ }^{2}$ A more recent study also found that vessel size predicted fistula failure in the first 3 months after surgery. ${ }^{9}$

\section{Conclusion}

The current analysis aggregates primary failure and primary and secondary oneyear patency rates from multiple studies regarding autogenous wrist RCAVFs for hemodialysis. The analysis showed a pooled estimated primary failure rate of $15.3 \%$. In addition the pooled estimated primary and secondary patency rates of $62.5 \%$ and $66.0 \%$ respectively were calculated.

Although, the autogenous RCAVF is considered to be the primary choice for vascular access, from the data showed in this meta-analysis, it appears to have a high primary failure rate and only moderate patency rates at 1 year of follow up. 


\section{References}

1. Brescia MJ, Cimino JE, Appel K, Hurwich BJ. Chronic hemodialysis using venipuncture and a surgically created arteriovenous fistula. N Engl J Med 1966;275:1089-1092.

2. Reilly DT, Wood RFM, Bell PRF. Prospective study of dialysis fistulas: problem patients and their treatment. Br J Surg 1982;69:549-553.

3. Wetzig GA, Gough IR, Furnival CM. One hundred cases of arteriovenous fistula for haemodialysis access: the effect of cigarette smoking on patency. Aust N Z J Surg 1985;55:551-554.

4. Wedgwood KR, Wiggins PA, Guillou PJ. A prospective study of end-to-side vs. side-toside arteriovenous fistulas for haemodialysis. Br J Surg 1984;71:640-642.

5. Dixon BS, Novak L, Fangman J. Hemodialysis vascular access survival: upper-arm native arteriovenous fistula. Am J Kidney Dis 2002;39:92-101.

6. Golledge J, Smith CJ, Farrington K, Thompson HH. Outcome of primary radiocephalic fistula for haemodialysis. Br J Surg 1999;86:211-216.

7. Malovrh M. Native arteriovenous fistula: Preoperative evaluation. Am J Kidney Dis 2002;39:1218-1225.

8. Lin $\mathrm{SH}$, Huang $\mathrm{CH}$, Chen HS, Hsu WA, Yen CJ, Yen TS. Effects of age and diabetes on blood flow rate and primary outcome of newly created hemodialysis arteriovenous fistula. Am J Nephrol 1998;18:96-100.

9. Wong V, Ward R, Taylor J, Selvakumar S, How TV, Bakran A. Factors associated with early failure of arteriovenous fistulae for haemodialysis access. Eur J Endovasc Surg 1996;12:207-213.

10. Cohen S, Lidksy I, Kest L, Kastagir B, Vertes V. Experience with arteriovenous fistulas. Trans Amer Soc Artif Int Organs 1968;14:421-425.

11. Röhl L, Franz HE, Möhring K, Ritz E, Schüler HW, Uhse HG, et al. Direct arteriovenous fistula for hemodialysis. Scand J Urol Nephrol 1968;2:191-195.

12. Kinnaert P, Vereerstraeten P, Toussaint C, Van Geertruyden J. Nine years' experience with internal arteriovenous fistulas for haemodialysis: a study of some factors influencing the results. Br J Surg 1977;64:242-246.

13. Tellis VA, Veith FJ, Soberman RJ, Freed SZ, Gliedman ML. Internal arteriovenous fistula for hemodialysis. Surg Gynecol Obstet 1971;132:866-870.

14. Zerbino VR, Tice DA, Katz LA, Nidus BD. A 6 year clinical experience with arteriovenous fistulas and bypasses for hemodialysis. Surgery 1974;76:1018-1023.

15. Thompson BW, Barbour G, Bissett J. Internal arteriovenous fistula for hemodialysis. Am J Surg 1972;124:785-788.

16. Cheek RC, Messina JJ, Acchiardo SR, Britt LG. Arteriovenous fistulas for hemodialysis: experience with 100 cases. Am Surg 1976;42:386-389.

17. Lindfors $\mathrm{O}$, Paldanius R. Experience with arteriovenous fistulas (Cimino) in chronic hemodialysis. Scand J Urol Nephrol 1976;10:80-83.

18. Paruk S, Koenig M, Levitt S, Hardy MA. Arteriovenous fistulas for hemodialysis in 100 consecutive patients. Am J Surg 1976;131:552-555.

19. Tordoir JHM, Kwan TS, Herman JMMPH, Carol EJ, Jakimowicz JJ. Primary and secondary access surgery for haemodialysis with the Brescia-Cimino fistula and the polytetrafluorethylene (PTFE) graft. Neth J Surg 1983;35:8-12.

20. Burger H, Kluchert BA, Kootstra G, Kitslaar PJ, Ubbink D TH. Survival of arteriovenous fistulas and shunts for haemodialysis. Eur J Surg 1995;161:327-334. 
21. Thomsen MB, Deurell SI, Elfström J, Alm A. What causes the failure in surgically constructed arteriovenous fistulas. Acta Chir Scand 1983;149:371-376.

22. Alm A, Lundberg M. Clinical experience with therapeutic arteriovenous fistulae. Scand J Urol Nephrol 1977;11:53-57.

23. Rohr MS, Browder W, Frentz GD, McDonald JC. Arteriovenous fistulas for long-term dialysis. Factors that influence fistula survival. Arch Surg 1978;113:153-155.

24. Fernström A, Hylander B, Olofsson P, Swedenborg J. Long and short term patency of radiocephaloc arteriovenous fistulas. Acta Chir Scand 1988;154:257-259.

25. Kherlakian GM, Roedersheimer LR, Arbaugh JJ, Newmark KJ, King LR. Comparison of autogenous fistula versus expanded polytetrafluorethylene graft fistula for angioaccess in hemodialysis. Am J Surg 1986;152:238-243.

26. Simoni G, Bonalumi U, Civalleri D, Decian F, Bartoli FG. End-to-end arteriovenous fistula for chronic haemodialysis: 11 years' experience. Cardiovasc Surg 1994;2:63-66.

27. Enzler MA, Rajmon T, Lachat M, Largiader F. Long-term function of vascular access for hemodialysis. Clin Transplant 1996;10:511-515.

28. Cassioumis D, Fatouros MS, Siamopoulos KC, Giannoukas AD. Short- an longterm evaluation of arteriovenous fistulas for chronic hemodialysis. Microsurgery 1992;13:236-237.

29. Al-Mohaya S, Al-Awami SM, Sadat-Ali M. Arteriovenous Fistula for Hemodialysis a report of 112 consecutive cases. Indian J Med Sci 1990;44:33-36.

30. Sparks SR, VanderLinden JL, Gnanadev DA, Smith JW, Bunt TJ. Superior patency of perforating antecubital vein arteriovenous fistulae for hemodialysis. Ann Vas Surg 1997;11:165-167.

31. Nazzal MMS, Neglen P, Naseem J, Christenson JT, al-Hassan HK. The brachiocephalic fistula: a successful secondary vascular access procedure. Vasa 1990;19:326-329.

32. Leapman SB, Boyle M, Pescovitz MD, Milgrom ML, Jindal RM, Filo RS. The arteriovenous fistula for hemodialysis access: fold standard of archaic relic? Am Surg 1996;62:652656.

33. Prischl FC, Kirchgatterer A, Brandstätter E, Wallner M, Baldinger C, Roithinger FX, Kramar R. Parameters of Prognostic Relevance to the patency of vascular access in hemodialysis patients. J Am Soc Nephrol 1995;6:1613-1618.

34. Miller A, Hölzenbein TJ, Gottlieb MN, Sacks BA, Lavin PT, Goodman WS, et al. Strategies to increase the use of autogenous arteriovenous fistula in end-stage renal disease. Ann Vasc Surg 1997;11:397-405.

35. Bender MHM, CMA Bruyninckx, PGG Gerlag. The brachiocephalic elbow fistula: A useful alternative angioaccess for permanent hemodialysis. J Vasc Surg 1994;20:808 813.

36. Lin SL, Chen HS, Huang CH, Yen TS. Predicting the outcome of hemodialysis arteriovenous fistulae using duplex utrasonography. J Formos Med Assoc 1997;96:864-868.

37. Zeebregts C, van den Dungen J, Bolt A, Franssen C, Verhoeven E, van Schilfgaarde R. Factors predictive of failure of Brescia-Cimino arteriovenous fistulas. Eur J Surg 2002;168:29-36.

38. Ascher E, Gade P, Hingorani A, Mazzariol F, Gunduz Y, Fodera M, et al. Changes in the practice of angioaccess surgery: Impact of dialysis outcome and quality initiative recommendations. J Vasc Surg 2000;31:84-92. 
39. Hingorani A, Ascher E, Kallakuri S, Greenberg S, Khanimov Y. Impact of reintervention for failing upper-extremity arteriovenous autogenous access for hemodialysis. J Vasc Surg 2001;34:1004-1009.

40. Sidawy AN, Gray R, Besarad A, Henry M, Ascher E, Silva M, et al. Recommended standards for reports dealing with arteriovenous hemodialysis accesses. J Vasc Surg 2002;35:603-610.

41. DerSimonian R, Laird N. Meta-analysis in clinical trials. Control Clin Trials 1986;7:177188

42. Houwelingen van JC, Arends LR, Stijnen T. Advanced methods in meta-analysis: multivariate approach and meta-regression. Stat Med 2002;21:589-624.

43. Egger M, Davey Smith G, Scheinder M, Minder C. Bias in meta-analysis detected by a simple, graphical test. Br Med J 1997;315:629-634.

44. Allon M, Lockhart ME, Lilly RZ, Gallichio MH, Young CJ, Barker J, et al. Effect of preoperative sonographic mapping on vascular access outcomes in hemodialysis patients. Kidney Int 2001;2013-2020.

45. Zibari GB, Rohr MS, Landreneau MD, Bridges RM, DeVaut GA, Petty FH, et al. Complications from permanent hemodialysis vascular access. Surgery 1988;140:681686.

46. Churchill DN, Taylor DW, Cook RJ, LaPlante P, Barre P, Cartier P, et al. Canadian Hemodialysis Morbidity Study, Am J Kidney Dis 1992;19:214-234.

47. Rocco MV, Bleyer AJ, Burkart JM. Utilization of inpatient and outpatient resources for the management of hemodialysis access complications. Am J Kidney Dis 1996;28:250256.

48. Sedlacek M, Teodorescu V, Falk A, Vassalotti JA, Uribarri J. Hemodialysis access placement with preoperative noninvasive vascular mapping: Comparison between patients with and without diabetes. Am J Kidney Dis 2001;38:560-564. 


\section{Prospective evaluation of failure modes in autogenous radial-cephalic wrist access for hemodialysis}




\begin{abstract}
Introduction: Radial-cephalic wrist arteriovenous fistulas (RCAVF) are the primary and best option for vascular access for hemodialysis treatment. However, 10 to $24 \%$ of these AVFs fail directly due to thrombosis and non-maturation. In a prospective study, the failure modes of RCAVFs and the impact of surgical and interventional treatment on fistula outcome were investigated.
\end{abstract}

Methods: The rate of thrombosis and non-maturation was evaluated in 43 RCAVFs. The selection of RCAVF creation was made on preoperatively determined duplex parameters. Fistula function was evaluated postoperatively by clinical examination and noninvasively measured AVF bloodflow. A policy of a liberal use of radiological and/or surgical revision of non-functioning RCAVFs was made on basis of duplex measured bloodflow and angiographically detected vessel stenosis.

Results: Primary fistula function was achieved in 26 out of 43 patients (60\%). Nonmaturation and thrombosis occurred in respectively $14(33 \%)$ and $3(7 \%)$ patients. A total of 12 interventions (PTA 6; surgery 6) were needed, resulting in salvage of 8 RCAVFs (47\%). The bloodflow in functioning AVFs was significantly higher compared to non-functioning AVFs at one (754 vs $440 \mathrm{cc} / \mathrm{min}$ ), seven (799 vs $524 \mathrm{cc} / \mathrm{min}$ ) and 42 days (946 vs $532 \mathrm{cc} / \mathrm{min}$ ) postoperatively. At the end, 34 RCAVFs (79\%) became functional as vascular access for hemodialysis treatment.

Conclusion: Primary RCAVFs have a high rate of non-functioning. An aggressive approach towards early interventional treatment of these non-functional AVFs is worthwile and leads to a considerable salvage rate. Early postoperative AVF flow measurement indicates the chance of successful maturation of RCAVF. 


\section{Introduction}

Autogenous radial-cephalic arteriovenous fistulas (RCAVF) have been awarded for the past 35 years as the primary and best choice for vascular access in hemodialysis patients. In Europe, an overall $80 \%$ of prevalent patients have autogenous AVFs as a vascular access while only $24 \%$ of patients in the United States uses an AVF. ${ }^{1}$ When a RCAVF after the surgical creation successfully matures, it may function for years with a low risk on complications and low incidence of revisions. However, 10 to $24 \%$ of RCAVFs thrombose directly after operation or does not function adequately due to failure of maturation. ${ }^{2-6}$ Usually, AVF thrombosis and non-maturation depend on the quality and size of the vessels used for the arteriovenous anastomosis and the ability of vessel adaptation induced by the augmented bloodflow volumes. A preoperative assessment of upper extremity vessel characteristics seems therefore worthwile to define arteries and veins suitable for autogenous AVF creation. Recently, several duplex-derived criteria have been developed, which showed a beneficial effect of using well-sized radial arteries and cephalic veins on the outcome of RCAVFs. ${ }^{7-9}$ However, AVF failure and non-maturation may still occur despite anastomosing adequate vessels and in a high percentage of these patients anatomical abnormalities, like stenoses, are correlated to non-functioning accesses. An aggressive approach to treat these lesions by surgical or radiological intervention has been advocated in recent years with a favourable outcome on fistula function. ${ }^{10}$

Therefore, we performed a prospective study to get insight into the failure modes of autogenous radial-cephalic wrist accesses and the impact of interventions on fistula function.

\section{Patients and methods}

Of the 82 AVFs performed in new patients at our institution between January 1999 and June 2002, 43 autogenous radial-cephalic wrist accesses were created. During the same period 141 secondary procedures were performed. The patients were operated by a single vascular surgeon or senior resident supervised by this surgeon. All patients underwent preoperative duplex ultrasonography of the arteries and superficial veins of the upper extremity. Vessel diameters, arterial obstructions, vein compressibility and vessel continuity were registered. On the basis of this preoperative duplex examination patients were allocated to receive a primary RCAVF (non-randomisation group), a primary prosthetic graft implantation or randomisation 
between primary RCAVF (randomisation group) and prosthetic graft implantation. The criteria for this algorithm are outlined in figure 1.

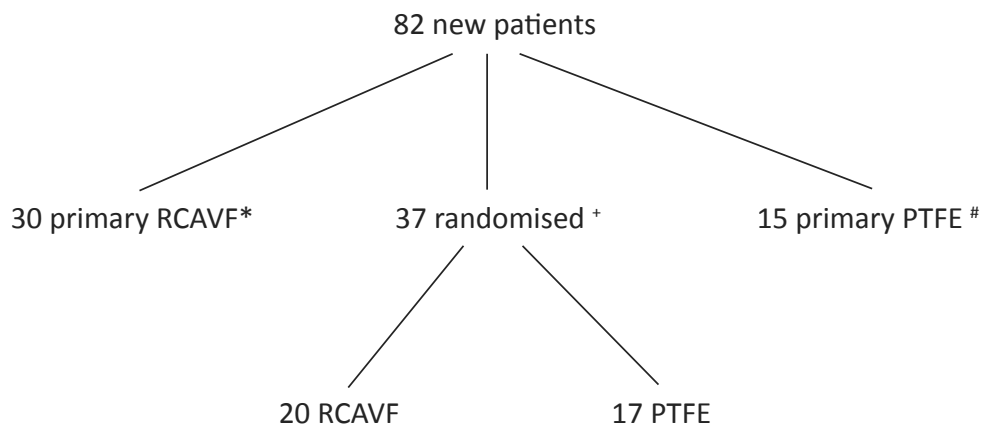

* radial artery $\geq 2 \mathrm{~mm}$ and cephalic vein $\geq 1.6 \mathrm{~mm}$

+ radial artery $\geq 1 \mathrm{~mm} /<2 \mathrm{~mm}$ or cephalic vein $<1.6 \mathrm{~mm}$

\# radial artery $<1 \mathrm{~mm}$ or cephalic vein occlusion

Figure 1. Algorithm for the creation of vascular access in new patients

\section{Operative procedure}

The construction of the RCAVF was performed under regional axillary block or general anesthesia with the use of antibiotic prophylaxis. The radial artery and cephalic vein were exposed through a longitudinal or transverse incision 4-5 cm proximal of the radial styloid process. After sufficient vein mobilisation an end-to-side vein-to-artery anastomosis was performed with running 7x0 Polypropylene (Prolene) suture. The length of the arteriotomy was 10 to $15 \mathrm{~mm}$ and vessel diameters were measured with coronary probes. AVF patency was confirmed peroperatively by palpation and Doppler examination. Postoperative evaluation was done by palpation and auscultation. Patients were regularly seen by the nephrologist and the decision to start dialysis treatment was made on the severity of detoriation of renal function. First cannulation was performed when the vessels had matured adequately, usually after 4 to 6 weeks. When cannulation was not possible, due to non-maturation, dialysis was started by means of central vein catheters. 


\section{Follow up}

All patients were followed with duplex ultrasound scanning including measurement of the amount of bloodflow through the radial artery, one, 7 and 42 days after operation. Patency was defined as functional patency with adequate dialysis.

Clinical criteria were used for detection of AVF thrombosis and non-maturation. Inability to cannulate the AVF or to obtain sufficient dialysis bloodflow (> 250cc/ $\min$ ) within 6 weeks after fistula creation were indicators of a poor-functioning AVF. All patients with non-maturating RCAVFs underwent angiography, visualising the proximal arterial inflow by retrograde contrast filling initiated through a proximal occluding cuff. Venous outflow vessels were imaged by contrast injection after the release of the proximal cuff.

\section{Revisions}

Short segmental stenotic lesions $(<1 \mathrm{~cm})$ in the cephalic vein underwent balloon angioplasty, while anastomotic stenoses were surgically revised by creating a more proximal anastomosis between the radial artery and the cephalic vein. RCAVFs without depictable stenoses, usually indicating poor vessel remodelling, were abandoned and replaced by new accesses. Failed balloon angioplasties underwent open surgical revision whenever possible.

\section{Statistical analysis}

Patient characteristics and duplex parameters of non-functioning and functioning AVFs were compared with Student t-test and the Fisher exact test when appriopiate. Functional patencies were determined by the Kaplan-Meier survival analysis and compared with the Log-rank method. A $P$-value $<0.05$ was considered statistically significant.

\section{Results}

During the $3 \frac{1}{2}$-year period 82 consecutive new patients needing a primary vascular access were enrolled in a prospective randomised study. According to defined vessel criteria from the preoperative duplex scanning, 30 patients were allocated to primary placement of a RCAVF of which 2 patients received PTFE grafts because of unsuitable vessels for a direct anastomosis found during operation. Fifteen patients underwent primary prosthetic graft implantation and 37 patients were randomised to receive either a RCAVF $(n=20)$ or prosthetic graft AVF $(n=17)$. Of the patients randomised for 
a RCAVF, 5 patients exhibited insufficient wrist vessels and received PTFE graft AVFs. A total of 28 and 15 RCAVFs in the non-randomisation and randomisation group respectively were subjected to further analysis (Figure 1).

\section{Non-randomisation group}

Primary thrombotic occlusion occurred within a week in one patient (4\%). No attempt to revision was done and this patient received a new AVF. A primary function for dialysis was achieved in 20 patients (71\%) with a mean time to first cannulation of 52 days (range 28-114 days). Seven RCAVFs (25\%) failed to mature and underwent a total of 4 procedures after a mean period of 79 days (range 47-112 days). A subclavian artery and cephalic vein stenosis in 2 patients were successfully treated by PTA and anastomotic stenoses in 2 patients by surgical revision performing a more proximal radiocephalic anastomosis. Three patients received new AVFs, while no evident cause for non-maturation was detected by angiography. At the end, the total number of functioning AVFs was 24 out of 28 initially created RCAVFs (86\%). Primary functional patencies were $71 \%$ and $64 \%$ after 90 and 180 days respectively.

\section{Randomisation group}

In the randomisation group there were two patients (13\%) with a thrombosed RCAVF and in these patients new AVFs were created. Primary function was observed in only 6 patients (40\%) and these fistulas could be used for dialysis after a mean period of 86 days (range 54-123 days). Non-maturation occurred in 7 patients (47\%) and a total of 8 interventions (PTA 4; new proximal anastomosis 3; graft interposition 1) were needed, resulting in functional accesses in 4 patients. In one patient surgical revision failed and in this patient a prosthetic graft was implanted. Two patients underwent primarily a new AVF, while no correctable lesions were detected on the angiogram. A total of 10 RCAVFs (67\%) became functional in the randomisation group.The primary patencies were $40 \%$ and $36 \%$ after 90 and 180 days respectively. These patencies were significantly different from the non-randomisation group.

\section{Clinical variables}

Patient characteristics in the non-functioning and functioning RCAVFs are shown in table 1. Female gender and cardiac disease were significantly correlated to failure of AVF maturation. The use of antiplatelet or anticoagulant drugs showed no relation with AVF malfunctioning. 


\begin{tabular}{lccc}
\hline & Non-functioning & Functioning & P-value \\
\hline $\mathrm{N}$ & 17 & 26 & \\
Male & $7(41)$ & $19(73)$ & $\mathbf{0 . 0 4 5}$ \\
Age (years) & $67.4 \pm 10.7$ & $65.8 \pm 10.3$ & 0.623 \\
Medical history & & & \\
$\quad$ Diabetes & $4(23)$ & $6(23)$ & 0.711 \\
$\quad$ Hypertension & $9(53)$ & $14(54)$ & 0.988 \\
Ischemic cardiac disease & $12(71)$ & $7(27)$ & $\mathbf{0 . 0 0 5}$ \\
$\quad$ Peripheral vascular disease & $4(23)$ & $4(15)$ & 0.863 \\
Cerebrovascular disease & $2(12-7)$ & $3(11)$ & 0.663 \\
Anticoagulation & $5(29)$ & $9(35)$ & 0.937 \\
Causes of ESRD & & & \\
$\quad$ Arteriosclerosis & $6(35)$ & $12(46)$ & 0.856 \\
$\quad$ Diabetic nephropathy & $2(12)$ & $2(8)$ & 0.505 \\
Pyelo-/glomerulonephritis & $3(18)$ & $3(11)$ & 0.460 \\
Polycystic kidney disease & $4(23)$ & $2(8)$ & 0.078 \\
Unknown & $1(6)$ & $2(8)$ & 0.746 \\
Others* & $1(6)$ & $5(19)$ & $\mathbf{0 . 0 1 4}$ \\
Pre-operative diameter & & & \\
$\quad$ Radial artery (mm) & $2.3 \pm 0.4$ & $2.5 \pm 0.7$ & 0.186 \\
Cephalic vein (mm) & $1.8 \pm 0.4$ & $2.2 \pm 0.6$ & $\mathbf{0 . 0 3 9}$ \\
\hline
\end{tabular}

Table 1. Clinical variables and duplex-derived vessel diameters in non-functioning and functioning RCAVF

*cyclosporin-induced nephropathy, IgA nephropathy, bilateral nephrectomy (kidney tumor), haemolytic uremic syndrome (HUS) and hydronephrosis

\section{Duplex parameters}

In figure 2 the radial artery and cephalic vein diameters, measured preoperatively by duplex scanning in the functional and failed RCAVFs are outlined. The mean radial artery diameters in both groups were similar (2.3 vs $2.5 \mathrm{~mm}$ ), however cephalic vein diameters were significantly smaller in the non-functioning AVFs (1.8 vs $2.2 \mathrm{~mm}$; $P=0.04)$. 


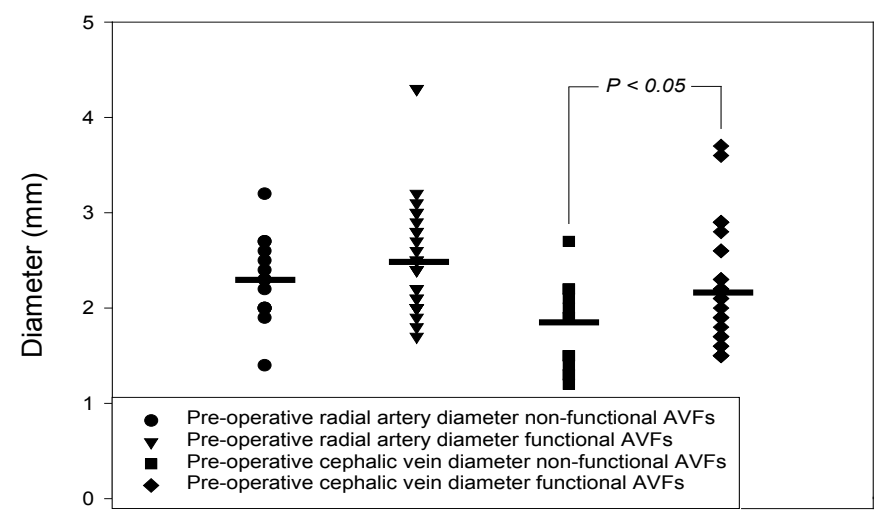

Figure 2. Preoperative radial artery and cephalic vein diameter (in $\mathrm{mm}$ ) in non-functioning and functioning RCAVF

Postoperative radial artery bloodflow, measured by duplex scanning, is outlined in figure 3. All patients, including those with non-maturating AVFs had a complete duplex follow up to 42 days. The thrombosed AVFs $(n=3)$ had only one flow measurement the first postoperative day. After 1, 7 and 42 days a significant increase in bloodflow was observed in the functional RCAVFs. However, in non-maturating AVFs the radial artery flow remained significantly lower compared to the functioning AVFs at 1,7 and 42 days (mean flows in cc/min: 440 vs 754; 524 vs 799; 532 vs 946; $P<0.05$ ).

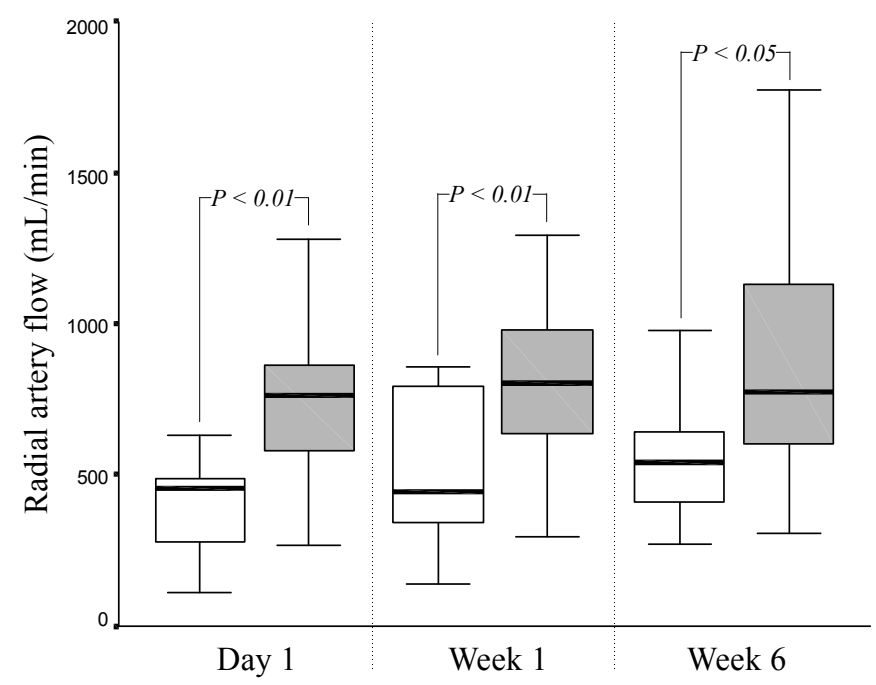

Figure 3. Postoperative radial artery blood flow ( $\mathrm{ml} / \mathrm{min}$ ) in non-functioning (white box) and functioning RCAVF (grey box) 


\section{Discussion}

Patients with autogenous AVFs need significant fewer interventions and hospital admissions to maintain functional vascular access compared to patients with prosthetic AVFs. Therefore, it seems obvious to obtain autogenous fistulas in all new dialysis patients. However with this "all autogenous" policy, it may be anticipated that in a considerable number of patients failure to create a functioning access due to thrombosis or non-maturation of the fistula will occur. Till today, it is not clear which type of patients are at risk for these problems and in recent years some authors have attempted to develop objective criteria which may be useful in selecting patients, which benefit from autogenous AVFs. Certain duplex-derived parameters may predict the risk on failure or dysmaturation. The internal radial artery diameter has been used in several studies to predict the outcome of RCAVFs or to plan strategies for vascular access creation. Wong et al. ${ }^{11}$ observed primary failure of RCAVFs in patients with a radial artery and/or cephalic vein diameter of $<1.6 \mathrm{~mm}$. In another study, successful AVFs had a preoperatively measured radial artery diameter of 2.7 $\mathrm{mm}$ vs $1.9 \mathrm{~mm}$ in failed AVFs. ${ }^{7}$ Malovrh discriminated between patients that received a RCAVF with a radial artery diameter greater or lesser than $1.5 \mathrm{~mm}$. Success rate in the $>1.5 \mathrm{~mm}$ group was $92 \%$ vs $45 \%$ in the $\leq 1.5 \mathrm{~mm}$ group. ${ }^{12}$ Though, the importance of using well-sized radial arteries for creating radiocephalic AVFs is well emphasized in the literature, we could not estimated a significant impact of arterial diameters on fistula outcome. Probably, a small variation of arterial diameters in the patients studied, may be the explanation for this observation. Cephalic vein diameters were significantly associated with non-maturation and this finding is well in line with the few data from the literature. An increase in the number of RCAVFs from 14 to $63 \%$ after the institution of a standard preoperative workup was observed in the study of Silva et al. ${ }^{8}$ Strategies for vascular access creation in this study were based on preoperative duplex scanning. Patients with a radial artery diameter of $\geq 2 \mathrm{~mm}$ and a cephalic vein of $\geq 2.5 \mathrm{~mm}$ received RCAVFs, while graft AVFs were placed in patients with insufficient radial arteries and cephalic veins and an outflow vein in the elbow with a diameter of $\geq 4 \mathrm{~mm}$. However, from these studies it appeared that still 8 to $10 \%$ of patients that were judged to have adequate vessels, developed non-functioning AVFs. From the published data, we have adapted the preoperative vessel criteria used in the present study. With this policy of selecting patients with "good" vessels (radial artery $\geq 2 \mathrm{~mm}$; cephalic vein $>1.6 \mathrm{~mm}$ ) for RCAVF creation, a high percentage of functioning fistulas could be established. However, $14 \%$ of these fistulas did not function at all and another $14 \%$ needed additional measures, like PTA and surgery, to 
get them working. On the other hand, the risk on early failure of RCAVFs when small vessels are selected for the arteriovenous anastomosis is much higher. In particular, small-calibre cephalic veins were significantly associated with access failure, while radial artery diameters were not correlated with failure. Only $40 \%$ in the group with small veins had an initial function for dialysis, while $27 \%$ could be salvaged by multiple interventions. From our data, we conclude that preoperative vessel evaluation can help in the decision to choose an autogenous vascular access which has a great chance on functioning ( $86 \%$ of patients with "good vessels" had a functioning radial-cephalic AVF). Still, $14 \%$ of patients encountered failed RCAVFs, and one might wonder if the accepted vessel diameters for RCAVF creation in this study were possibly too small. In patients with small arteries and veins it is probably wise to create primarily an AVF at another site in the upper extremity using large calibre vessels. Only 43 RCAVFs out of 82 new vascular accesses could be established in this study. We decided to randomise patients with small vessels for an RCAVF or prosthetic graft implantation. Patients with occluded forearm vessels were directly allocated to a prosthetic graft AVF. This policy is different from some European studies in which mainly autogenous elbow or upper arm AVFs were created when a RCAVF was not possible. ${ }^{1}$ This means that in these studies a high percentage of autogenous AVFs has been reported. Also the percentage of functioning RCAVFs from the present study was lower compared to other studies. This might be explained by the fact that also RCAVF were created with the use of small vessels, resulting in a high failure rate. Anastomotic and cephalic vein stenoses were angiographically diagnosed in most patients and were eligible to intervention, however in 5 patients no anatomical abnormalities could be detected. Inability of vessel adaptation (remodelling) in response to an increase in flow may be responsible for non-maturation in these patients. ${ }^{13}$ To what extent, vesselwall stiffness or calcification, for example in diabetic or arteriosclerotic patients, may influence non-maturation is still unknown. In published series, controversial influences of diabetis mellitus on fistula outcome were reported.${ }^{14}$ We were not able to show a significant negative effect of diabetes mellitus on fistula outcome. Surprisingly, cardiac comorbidity did result in higher non-maturation rates. It is wellknown, that patients with coronary artery sclerosis may exhibit peripheral vascular disease too. This feature may be the reason for non-maturation in these patients. On the other hand, it remains peculiar why diabetics with usually inherent coronary artery disease, showed no increased risk of AVF failure in our study. Probably, smaller vessels are the reason for significantly higher percentages of non-maturation in females. No data on the accuracy of imaging superficial veins in the forearm are known. In this respect, we did find a discrepancy between operative findings and 
duplex measurements in 2 patients in the group with so-called "good vessels" and in 5 patients in the randomisation group. The outcome of duplex scanning depends on the experience of the vascular technician and therefore is a purely subjective method of investigation. More objective techniques like magnetic resonance angiography or CTA may possibly increase the accuracy of the preoperative imaging. ${ }^{15}$

Blood flow in the radial artery, measured by duplex ultrasound one and seven days after the operation may predict maturation. ${ }^{11}$ Low blood flow rates and velocities in the fistula within the first 2 weeks usually result in fistula failure. A radial artery cross-sectional area of $>8.5 \mathrm{~mm}^{2}$ and venous flow of $>425 \mathrm{ml} / \mathrm{min}$ measured postoperatively, have a positive predictive value of 0.95 and 0.97 respectively, for the outcome of radial-cephalic AVFs. ${ }^{16}$ This predictive value of postoperative flow measurement was also proven in the present study. Failed RCAVFs had lower bloodflows through the radial artery compared to succesfull fistulas one, seven and 42 days after operation. Also, insufficient augmentation of bloodflow after 42 days was observed in non-maturating AVFs and on the basis of these measurements, angiography was indicated.

In the current study a prospective analysis of failure modes of autogenous RCAVFs was performed from duplex parameters and angiographic findings. In $64 \%$ of the patients an anatomical lesion at or near the AV anastomosis, amenable to radiological or surgical intervention, was visualised. Similar observations were reported in 52 patients with non-maturating AVFs. ${ }^{10}$ All fistulas showed significant stenoses, half of which were located in the anastomotic area. Interventional treatment by means of PTA and stent placement resulted in maturation in $97 \%$ of patients. The impact of reintervention on fistula maturation and maintenance was recently published by two american studies. ${ }^{17,18}$ In these patient series not only radial-cephalic but also a significant number of brachial-cephalic and brachial-basilic AVFs were included. A $10 \%$ improvement in accomplishing a functional autogenous access was achieved by either PTA or surgical procedures. Balloon angioplasty, vein patch, interposition or transposition and new proximal radial artery-to-cephalic vein anastomosis were employed. The authors suggest that simple and extended salvage procedures may allow maturation with an advantage for surgical revision as compared with percutaneous techniques, in terms of requiring fewer subsequent procedures. Patients with non-matured AVFs due to insufficient augmentation of bloodflow because of remodelling failure of the radial artery (inability to dilate in anatomically small or atherosclerotic vessels), are not cured by AVF revision, but by the construction of a new AVF anastomosing large vessels, usually at the site of the elbow. 
Chapter 3

In summary, we have investigated the failure modes of radial-cephalic wrist accesses and the impact of radiological and surgical intervention on fistula outcome. Non-maturation occurred in 33\% of RCAVFs and in $64 \%$ of patients anatomical abnormalities were found with angiography. The liberal use of interventions resulted in a salvage rate of $47 \%$ of non-matured AVFs. 


\section{References}

1. Pisoni RL, Young EW, Dykstra DM, Greenwood RN, Hecking E, Gillespie B, et al. Vascular access use in Europe and the United States: results from the DOPPS. Kidney Int 2002;61:305-316.

2. Reilly DT, Wood RF, Bell PR. Arteriovenous fistulas for dialysis: blood flow, viscosity, and longterm patency. World J Surg 1982;6:628633.

3. Tordoir JH, Kwan TS, Herman JM, Carol EJ, Jakimowicz JJ. Primary and secondary access surgery for haemodialysis with the BresciaCimino fistula and the polytetrafluoroethylene (PTFE) graft. Neth J Surg 1983;35:812.

4. Wedgwood KR, Wiggins PA, Guillou PJ. A prospective study of endtoside vs. sidetoside arteriovenous fistulas for haemodialysis. Br J Surg. $1984 ; 71: 6402$.

5. Kherlakian GM, Roedersheimer LR, Arbaugh JJ, Newmark KJ, King LR. Comparison of autogenous fistula versus expanded polytetrafluoroethylene graft fistula for angioaccess in hemodialysis. Am J Surg 1986;152:238243.

6. Palder SB, Kirkman RL, Whittemore AD, Hakim RM, Lazarus JM, Tilney NL. Vascular access for hemodialysis. Patency rates and results of revision. Ann Surg 1985;202:235239.

7. Lemson MS, Leunissen KM, Tordoir JH. Does preoperative duplex examination improve patency rates of BresciaCimino fistulas? Nephrol Dial Transplant 1998;13:13601361.

8. Silva MB Jr, Hobson RW II, Pappas PJ, Jamil Z, Araki CT, Goldberg MC, et al. A strategy for increasing use of autogenous hemodialysis access procedures: impact of preoperative noninvasive evaluation. J Vasc Surg 1998;27:302307

9. Ascher E, Gade P, Hingorani A, Mazzariol F, Gunduz Y, Fodera M, et al. Changes in the practice of angioaccess surgery: impact of dialysis outcome and quality initiative recommendations. J Vasc Surg 2000;31:8492.

10. Turmel-Rodrigues L, Mouton A, Birmele B, Billaux L, Ammar N, Grezand O, et al. Salvage of immature forearm fistulas for haemodialysis by interventional radiology. Nephrol Dial Transplant 2001;16:2365-2371.

11. Wong V, Ward R, Taylor J, Selvakumar S, How TV, Bakran A. Factors associated with early failure of arteriovenous fistulae for haemodialysis access. Eur J Vasc Endovasc Surg 1996;12:207-213.

12. Malovrh M. Non-invasive evaluation of vessels by duplex sonography prior to construction of arteriovenous fistulas for haemodialysis. Nephrol Dial Transplant 1998;13:125-129.

13. Dammers R, Tordoir JH, Welten RJ, Kitslaar PJ, Hoeks AP. The effect of chronic flow changes on brachial artery diameter and shear stress in arteriovenous fistulas for hemodialysis. Int J Artif Organs 2002;25:124-128.

14. Konner K. Primary vascular access in diabetic patients: an audit. Nephrol Dial Transplant 2000;15:13171325.

15. Menegazzo D, Laissy JP, Durrbach A, Debray MP, Messin B, Delmas V, et al. Hemodialysis access fistula creation: preoperative assessment with MR venography and comparison with conventional venography. Radiology 1998;209:723-728.

16. Lin SL, Chen HS, Huang CH, Yen TS. Predicting the outcome of hemodialysis arteriovenous fistulae using duplex ultrasonography. J Formos Med Assoc 1997;96:864-868. 
Chapter 3

17. Hingorani A, Ascher E, Kallakuri S, Greenberg S, Khanimov Y. Impact of reintervention for failing upper-extremity arteriovenous autogenous access for hemodialysis. J Vasc Surg 2001;34:1004-1009.

18. Berman SS, Gentile AT. Impact of secondary procedures in autogenous arteriovenous fistula maturation and maintenance. J Vasc Surg 2001;34:866-871. 


\section{Autogenous radial-cephalic or prosthetic brachial-antecubital}

forearm loop AVF in patients with compromised vessels? A randomized, multicenter study of the patency of primary hemodialysis access 


\begin{abstract}
Objective: The construction of an autogenous radial-cephalic direct wrist arteriovenous fistula (RCAVF) is the primary and best option for vascular access for hemodialysis. However, $10-24 \%$ of RCAVFs thrombose directly after operation or do not function adequately due to failure of maturation. In case of poor arterial and/ or poor venous vessels for anastomosis, the outcome of RCAVFs may be worse and an alternative vascular access probably indicated. A prosthetic graft implant may be a second best option. Therefore a randomized multicenter study comparing RCAVF with prosthetic (PTFE) graft implantation in patients with poor vessels was performed.
\end{abstract}

Methods: A total of 383 consecutive new patients needing primary vascular access were screened for enrollment in a prospective randomized study. According to defined vessel criteria from the preoperative duplex scanning, 140 patients were allocated to primary placement of a RCAVF and 61 patients to primary prosthetic graft implantation. The remaining 182 patients were randomized to receive either a RCAVF $(n=92)$ or prosthetic graft implant $(n=90)$. Patency rate was defined as the percentage of AVFs that functioned well after implantation.

Results: Primary and assisted-primary one-year patencies were 33\% ( $\pm 5.3 \%$ ) vs $44 \%$ $( \pm 6.2 \%)(P=.03)$ and $48 \%( \pm 5.5 \%)$ vs $63 \%( \pm 5.9 \%)(P=.035)$ for RCAVF and prosthetic AVF, respectively. Secondary patencies were $52 \%$ ( $\pm 5.5 \%)$ vs $79 \%( \pm 5.1 \%)(P=.0001)$ for RCAVF and prosthetic AVF, respectively. Patients with RCAVFs developed a total of $102(1.19 /$ py) vs $122(1.45 /$ py; $P=.739)$ complications in the prosthetic AVFs. A total of $43(0.50 /$ py) interventions in the RCAVF group and $79(0.94 / p y)$ in the prosthetic graft group were needed for access salvage $(P=.077)$.

Conclusion: Although there were more interventions needed for access salvage in the patients with prosthetic graft implants, we may conclude that patients with poor forearm vessels do benefit from implantation of a prosthetic graft for vascular access. 


\section{Introduction}

A well-functioning vascular access remains the lifeline of end-stage renal disease patients needing chronic intermittent hemodialysis. The Kidney Dialysis Outcomes Quality Initiative (K/DOQI) and European guidelines for vascular access propose the construction of an autogenous radial-cephalic direct wrist access (RCAVF) as the primary and best option. ${ }^{1,2}$ The usefulness of a RCAVF depends on an efficient dilatation and arterialization of the forearm veins used for the creation of arteriovenous anastomosis, which makes repeated successful cannulations possible. RCAVFs that mature without any early complications may function for many years. However, $10-24 \%$ of RCAVFs thrombose directly after operation or do not function adequately due to failure of maturation..$^{3-7}$ This results in delay of initiation of dialysis treatment with the need for placement of central venous catheters with their related morbidity and mortality. Usually, arteriovenous fistula (AVF) non-maturation depends on the quality and size of the vessels used for the arteriovenous anastomosis and the ability of vessel adaptation induced by the augmented bloodflow volumes. To predict successful maturation, duplex-derived criteria have shown beneficial effects of using well-sized radial arteries and cephalic veins ${ }^{8-10}$.

In case of tiny or diseased arteries and/or veins, the risk on access failure is probably higher and an alternative vascular access may be considered. However, there are only few data on the outcome or RCAVFs in patients with poor or doubtfull vessels and also no information on the performance of alternative accesses in these patients is available. An upper arm direct AVF, anastomosing the brachial artery with the cephalic or basilic vein may be a good second best option after failure of RCAVF, but from K/DOQI guidelines no consensus for either this option or the implantation of a prosthetic graft implant has been outlined. In addition upper arm access has a considerably higher incidence of peripheral ischemia and cardiac failure due to high access flow. Therefor to adress this subject, we have performed a randomized multicenter study comparing RCAVF vs forearm prosthetic graft (PTFE) implantation in patients with poor (doubtfull) vessels. 


\section{Methods}

Between January 1999 and April 2003, 383 consecutive new patients from 6 dialysis facilities, with end-stage renal failure were screened for enrollement in the study. This study was approved by the Medical Ethical Committee of all participating hospitals. According to the defined vessel criteria from the preoperative duplex scanning, 140 patients were allocated to primary placement of a RCAVF and 61 patients to primary prosthetic graft implantation. The remaining 182 patients (97 men / 85 females; mean age 59 yrs) were randomized to receive either a RCAVF ( $\mathrm{n}$ = 92) or prosthetic graft implant $(n=90)$ (Figure 1). Patient characteristics of both groups are shown in table 1. Preoperative assessment included a standard physical examination and bloodpressure measurement on both arms according to the RivaRocci method with a proximal pressure cuff and auscultation of the brachial artery. All patients underwent preoperative duplex ultrasonograpy of the arteries and superficial veins of the upper extremity. Duplex scanning was performed according to a standard protocol by experienced vascular techniciens. The angle of the emitted Doppler ultrasound wave from the probe was adjusted to $60^{\circ}$ to achieve the Doppler signal of the strongest intensity. The anterior-posterior internal diameter of the vessel was measured using B-mode technique with a proximal tourniquet to engorge the veins. Vessels were diagnosed as obstructed when no Doppler signal could be obtained. From the literature, we defined certain vessel diameters as cutoff values for randomization. When the radial artery had a diameter less than $1 \mathrm{~mm}$ with or without an absent cephalic vein, patients were allocated to implantation of a prosthetic brachial-antecubital forearm loop access. When the radial artery was $>2$ $\mathrm{mm}$ and the cephalic vein was $>1.6 \mathrm{~mm}$, a RCAVF was created. Patients with a radial artery between 1 and $2 \mathrm{~mm}$ and/or a cephalic vein $\leq 1.6 \mathrm{~mm}$. were randomized for the creation of either a RCAVF or prosthetic brachial-antecubital forearm loop. The number of complications and interventions were registered and primary, assisted primary and secondary patencies were calculated by life-table methods.

\section{Surgical procedure}

All procedures were performed under locoregional or general anesthesia with the use of antibiotic prophylaxis. RCAVFs were constructed by exposing the radial artery and cephalic vein through a longitudinal or transverse incision 4-5 cm proximal of the radial styloid process. 


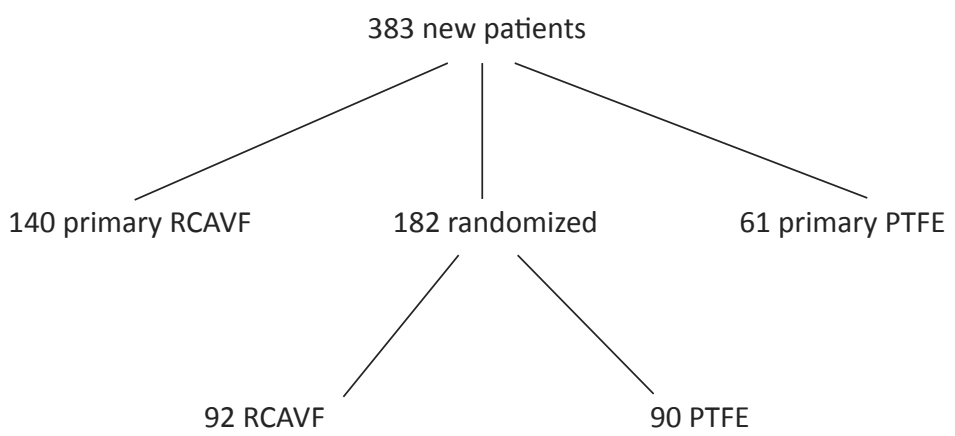

Figure 1. Algorithm for the creation of vascular access in new patients.

After sufficient vein mobilisation an end-to-side vein-to-artery anastomosis was performed with a running 7-0 polypropylene monofilament suture (Prolene, Ethicon, Johnson \& Johnson, Amersfoort, The Netherlands). The length of the arteriotomy was $10-15 \mathrm{~mm}$ and internal vessel diameters were measured with coronary probes. Thin-walled stretch polytetrafluorethylene-grafts (PTFE; Gore-Tex, WL Gore \& Associates, Flagstaff, Ariz) with a wall thickness of $0.5 \mathrm{~mm}$ and an internal diameter of $6 \mathrm{~mm}$, were positioned in a subcutaneous loop with the use of a tunneler device in the forearm between the brachial artery and a suitable elbow vein. Arterial and venous anastomoses were created with running 7-0 polypropylene sutures. AVF patency was confirmed peroperatively by palpation and Doppler examination. Coumarin (Sintrom, acenocoumarol, Novartis Pharma GmbH, Nürnberg, Germany) was given after surgery to all patients in a dosage that was sufficient for an adequate anticoagulation (international normalized ratio: > 2.5) for a period of 3 months. Postoperative evaluation was done by palpation and auscultation. Patients were regularly seen by the nephrologist and the decision to start dialysis treatment was made on the severity of deterioration of renal function. First cannulation of the RCAVF was performed when the vessels had matured adequately, usually after 4-6 weeks. When cannulation was not possible due to non-maturation, dialysis was started by means of a central-vein catheter. 


\begin{tabular}{lcc}
\hline & RCAVF & Prosthetic AVF \\
\hline$n$ & 86 & 84 \\
Male & $44(51)$ & $45(54)$ \\
Mean age (years) & 57.6 & 62.5 \\
Diabetes & $27(31)$ & $26(31)$ \\
Hypertension & $69(80)$ & $56(67)$ \\
Ischaemic cardiac disease & $11(13)$ & $17(20)$ \\
Peripheral arterial obstructive disease & $13(15)$ & $18(21)$ \\
Cerebrovascular disease & $9(10)$ & $12(14)$ \\
\hline
\end{tabular}

Table 1. Patient characteristics in patients with RCAVF and prosthetic AVF (\%).

\section{Follow-up}

Clinical follow-up was performed during a period of 12 months. Early and late complications and radiological and surgical interventions were registered. Complications were treated according to the standard clinical practice of the hospital where the patient was being dialysed.

Patency was defined as functional patency with adequate dialysis. Clinical criteria were used for detection of AVF thrombosis and non-maturation. Inability to cannulate the AVF or to obtain sufficient dialysis blood flow ( $\geq 250 \mathrm{cc} / \mathrm{min}$ ) within 6 weeks after fistula creation were indicators of a poorly functioning AVF. All patients with nonmaturating RCAVFs underwent angiography, visualizing the proximal arterial inflow by retrograde contrast filling initiated through a proximal occluding cuff. Venous outflow vessels were imaged by contrast injection after the release of the proximal cuff.

\section{Endpoints}

Endpoints were defined as AVF failure, death, successful kidney transplantation, or transfer to continuous ambulatory peritoneal dialysis (CAPD) treatment.

\section{Statistical analysis}

For statistical analysis, the statistical package of SPSS 11.0 for Windows (SPSS, Inc, Chicago, III) was used. Before the start of the study, a powercalculation had been performed to determine the number of patients needed per group to demonstrate an improvement in 1-year primary patency rate of $18 \%$. For a power of $80 \%$, at alpha $=0.05$, the resulting group size was 90 patients per study group. The incidence rate was defined as the number of complications or interventions per patient-year (py), the cumulative follow up time of all patients and analyzed with the Mann-Whitney test. Patency rates were obtained by Kaplan-Meier life-table analysis and compared with the log-rank test. Primary patency rate was defined as the percentage of AVFs 
that functioned well without any intervention after implantation. Assisted-primary patency rate was defined as the percentage of failing but still patent AVFs undergoing elective intervention, and secondary patency was defined as the proportion of patent AVFs still in use for hemodialysis after successful intervention for thrombosis. ${ }^{11}$ Patients with a patent AVF who died, received a kidney transplant, or were withdrawn from hemodialysis alive were censored. Differences were considered statistically significant when the $P$-value was less than 0.05 .

\section{Results}

Of the patients randomized for a RCAVF, one patient was still waiting for operation, one patient had a successful kidney transplantation while waiting for operation, three patients died before operation, and one patient was lost to follow-up. A total of 86 patients randomized for a RCAVF were subjected to further analysis. Six patients exhibited insufficient wrist vessels noticed during operation, and received PTFE graft AVFs. These six cases were considered as primary failures. Fifty-nine percent of the RCAVFs were functional for dialysis treatment after 6 weeks, resulting in a primary failure rate of $41 \%$, due to early thrombosis $(n=8)$, failure to mature ( $n$ $=21$ ) or insufficient vessels noticed during operation $(n=6)$. After 6 weeks, one patient developed steal (1.2\%) with the need for fistula ligation, one patient was lost to follow-up, one patient stopped dialysis treatment, and 8 patients died in the first year after creation of the RCAVF. Of the patients randomized for a prosthetic AVF, two patients were still on the list for operation, and four patients died before operation. A total of 84 patients randomized for prosthetic graft implant were subject for further analysis. In one patient it was not possible to implant a prosthetic graft due to abnormal vascular anatomy at the elbow, this patient received a RCAVF. The mean brachial artery diameter in the prosthetic group was $3.8 \mathrm{~mm}$ (range 2.0-6.0 $\mathrm{mm}$ ) and the mean cephalic vein diameter at the elbow was $3.1 \mathrm{~mm}$ (range $0.8-7.2$ $\mathrm{mm}$ ). In only one patient thrombotic occlusion occurred within the first 6 weeks after operation. No attempt at revision was made and this patient received a new vascular access. Thus $98 \%$ of prosthetic graft AVFs were functional for dialysis treatment. One patient developed a steal syndrome $(0.01 / \mathrm{py})$, five patients were lost to follow-up, one patient stopped cooperation with the study, 17 patients died of complications of their renal failure with a patent graft, three patients underwent successful kidney transplantation, two patients switched to peritoneal dialysis and in two patients the graft was explanted because of infection (0.02/py). 
Patients with RCAVFs developed a total of $102(1.19 /$ py) vs $122(1.45 /$ py; $P=.739)$ complications in the prosthetic AVFs (Table 2). The incidence of thrombosis was significantly higher in the prosthetic graft group (0.54/py vs $0.19 / \mathrm{py} ; P=.049$ ). Also infection was seen significantly more often in patients with prosthetic grafts $(0.13 /$ py vs $0.03 /$ py; $P=.009$ ). Pseudoaneurysm formation was only seen in the prosthetic AVF group.

\begin{tabular}{lccc}
\hline & RCAVF & Prosthetic AVF & P -value \\
\hline$n$ & 86 & 84 & - \\
Hematoma & 0.20 & 0.13 & $\mathrm{~ns}$ \\
Seroma & 0 & 0.02 & $\mathrm{~ns}$ \\
Infection & 0.03 & 0.13 & .009 \\
Thrombosis & 0.19 & 0.54 & .049 \\
Pseudoaneurysm & 0 & 0.10 & .006 \\
Steal syndrome & 0.01 & 0.01 & $\mathrm{~ns}$ \\
Stenosis & 0.29 & 0.30 & $\mathrm{~ns}$ \\
Non-maturation & 0.24 & - & - \\
Inability to cannulate & 0.14 & 0.05 & $\mathrm{~ns}$ \\
Bleeding & 0.02 & 0.04 & $\mathrm{~ns}$ \\
Others & 0.06 & 0.14 & $\mathrm{~ns}$ \\
Total number of complications & 1.19 & 1.45 & $\mathrm{~ns}$ \\
\hline
\end{tabular}

Table 2. Number of complications per patient-year in RCAVF group and prosthetic AVF group. $n s$, not significant

A total of $43(0.50 / p y)$ interventions in the RCAVF group and $79(0.94 / p y)$ in the prosthetic graft group were needed for access salvage $(P=.077)$ (Table 3$)$. Significantly more surgical thrombectomies were done in the prosthetic graft group $(0.45 /$ py vs $0.10 /$ py; $P=.008)$. However, percutaneous transluminal angioplasty (PTA) was almost equally performed in both groups (0.26/py in the RCAVF group vs 0.30 / py in the prosthetic graft group; $P=.437)$. In addition, surgical revisions $(0.10 /$ py in the RCAVF group vs $0.05 /$ py in the prosthetic graft group; $P=.086)$, were executed for access salvage. 


\begin{tabular}{lccc}
\hline & RCAVF & Prosthetic AVF & P-value \\
\hline$n$ & 86 & 84 & - \\
PTA & 0.26 & 0.30 & $\mathrm{~ns}$ \\
Surgical thrombectomy & 0.10 & 0.45 & .008 \\
Surgical revision & 0.10 & 0.05 & $\mathrm{~ns}$ \\
Other interventions & 0.03 & 0.14 & .028 \\
Total number of interventions & 0.50 & 0.94 & $\mathrm{~ns}$ \\
\hline
\end{tabular}

Table 3. Number of interventions per patient-year in RCAVF group and prosthetic AVF group. ns, not significant

Of the 43 interventions in the RCAVF group, 13 interventions were performed in 9 patients to improve maturation. Anastomotic stenosis in two patients were successfully treated by PTA. In two other patients PTA failed and in these two subjects a prosthetic graft was implanted. One subject underwent repeated PTA for cephalic vein stenosis, without success. Therefore a surgical revision was performed, also without success. Finally after a last unsuccessful PTA, the patient received a new AVF in the contralateral arm. Another 3 patients underwent unsuccessful surgical revisions, including basilic vein transposition, venous interposition, and ligation of tributary veins. At last, one patient underwent two surgical interventions, with ligation of tributary veins, followed by a new proximal radiocephalic anastomosis. However in these patients surgical revisions failed and prosthetic grafts were implanted. At the end, 2 out of 9 patients with nonmatured RCAVFs were successfully intervened. Primary and assisted-primary one-year patencies were $33 \%( \pm 5.3 \%)$ vs $44 \%( \pm 6.2 \%)$ $(P=.03$; Figure 2$)$ and $48 \%( \pm 5.5 \%)$ vs $63 \%( \pm 5.9 \%)(P=.035$; Figure 3$)$ for RCAVF and prosthetic AVF, respectively. Secondary patencies were $52 \%$ ( $\pm 5.5 \%)$ vs $79 \%( \pm 5.1 \%)$ $(P=.0001$; Figure 4) for RCAVF and prosthetic AVF, respectively. 


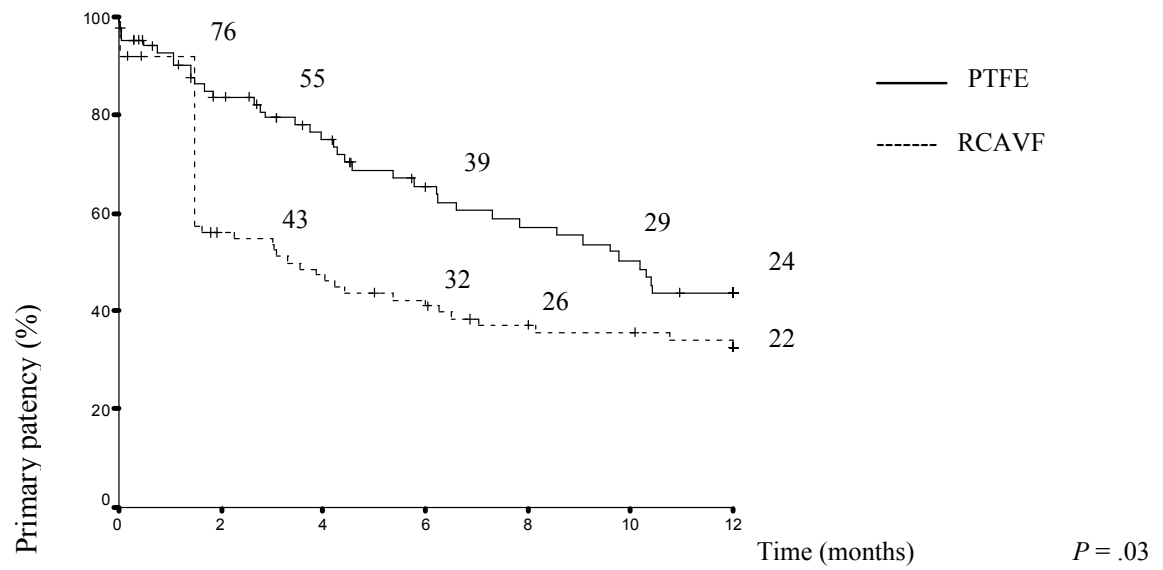

Figure 2. Primary patency rates. Patency rate is shown in percentages, and time in months. Number of patients is presented in graph. $P$ values calculated with the log rank test.

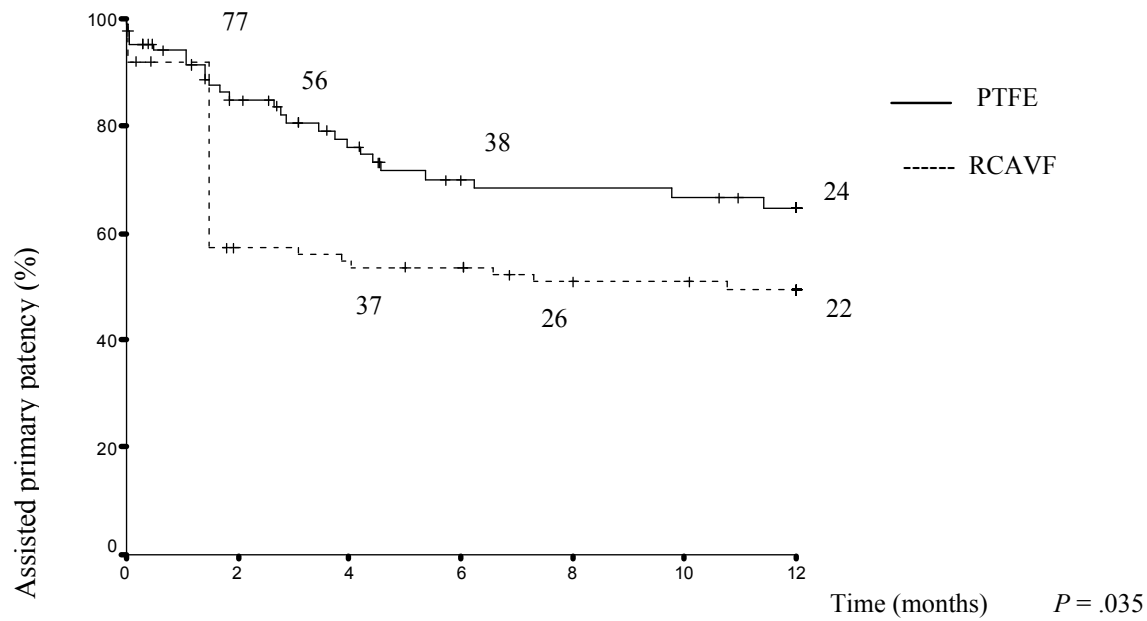

Figure 3. Assisted primary patency rates. Patency rate is shown in percentages, and time in months. Number of patients is presented in graph. $P$ values calculated with the log rank test. 


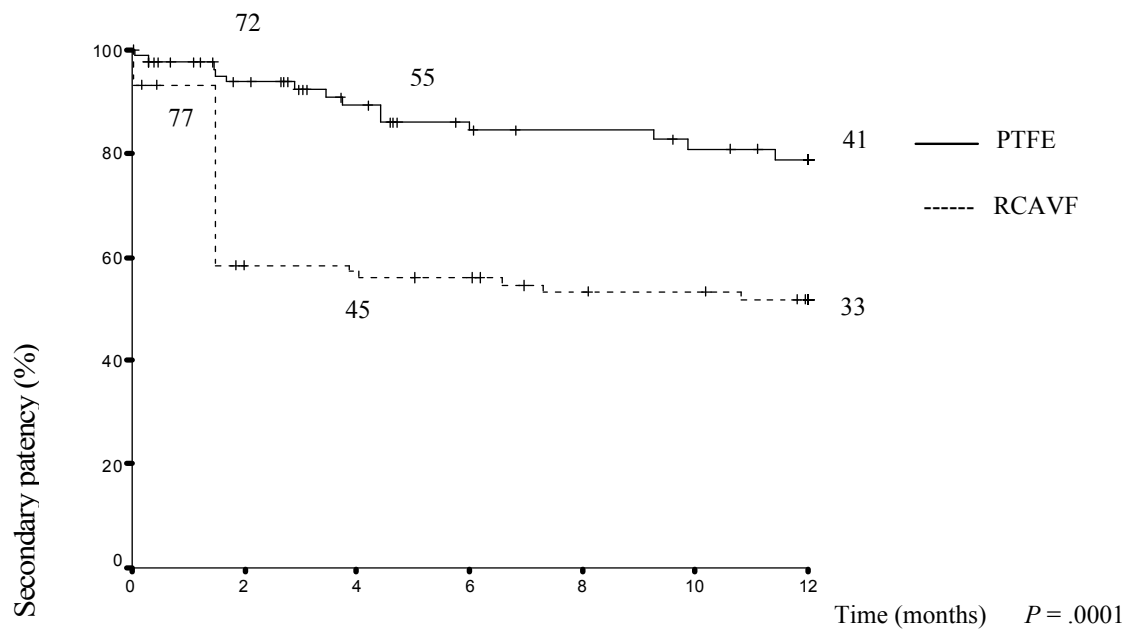

Figure 4. Secondary patency rates. Patency rate is shown in percentages, and time in months. Number of patients is presented in graph. $P$ values calculated with the log rank test.

\section{Discussion}

For the past decades the autogenous RCAVF has been accepted as the vascular access of first choice. Therefore, it seems logical to obtain autogenous fistulas in all new dialysis patients. However, data from a recent meta-analysis, show a high primary failure rate and moderate patency rates at one year of follow up. ${ }^{12}$ Similar outcomes could be confirmed by the current study where a high primary failure rate of $41 \%$ and moderate one-year patencies of 33\% and 52\% (primary and secondary) were found in the patients with RCAVFs. This is mainly due to early postoperative thrombosis and failure to mature. Non-functioning vascular access result in delay of initiation of dialysis treatment with additional morbidity. Access abandonment leads to the need of temporary central vein catheter placement with the risk of catheter thrombosis $(24-40 \%)^{13-15}$, infection and sepsis $(2-18 \%)^{14-16}$ and central vein obstruction (30\%). ${ }^{17}$ Usually, primary failure of RCAVFs depends on the quality and size of the vessels used for the arteriovenous anastomosis and the ability of vessel adaptation (remodelling) induced by the augmented blood-flow volumes. An adequate preoperative vessel assessment with non-invasive Doppler ultrasonography can select well-sized arteries and veins for RCAVF creation with subsequently improvement of the outcome of the vascular access ${ }^{8-10}$. Certain duplex-derived parameters may predict the risk on failure or dysmaturation. The internal radial artery diameter has been used in several 
studies to predict the outcome of RCAVFs or to plan strategies for vascular access. Wong et al. observed primary failure of RCAVFs in patients with a radial artery and/ or cephalic vein diameter $<1.6 \mathrm{~mm} .{ }^{18}$ Strategies for vascular access creation can be based on preoperative duplex scanning. Patients with a radial-artery diameter of ${ }^{3} 2$ $\mathrm{mm}$ and a cephalic vein diameter of ${ }^{3} 2.5 \mathrm{~mm}$ received RCAVFs, with as result a low primary failure rate of $8 \% .{ }^{9}$ However, there is still debate whether RCAVFs should be performed in patients with tiny and/or diseased poor vessels. An "all autogenous" vascular access policy, including creation of fistulas with small vessels, probably results in high primary failure rates and the need for multiple interventions. Until today, no studies are available elucidating on this subject and that was the reason to perform the present study and to investigate which method for hemodialysis vascular access in patients with poor forearm vessels may be the best option. In this study we found a dismal one year primary patency of $33 \%$ in the RCAVF group compared to $44 \%$ in the prosthetic AVF group. Also, a secondary patency of $52 \%$ at one year in the RCAVF group was significantly lower compared to $79 \%$ in the PTFE graft group. From these results we conclude that patients with poor forearm vessels may possibly benefit from implantation of a prosthetic graft and this may a better option than a primary autogenous radial-cephalic direct wrist access. In addition primary selection of a PTFE AVF in elderly patients may be worthwhile, given the reduced life expectancy of these patients ( $50 \%$ mortality at 2 years), ${ }^{19}$ and the risk on long periods of indwelling central vein catheters with their related morbidity, when attempts to make non-matured fistulas functioning, fail.

One limitation of this study is the relatively short follow up period of one year. Because it is conceivable that there may be patency advantage for the RCAVF beyond one year. Another limitation is the fact that the duplex measurements of the vessel diameters was performed only one time. Because there may be some variation in vessel diameter measured on different times and different days. Also, there may be some influence of regional anesthesia on vessel diameters due to a vasodilatation mechanism.

One may argue about trying to create autogenous fistulas in patients with poor vessels and indeed still $52 \%$ of patients that received a RCAVF in this study did develop functioning access with ultimatedly lessinterventions for access salvage (0.94/py vs $0.50 /$ py interventions). Also, when a RCAVF does fail, it is still possible to implant a forearm prosthetic AVF. The total number of complications in RCAVFs is similar to the prosthetic AVFs (1.19/py vs $1.45 /$ py). The number of thrombotic occlusions were significantly higher in grafts, while non-maturation and cannulation difficulties occurred in RCAVFs in particular. 
Of the 43 interventions in the RCAVF group, 13 interventions were performed in 9 patients to improve maturation. Interventional treatment by means of PTA and surgical revision resulted in maturation in only two patients $(22 \%)$. The impact of reintervention on fistula maturation and maintenance was recently published by two studies. ${ }^{20,21}$ In these studies, not only concerning radial-cephalic but also brachialcephalic and basilic AVFs, a $10 \%$ improvement was seen in accomplishing a functional AVF, achieved by either PTA or surgical intervention. In the current study, only PTA was successfull in accomplishing a functional access in a minority of patients. In the other patients with non-matured accesses, beyond the period of 6 weeks no futher improvement was observed and these accesses were replaced by alternative fistulas. An aggressive approach to evaluate and intervene on immature fistulas may improve maturation rates. Beathard et al. reported on their experience with 71 patients referred because of inadequate maturation of their fistulas. ${ }^{22}$ Eight were not evaluated further because they were believed to have an inadequate arterial inflow. The remaining 63 patients underwent angioplasty of a stenotic lesion in the draining vein, ligation of one or more tributary veins, or a combination of both procedures. As a result of these salvage attempts $82.5 \%$ of the fistulas matured adequately to be used for dialysis. Turmel-Rodriques et al. reported in their study that interventional radiology can treat the majority of cases and achieve $97 \%$ success rate. However they also found out that early recurrence of stenoses can occur. ${ }^{23}$

Early detection and correction of hemodynamically significant stenosis in both autogenous and prosthetic AVFs reduces thrombosis rates. In addition, intervention with PTA or surgical revision to correct stenosis reduces the rate of AVF thrombosis. ${ }^{24-28}$ This pre-emptive correction of AVF at risk for thrombosis should have the additional economic impact of reducing emergency admissions due to access thrombosis, reducing the need for temporary access catheters with their attendant complications, and preventing underdialysis with its associated morbidity and mortality rates. All patients in our study were on anticogulances for a period of 3 months. In Europe anticoagulant treatment of in particular prostethic graft is quite common.

In the current study a low infection incidence of $0.03 /$ py in the RCAVF group and $0.13 /$ py in the prosthetic AVF group was seen. Early postoperative wound infection after RCAVF and prosthetic AVF construction poses a high risk of wound dehiscense and secondary haemorrhage. These patients require treatment with intravenous antibiotics and drainage of pus collections. Late-onset infections of prosthetic AVFs often occur at cannulation sites and may resolve with simple antibiotic therapy, eventually combined with segmental graft replacement through a new subcutaneous route..$^{29,30}$ In case of severe infection and risk of sepsis, graft explantation is required. 
The incidence of steal syndrome, in which a sufficient proportion of the arterial flow is shunted away from the distal upper extremity, resulting in peripheral ischaemia, is usually low in distal AVFs Only 2 patients (with RCAVF and a prosthetic graft) in our study developed steal syndrome, necessitating access ligation.

In summary, we performed a prospective randomized study comparing primary RCAVF vs prosthetic (PTFE) implantation in patients with poor vessels. Although there were more interventions needed for access salvage in the PTFE group, we conclude that patients with poor forearm vessels may benefit from implantation of a prosthetic graft. 


\section{References}

1. The Vascular Access Work Group. NKF-DOQI clinical practice guidelines for vascular access. National Kidney Foundation-Dialysis Outcomes Quality Initiative. Am J Kidney Dis 1997;30(suppl 3):S150-191.

2. National Kidney Foundation. K/DOQI clinical practice guidelines for vascular access, 2000. Am J Kidney Dis 2001;37(suppl 1):S137-181.

3. Reilly DT, Wood RF, Bell PR. Arteriovenous fistulas for dialysis: blood flow, viscosity, and long-term patency. World J Surg 1982;6:628-633.

4. Tordoir JH, Kwan TS, Herman JM, Carol EJ, Jakimowicz JJ. Primary and secondary access surgery for haemodialysis with the Brescia-Cimino fistula and the polytetrafluorethylene (PTFE) graft. Neth J surg 1983;35:8-12.

5. Wedgwood KR, Wiggins PA, Guillou PJ. A prospective study of end-to-end vs. end-toside arteriovenous fistulas for haemodialysis. Br J Surg 1984;71:640-642.

6. Kherlakian GM, Roedersheimer LR, Arbaugh JJ, Newark KJ, King LR. Comparison of autogenous fistula versus expanded polytetrafluorethylene graft fistula for angioaccess in hemodialysis. Am J Surg 1986;152:238-243.

7. Palder SB, Kirkman RL, Whittemore AD, Hakim RM, Lazarus JM, Tilney NL. Vascular access for hemodialysis. Patency rates and results of revision. Ann Surg 1985;202:235239.

8. Lemson MS, Leunissen KM, Tordoir JH. Does pre-operative duplex examination improve patency rates of Brescia-Cimino fistulas? Nephrol Dial Transplant 1988;13:1360-1361.

9. Silva MB Jr, Hobson RW II, Pappas PJ, Jamil Z, Araki CT, Goldberg MC, et al. A strategy for increasing use of autogenous hemodialysis access procedures: impact of preoperative noninvasive evaluation. J Vasc Surg 1998;27:302-307.

10. Ascher E, Gade P, Hingorani A, Mazzariol F, Gunduz Y, Fodera M, et al. Changes in the practice of angioaccess surgery: impact of dialysis outcome and quality initiative recommendations. J Vasc Surg 2000;31:84-92.

11. Rutherford RB. Standards for evaluating results of interventional therapy for peripheral vascular disease. Circulation 1991;83:16-11.

12. Rooijens PPGM, Tordoir JHM, Stijnen T, Burgmans JPJ, Smet de AAEA, Yo TI. Radiocephalic wrist arteriovenous fisula for hemodialysis: meta-analysis indicates a high primary failure rate. Eur J Vasc Endovasc Surg 2004;28:583-589.

13. McLaughlin K, Jones $B$, Mactier R, Porteus $C$. Long-term vascular access for hemodialysis using silicon dual-lumen catheters with guidewire replacement of catheters for technique salvage. Am J Kidney Dis 1997;29:553-559.

14. McDowell DE, Moss AH, Vasilakis C, Bell R, Pillai L. Percutaneously placed dual-lumen silicone catheters for long-term hemodialysis. Am Surg 1993;59:569-573.

15. Moss AH, McLaughlin MM, Lempert KD, Holley JL. Use of a silicone catheter with a Dacron cuff for dialysis short-term vascular access. Am J Kidney Dis 1988;12:492-498.

16. Dryden MS, Samson A, Ludlam HA, Wing AJ, Phillips I. Infective complications associated with the use of the Quinton 'Permacath' for long-term central vascular access in haemodialysis. J Hosp Infect 1991;19:257-262.

17. Grote J, Lufft V, Nikutta P, van der Lieth H, Bahlmann J, Daniel WG. Transesophageal echocardiographic assessmant of superior vena cava thrombosis in patients with longterm central venous hemodialysis catheters. Clin Nephrol 1994;42:183-188. 
18. Wong V, Ward R, Yaylor J, Selvakumar S, How TV, Bakran A. Factors associated with early failure of arteriovenous fistulae for haemodailysis access. Eur J Vasc Endovasc Surg 1996;12:207-213.

19. Culp K, Taylor L, Hulme PA. Geriatric hemodialysis patients: a comparative study of vascular access. J Am Nephrol Nurses Assoc 1996;23:583-590.

20. Hingorani A, Asher E, Kallakuri S, Greenberg S, Khanimov Y. Impact of reintervention for failing upper-extremity arteriovenous autogenous access for hemodialysis. J Vasc Surg 2001;34:1004-1009.

21. Berman SS, Gentile AT. Impact of secondary procedures in autogenous arteriovenous fistula maturation and maintenance. J Vasc Surg 2001;34:866-871.

22. Beathard GA, Settle SM, Shields MW. Salvage of the nonfunctioning arteriovenous fistula. Am J Kdiney Dis 1999;33:910-916.

23. Turmel-Rodrigues L, Mouton A, Birmele B, Billaux L, Ammar N, Grezard O, et al. Salvage of immature forearm fistulas for haemodialysis by interventional radiology. Nephrol Dial Transplant 2001;16:2365-2371.

24. Safa AA, Valji K, Roberts AC, Ziegeler TW, Hye RJ, Oglevie SB. Detection and treatment of dysfunctional hemodailysis acess grafts: effect of a surveillance program on graft patency and the incidence of thrombosis. Radiology 1996;199:653-657.

25. Burger H, Zijlstra JJ, Kluchert SA, Scholten AP, Kootstra G. Percutaneous transluminal angioplasty improves longevity in fistulae and shunts for haemodialysis. Nephrol Dial Transplant 1990;5:608-611.

26. Schwab SJ, Raymond JR, Saeed M, Newman DE, Dennis PA, Bollinger RR. Prevention of haemodialysis fistula thrombosis. Early detection of fistula stenoses. Kidney Int 1989; 36:707-711.

27. Turmel-Rodriques L, Pengloan J, Blanchier D, Abaza M, Birmele B, Haillot O, et al. Insufficient dialysis shunts: improved long-term patency rates with close hemodynamic monitoring, repeated percutaneous balloon angioplasty, and stent placement. Radiology 1993;187:273-278.

28. Glanz S, Gordon DH, Butt KMH, Hong J, Lipkowitz GS. The role of percutaneous angioplasty in the management of chronic hemodialysis fistulas. Ann Surg 1987;206:777-781.

29. Raju S. PTFE graft for hemodialysis access. Techniques for insertion and management of complications. Ann Surg 1987;206:666-673.

30. Fillinger MF, Reinitz ER, Schwartz RA, Resetarits DE, Paskanik AM, Bruch D, et al. Graft geometry and venous intimal-hyperplasia in arteriovenous loop grafts. J Vasc Surg 1990;11:556-566. 


\section{Current imaging techniques for stenosis detection in hemodialysis \\ vascular access}

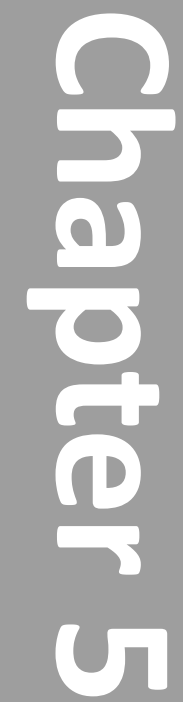


Chapter 5 


\section{Introduction}

A well functioning vascular access is the cornerstone of hemodialysis treatment in endstage renal disease (ESRD) patients. However, these vascular accesses have a high risk of thrombosis due to stenoses that jeopardize flow and patency. ${ }^{1}$ Clinical examination should remain the key method for the diagnosis of stenosis in arteriovenous fistulas (AVF) and prosthetic arteriovenous grafts (AVG). ${ }^{2}$ If a hemodynamically significant stenosis is suspected by physical examination or dialysis parameters, access imaging should be performed as soon as possible.

\section{Stenosis distribution in dysfunctional access}

A stenotic lesion, due to intimal hyperplasia, is the most common cause for low access flow. In radial-cephalic ateriovenous fistulas (RCAVF), 55-75\% of these stenoses are located close to the arteriovenous (AV) anastomosis and $25 \%$ in the venous outflow tract. $^{3,4}$ In brachial-cephalic and/or basilic AVFs, the typical location (55\%) is at the junction of the cephalic with the subclavian vein and the basilic vein with the axillary vein, respectively. ${ }^{3} \mathrm{An}$ arterial inflow stenosis $>2 \mathrm{~cm}$ from the anastomosis is uncommon, but may endanger the flow in the AVF. In grafts $50-70 \%$ of the venous stenoses occur within $3 \mathrm{~cm}$ of the vein-to-graft anastomosis.,

\section{Imaging techniques}

\section{Duplex ultrasonography}

Duplex ultrasonograpy (DUS) enables assessment of vessel parameters such as diameter, flow-volume and flow-velocities. Whenever a stenosis is suspected, DUS can be performed to locate and quantify the degree of diameter reduction due to the stenosis. ${ }^{7-10}$ DUS in the hand of an experienced vascular technician is an adequate diagnostic tool except for the diagnosis of obstruction in hand arteries and central veins $^{11}$ and can be helpful in defining thrombus extent. Duplex examination is especially valuable in detecting stenoses and to perform flow measurements in nonmaturing AVFs. In addition, in a recently published study the authors suggest that duplex-guided balloon angioplasty of failing or nonmaturing AVFs is feasible and safe, even when it is performed as an office-based procedure. ${ }^{12}$ The superficial location of the AVF facilitates duplex scan visualization. This approach avoids the use of contrast material and radiation exposure. Also it may be financially more lucrative compared to the same hospital-based procedures. The major drawback is that imaging of the central veins is not possible with this technique. 


\section{Digital subtraction angiography}

Digital subtraction angiography (DSA), using X-ray techniques and iodinated contrastmedia is considered the standard method of reference for assessment of stenoses in AVFs. The in-plane resolution as acquired with conventional angiography or DSA is superior to other imaging modalities like DUS or magnetic resonance angiography (MRA). ${ }^{13}$ A disadvantage is that acquired data are two-dimensional (2D) projections of the complex three-dimensional (3D) vascular network in the upper extremity. Therefore analysis is limited by the number and quality of the acquired projections. DSA is typically performed before, during and after percutaneous dilatation or thrombolysis and after surgical thrombectomy in order to guide the treatment and depict arterial inflow as well as residual stenoses and/or clots or central venous obstruction. ${ }^{14} \mathrm{~A}$ drawback however, is the use of iodine nephrotoxic contrast-media that may lead to temporary or permanent deterioration of residual renal function in up to $20 \%$ of the cases in patients with end-stage renal disease (ESRD). ${ }^{15}$ To avoid impairment of residual renal function, gadolinium-enhanced DSA may be an alternative. Le Blanche et al. found no impairment of residual renal function using gadolinium in their patient group. ${ }^{16}$ They concluded, that gadolinium-enhanced DSA is an effective and safe method to assess the cause for malfunctioning AVFs. It can also be used to plan and perform percutaneous transluminal angioplasty (PTA). Normally this is done by a potentially hazardous brachial artery or more invasive femoral artery approach, for which hospitalization of the patient in most cases is necessary. However, retrograde venous access puncture and catheterization should be considered as an alternative for the visualization of the arterial inflow and endovascular treatment of inflow stenoses. ${ }^{17}$ An additional drawback of DSA is that arterial inflow stenosis may be missed. However, by introduction of a catheter through the access up into the arterial tree, also the subclavian and brachial arteries can be visualised. ${ }^{18}$

\section{Magnetic resonance angiography}

Due to ongoing technical improvements MRA has become an important and valuable imaging modality in the recent years in detecting stenosis in AVFs. MRA is an useful, safe and practical imaging modality in complex fistulas with fewer complications and side effects compared to DSA. ${ }^{19}$ If MRA is performed for stenosis detection, it should be employed with the contrast-enhanced technique (CE-MRA). This is due to the fact that the non-enhanced time-of-flight (TOF) MRA is prone to artefacts and stenoses are frequently overestimated. ${ }^{20}$ Planken et al. concluded that CE-MRA is a useful diagnostic tool for detecting stenoses in hemodialysis AVF with a flow decline prior to interventional treatment using DSA. ${ }^{21}$ An other study found a sensitivity, specificity 
and positive and negative predictive values of MRA in the detection of stenosed vessel segments of 97, 99, 96 and 99\%, respectively. ${ }^{22}$ When a deep venous obstruction is suspected, contrast-enhanced $3 D$ MR venography is a well tolerated sensitive technique in detecting the cause of the malfunctioning AVFs for-surgical planning. It is possible to obtain high-quality images with this technique as an alternative to angiography. ${ }^{23}$ However, it is an intricate procedure, and therefore not possible in every hospital. Also, a major drawback is the fact that an additional intervention is not possible at the same time. ${ }^{24}$ Recently concerns have arisen regarding the used gadolinium chelates as a contrast medium for CE-MRA in patients with renal failure. ${ }^{25}$ During the last decade approximately 200 cases of nephrogenic systemic fibrosis (NSF), previously known as nephrogenic fibrosing dermopathy, have been reported worldwide. ${ }^{26}$ Because of this reported possibly serious complication, prevention of dehydration and dialysis soon after gadodiamide injection are recommended as prophylactic measures.

\section{Multi-slice computed tomographic angiography}

Multi-slice computed tomographic angiography (MS-CTA) is a relatively new minimal invasive technique for stenosis detection in hemodialysis access. The spiral CT, using a slip- ring CT scanner, can obtain volumetric data by transporting the patient table at a constant speed. ${ }^{27}$ In the beginning single-detector CTA has been reported to be an useful tool for assessing hemodialysis AVFs. However this technique has limited spatial resolution and anatomic coverage. ${ }^{27,28}$ Recently, multi-detector CTA technology has been developed offering improved temporal and spatial resolution and greater anatomic coverage, allowing an expanded application in the evaluation of vascular diseases. ${ }^{29}$ Ko et al. concluded in their study that MS-CTA is clinically feasible for evaluating the complete vascular tree of failing AVFs and in showing uncommon complications, including brachial aneurysms and central vein lesions. ${ }^{29}$ In addition, the 3D capability of MS-CTA can offer freely rotated projection angiograms to show vascular lesions from the appropriate perspective. MS-CTA examinations can be accomplished quickly (8-10 min for patient preparation and CT), and subsequent postprocessing usually takes about 5 minutes with current computer capacity. MS-CTA has several drawbacks. First, the use of intravenous (IV) contrast material is associated with the risk of anaphylactic reaction and deterioration of renal function. Second, this method has radiation exposure. Third, MS-CTA cannot provide hemodynamic details including the flow velocity and pressure gradient across the stenosis. Finally, it is not possible to perform direct a corrective intervention, should a hemodynamically significant stenosis be detected by MS-CTA. 


\section{Summary and conclusion}

DUS is a readily available, inexpensive, noninvasive technique, and has no radiation exposure. Therefore DUS is suggested as the initial imaging modality of stenosis detection in hemodialysis vascular access. However, the complete vascular access can only be depicted with DSA to detect all significant stenoses eligible for intervention, which can be performed in the same session. MRA or MS-CTA are useful, safe and practical imaging modalities in complex vascular accesses or when DSA is inconclusive. 


\section{References}

1. Murphy GJ, White SA, Nicholson ML. Vascular access for haemodialysis. Br J Surg 2000;87:1300-1315.

2. Turmel-Rodriques L, Pengloan J, Bourquelot P. Interventional radiology in hemodialysis fistulae and grafts: a multidisciplinairy approach. Cardiovasc Intervent Radiol 2002;25:316.

3. Turmel-Rodriques L, Pengloan J, Baudin S, Testou D, Abaza M, Dalidah G, et al. Treatment of stenosis and thrombosis in haemodialysis fistulas and grafts by interventional radiology. Nephrol Dial Transplant 2000;15:2029-2036.

4. Turmel-Rodriques L, Pengloan J, Blanchier D, Abaza M, Bunielé B, Haillot $O$, et al. Insufficient dialysis shunts: improved long-term patency rates with close hemodynamic monitoring, repeated percutaneous balloon angioplasty, and stent placement. Radiology 1993;187:273-278.

5. Choudhury D, Lee J, Elivera HS, Ball D, Roberts AB, Ahmed Z. Correlation of venography, venous pressure, and hemoaccess function. Am J Kidney Dis 1995;25:269-275.

6. Berkoben M, Schwab SJ. Maintenance of permanent hemodialysis vascular access patency. J Am Nephrol Nurses Assoc 1995;22:17-24.

7. Tordoir JH, de Bruin HG, Hoeneveld H, Eikelboom BC, Kitslaar PJ. Duplex ultrasound scanning in the assessment of arteriovenous fistulas created for hemodialysis access: comparison with digital subtraction angiography. J Vasc Surg 1989;10:122-128.

8. Gadallah MF, Paulson Wo, Vickers B, Work J. Accuracy of Doppler ultrasound in diagnosing anatomic stenosis of hemodialysis arteriovenous access as compared with fistulography. Am J Kidney Dis 1998;32:273-277.

9. Shackleton CA, Taylor OC, Buckley AR, Rowley VA, Cooperberg PL, Fry PD. Predicting failure in polytetrafluoroethylene vascular access grafts for hemodialysis: a pilot study. Can J Surg 1987;30:442-444.

10. Tordoir JH, Hoeneveld H, Eikelboom BC, Kitslaar PJ. The correlation between clinical and duplex ultrasound parameters and the development of complications in arteriovenous fistulae for haemodialysis. Eur J Vasc Surg 1990;4:179-184.

11. MacDonald MJ, Martin LG, Hughes JD, Kikeri D, Scout DC, Harker LA. Distribution and severity of stenoses in functioning arteriovenous grafts: a duplex and angiographic study. J Vasc Technol 1996;20:131-136.

12. Ascher E, Hingorani A, Marks N. Duplex-guided balloon angioplasty of failing or nonmaturing arterio-venous fistulae for hemodialysis: A new office-based procedure. J Vasc Surg 2009;50:594-599.

13. Planken RN, Tordoir JHM, Duijm LEM, de Haan MW, Leiner T. Current techniques for assessment of upper extremity vasculature prior to hemodialysis vascular access creation. Eur Radiol 2007;17:3001-3011.

14. Haage P, Vorwerk D, Piroth W, Schürman K, Günther RW. Treatment of hemodialysisrelated central venous stenosis or occlusion: results of primary Wallstent placement and follow-up in 50 patients. Radiology 1999;212:175-180.

15. Geoffroy O, Tassart M, Le Blanche AF, Khalil A, Duédal V, Rossert J, et al. Upper extremity digital subtraction venography with gadoterate meglumine before fistula creation for hemodialysis. Kidney Int 2001;59:1491-1497.

16. Le Blanche AF, Tassart M, Deux JF, Rossert J, Bigot JM, Boudghene F. Gadoliniumenhanced digital subtraction angiography of hemodialysis fistulas: a diagnostic and therapeutic appraoch. AJR Am J Roentgenol 2002;179:1023-1028. 
17. Duijm LEM, van der Rijt RHH, Cuypers PWM, Tielbeek AV, Receveur KJG, DouwesDraaijer $P$, et al. Outpatient treatment of arterial inflow stenoses of dysfunctional hemodialysis access fistulas by retrograde venous access puncture and catheterization. J Vasc Surg 2008; 47:591-598.

18. Duijm LE, Liem YS, van der Rijt RH, Nobrega FJ, van den Bosch HC, Douwes-Draaijer P, et al. Inflow stenoses in dysfunctional hemodialysis access fistulae and grafts. Am J Kidney Dis 2006; 48:98-105.

19. Paksoy $\mathrm{Y}$, Gormus N, Tercam MA. Three-dimensional contrast-enhanced magnetic resonance angiography (3-D CE-MRA) in the evaluation of hemodialysis access complications, and the condition of central veins in patients who are candidates for hemodialysis access. J Nephrol 2004;17:57-65.

20. Meany JF. Magnetic resonance angiography of the peripheral arteries: current status. Eur Radiol 2003;13:836-852.

21. Planken RN, Tordoir JHM, Dammers R, de Haan MW, Oei TK, van de Sande FM, et al. Stenosis detection in forearm hemodialysis arteriovenous fistulae by multiphase contrast-enhanced magnetic resonance angiography: preliminary experience. J Magn Reson Imaging 2003;17:54-64.

22. Froger CL, Duijm LEM, Liem YS, Tielbeek AV, Donkers-van Rossum AB, Douwes-Draaijer $\mathrm{P}$, et al. Stenosis detection with MR angiography and digital subtraction angiography in dysfunctional hemodialysis access fistulas and grafts. Radiology 2005; 234:284-291.

23. Tanju S, Sancak T, Düşünceli E, Yağmurlu B, Erden I, Sanlidilek U. Direct contrastenhanced 3 D MR venography evaluation of upper extremity deep venous system. Diagn Interv Radiol 2006;12:74-79.

24. Haage $P$, Krings $T$, Schmitz-Rode T. Nontraumatic vascular emergencies: imaging and intervention in acute venous occlusion. Eur Radiol 2002;12:2627-2443.

25. Shellock FG, Kanal E. Safety of magnetic resonance imaging contrast agents. J Magn Reson Imaging 1999;10:477-484.

26. Marckmann P, Skov L, Rossen K, Dupont A, Damhalt MB, Heaf JG, et al. Nephrogenic systemic fibrosis: suspected causative role of gadodiamide used for contrast-enhanced magnetic resonance imgaging. J Am Soc Nephrol 2006;17:2359-2362.

27. Lin YP, Wu MH, Ng YY, Lee RC, Liou JK, Yang WC, et al. Spiral computed tomographic angiography - A new technique for evaluation of vascular access in hemodialysis patients. Am J Nephrol 1998;18:117-122.

28. Cavagna E, D'Andrea P, Schiavon F, Tarroni G. Failing hemodialysis arteriovenous fistula and percutaneous treatment: imaging with $\mathrm{CT}, \mathrm{MRI}$ and digital subtraction angiography. Cardiovasc Intervent Radiol 2000; 23: 262-265.

29. Ko SF, Huang CC, Ng SH, Lee TY, Hsieh MJ, Lee FY, et al. MDCT angiography for evaluation of the complete vascular tree of hemodialysis fistulas. AJR 2005;185:1268-1274. 


\section{Multi-slice computed tomographic angiography for stenosis}

detection in forearm hemodialysis arteriovenous fistulas

P.P.G.M. Rooijens, G.P. Serafino, D. Vroegindeweij, R. Dammers, T.I. Yo, A.A.E.A. de Smet, J.H.M. Tordoir 


\begin{abstract}
Purpose: A method of diagnosing the extent and severity of arteriovenous fistula (AVF) stenoses is multi-slice computed tomographic angiography (MS-CTA). The aim of this prospective study was to assess the accuracy of MS-CTA for the detection and grading of stenoses in AVF in comparison to digital subtraction angiography (DSA), which was used as the gold standard of reference.
\end{abstract}

Methods: A total of 15 hemodialysis patients with dysfunctioning forearm AVF were included. These AVFs were evaluated by both DSA and MS-CTA and were read in a prospective, blinded manner by two radiologists experienced in vascular imaging.

Results: ROC analysis revealed areas under the curve of $0.90 \pm 0.07$ for observer I and $0.87 \pm 0.08$ for observer II at a stenosis cut-off level of $\geq 50 \%$ diameter reduction. The combined results for MS-CTA showed a sensitivity, specificity, and positive and negative predictive values of $82 \%, 98 \%, 82 \%$, and $98 \%$ for stenoses $\geq 50 \%$ and $71 \%$, $99 \%, 77 \%$, and $98 \%$ for stenoses $\geq 75 \%$, respectively. Interobserver agreement for the detection of stenoses $\geq 50 \%$ diameter reduction was 0.70 and 1.0 , for MS-CTA and DSA, respectively.

Conclusion: MS-CTA can provide good visualization of forearm hemodialysis access AVF and has moderate sensitivity, but high specificity for the detection of flowlimiting stenoses. 


\section{Introduction}

Patients with end-stage renal disease depend on a well-functioning arteriovenous fistula (AVF) for hemodialysis treatment. However, the most important complication of AVFs is thrombotic occlusion due to intimal hyperplastic stenoses, eliminating bloodflow. ${ }^{1}$ Access monitoring, by means of flow measurement, with the purpose of early detection and pre-emptive intervention of these stenoses has proved to be beneficial to diminish thrombosis and improve patency rates. ${ }^{2}$ In current clinical practice, vascular access stenosis detection and grading are usually performed using duplex utrasonography and digital subtraction angiography (DSA). Analysis of the DSA images can be difficult due to vessel overlap, in particular at the level of the anastomoses, where multiple vessels may cross.

An alternative method of diagnosing the extent and severity of AVF stenoses is multislice computed tomographic angiography (MS-CTA). The MS-CTA offers the ability to acquire three-dimensional (3D) data sets, which may potentially solve the problem of vessel overlap and increase the diagnostic accuracy. Until now, the experience with MS-CTA for imaging of stenoses and diagnosis of access malfunction is limited. ${ }^{3-6}$ The aim of this prospective study was to assess the accuracy of MS-CTA for the detection and grading of stenoses in AVF in comparison to DSA, which was used as the gold standard of reference.

\section{Patients and methods}

\section{Patients}

In this study 15 consecutive hemodialysis patients (12 males, 3 females; mean age 55 years; range $26-75$ yrs) with failing AVF were included. All patients had a forearm AVF (7 radial-cephalic and 8 prosthetic forearm loop graft). The mean dialysis vintage was $7.2 \pm 2.3$ months (range 4-14 months). In all radial-cephalic AVFs sufficient blood flow ( $\geq 250 \mathrm{~mL} / \mathrm{min}$ ) within 6 weeks after fistula creation was obtained, and therefore they were considered as matured. Patients were only included when their forearm AVF was considered at risk for thrombosis. An AVF was considered at risk for thrombosis if absolute AVF at any time was $<600 \mathrm{~mL} /$ minute or if a patient exhibited a flow decline of $>25 \%$ between two consecutive measurements in combination with an absolute flow of $<1000 \mathrm{~mL} /$ minute measured using an ultrasound dilution technique (Transonic ${ }^{\circledR}$ Systems Inc., Ithaca, NY). ${ }^{2}$ Also study inclusion required DSA imaging within 3 weeks of MS-CTA. 
All patients signed informed consent before they were enrolled in the study. This study was approved by the Medical Ethics Committee of the participating hospital, and all patients signed informed consent.

\section{MS-CTA}

MS-CTA was performed with a General Electric (Milwaukee,Wisc.,USA) 4 slices CT scanner. An unenhanced scan with $2.5 \mathrm{~mm}$ collimation was obtained from axilla to wrist to cover the arteriovenous anastomosis, the inflow artery and the outflow vein. A 20 gauge intravenous catheter was inserted into a peripheral vein of the contralateral arm. By power injector, $100 \mathrm{ml}$ preloaded nonionic contrast (ultravist 300 , Schering, Berlin, Germany) was infused with a speed of $3 \mathrm{ml} / \mathrm{s}$. Bolus tracking (SmartPrep, GE Healthcare) was applied by selecting an engorged vessel proximal to the AVF with a threshold level of $120 \mathrm{H} .^{6}$

\section{DSA}

All DSA examinations were performed by experienced interventional radiologists. Selective arteriograms were obtained by puncturing the AVF in a retrograde fashion with a 19-gauge needle. Images of the feeding artery, arterial anastomosis (in the case of prosthetic AVF), the AVF, venous anastomosis and efferent vein(s) were obtained by retrograde filling of the AVF with contrast material due to flow interruption, according to Staple. ${ }^{7}$ The total amount of contrast medium that was used varied between 60 and $80 \mathrm{~mL}$ lohexol (Visipaque; Nycomed-amersham, Oslo, Norway) and was administered in a variable number of runs. Contrast medium was administered with a power injector (Medrad, Indianola, PA). The number of contrast injections and view angles varied per patient and depended on the complexity of the vascular anatomy. If a stenosis $\geq 50 \%$ luminal diameter reduction was found on DSA imaging, subsequently percutaneous transluminal angioplasty was performed. If no significant stenosis was found at DSA, CTA images were made available and compared with DSA images. Any significant lesions found on CTA and initially not visualized at DSA were then, if possible, depicted with DSA and, subsequently treated.

\section{Image Analysis}

For image analysis purpose, all MS-CTA data sets were transferred to an off-line workstation (GE, Milwaukee,Wisc.,USA), with dedicated post processing software. Review was done on the dynamic series, which exhibited the best selective AVF enhancement. The reviewers used real-time 3D volume rendering (SSD) and maximum intensity projection (MIP) and had the availability over source images 
when necessary. Stenosis measurements were carried out using an electronic caliper with an accuracy of $0.1 \mathrm{~mm}$. DSA images were filmed and analyzed on the hard copies with a loupe and caliper.

MS-CTA and DSA images were read in random order, in a prospective, blinded manner by two radiologists experienced in vascular imaging. Between the two reads of the same patient, a period of at least 2 weeks elapsed. Both radiologists were not involved in either the DSA or MS-CTA procedures and were unaware of each other's results and of results obtained with any other imaging modality (e.g., duplex ultrasonograpy). Upper extremity vessels and AVF were subdivided into segments for analysis, which are shown in figure $1 .^{8}$ In every segment, all visible vessel diameter reductions were measured. Stenoses were measured by dividing the luminal diameter that exhibited the highest grade of stenosis by the luminal diameter of the closest adjacent normal part of the vessel and classified on a 5-point scale ( $1=0 \%-20$ $\%, 2=21 \%-49 \%, 3=50 \%-74 \%, 4=75 \%-99 \%, 5$ = occlusion). Diameter reductions $\geq 50 \%$ were considered hemodynamically significant. ${ }^{2}$ For analysis purposes, only the most severe stenosis per vessel segment was taken into account. In addition to the number and grading of stenoses, the MS-CTA and DSA images were also judged with respect to image quality on a 3 -point scale $(0=$ non diagnostic, $1=$ mediocre diagnostic, 2 = excellent diagnostic).

\section{Statistical analysis}

Upper extremity vessels and AVF were subdivided into segments for analysis. ${ }^{8}$ Sensitivity, specificity, positive predictive value (PPV), and negative predictive value (NPV) were calculated for each observer using DSA as the gold standard. The diagnostic properties of MS-CTA were evaluated using ROC analysis, in which the sensitivity of MS-CTA was plotted against the complement of specificity for different grades of stenosis. To assess overall accuracy of MS-CTA compared to the standard of reference, areas under the curve were calculated for both observers. ${ }^{9}$ With the Wilcoxon signed ranks test (SPSS, version 10.1; SPSS Inc., Chicago, IL), any differences between MS-CTA and DSA in image quality were analyzed on patient level. To determine interobserver agreement with regard to stenosis detection between the two radiologists, the linear weighted kappa statistic was calculated for both DSA and MS-CTA. ${ }^{10} P$-values less than .05 were considered significant. 


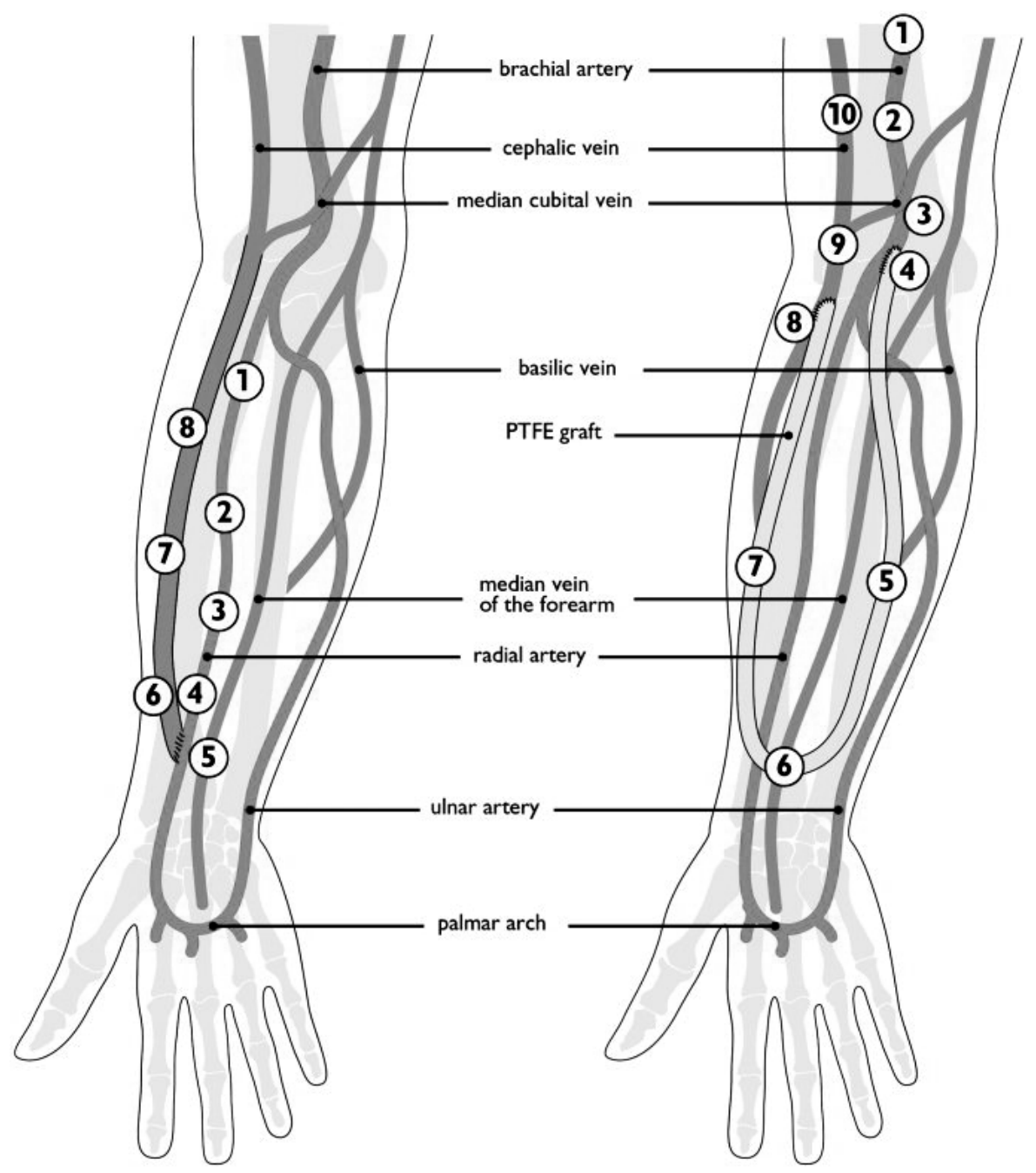

1 afferent artery $>10 \mathrm{~cm}$ proximal from anastomosis

2 afferent artery $5.10 \mathrm{~cm}$ proximal from anastomosis

1 afferent artery $>5 \mathrm{~cm}$ proximal from arterial anastomosis

3 afferent artery $2-5 \mathrm{~cm}$ proximal from anastomosis

2 afferent artery $2-5 \mathrm{~cm}$ proximal from arterial anastomosis

4 afferent artery $<2 \mathrm{~cm}$ proximal from anastomosis

3 afferent artery $<2 \mathrm{~cm}$ proximal from arterial anastomosis

4 arterial anastomosis

5 arterial part of the PTFE loop graft

6 efferent vein $<2 \mathrm{~cm}$ proximal from anastomosis

7 efferent vein $2-5 \mathrm{~cm}$ proximal from anastomosis

6 middle part of the PTFE loop graft

7 venous part of the PTFE loop graft

8 efferent vein $>5 \mathrm{~cm}$ proximal from anastomosis

8 venous anastomosis

9 efferent vein $<2 \mathrm{~cm}$ proximal from venous anastomosis

10 efferent vein $<5 \mathrm{~cm}$ proximal from venous anastomosis

Figure 1. Schematic overview of both AVF types with the different segmental subdivisions. On the left, the radiocephalic AVF is shown (divided into 8 segments), and on the right, the polytetraflourethylene (PTFE) loop graft AVF is shown (divided into 10 segments) (8). 


\section{Results}

\section{Imaging procedures}

All 15 patients ( 7 radial-cephalic and 8 prosthetic forearm loop AVFs) underwent DSA and MS-CTA successfully. A typical example of both modalities is shown in figure 2
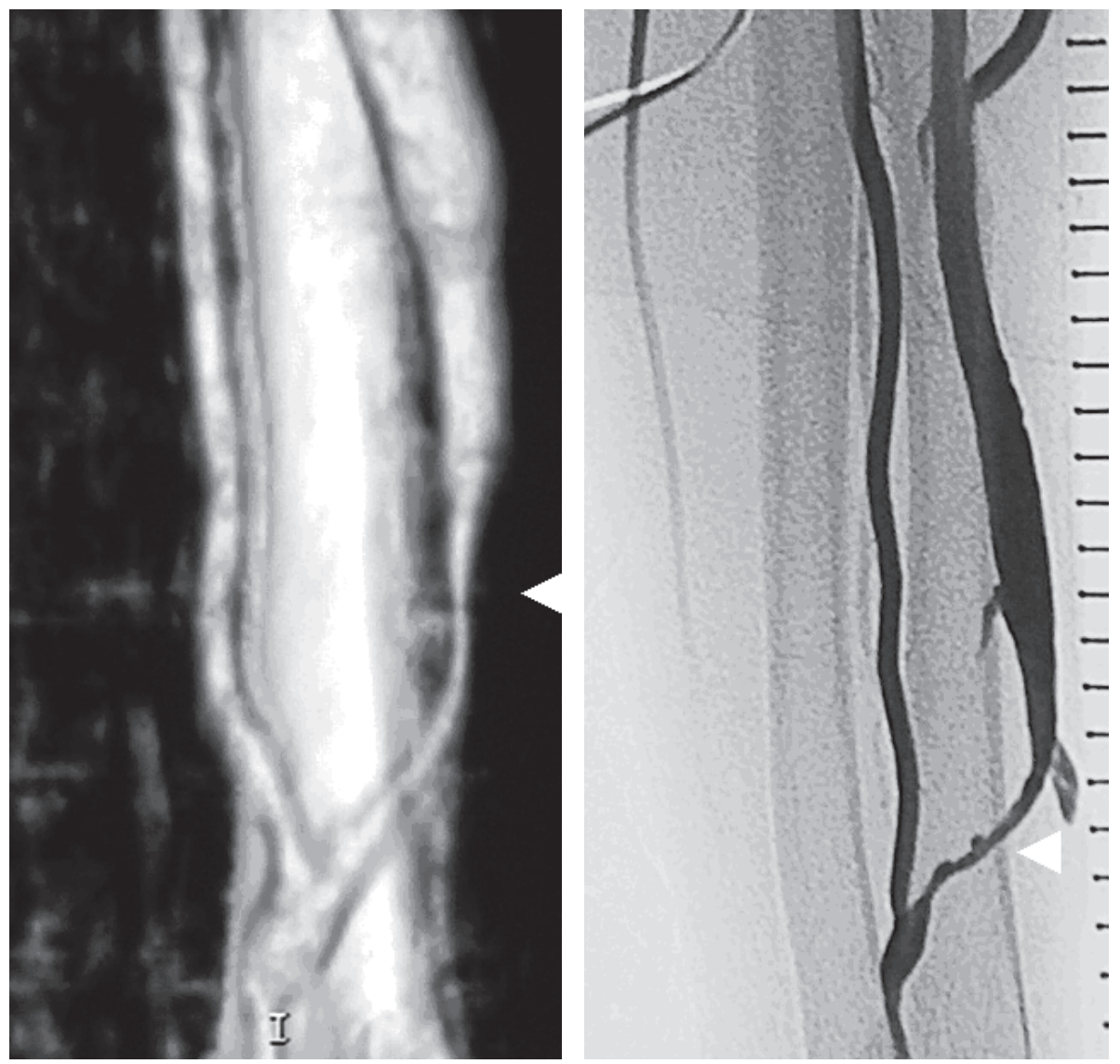

Figure 2a. Semicoronal image obtained with MS-CTA of a radial-cephalic AVF, displayed a grade 4 stenosis in the efferent vein (arrow head).

Figure $\mathbf{2 b}$. Antero-posterior image obtained with DSA of the same radial-cephalic AVF displayed almost the mirror image of MS-CTA. Also the stenosis in the efferent vein (arrow head) is scored as a grade 4 stenosis. 


\section{Stenosis detection}

A total of 136 vessel segments were available for analysis with MS-CTA in 15 patients. All segments were considered diagnostic by both observers. Observer I found $99 \%$ of the segments of excellent diagnostic quality and observer II $88 \%$, respectively. With the use of DSA, observer I considered 134 vessel segments diagnostic (87\% of which excellent) and observer II found all segments diagnostic (99\% of which excellent). ROC analysis of both observers' interpretations yielded areas under the curve of 0.90 \pm 0.07 for observer I and $0.87 \pm 0.08$ for observer II at a stenosis cut-off level of $\geq 50 \%$ diameter reduction. At a threshold of $\geq 75 \%$ stenosis detection the area under the curve was $0.85 \pm 0.10$ and $0.86 \pm 0.10$, respectively (Figure 3 ).

On patient level, table 1 shows the sensitivity and specificity for identifying $\geq 50 \%$ and $\geq 75 \%$ stenosis for both observers. Furthermore, positive and negative predictive values are reported. The combined results of both observers showed a sensitivity, specificity, and positive and negative predictive values of $82 \%, 98 \%, 82 \%$, and $98 \%$ for stenoses $\geq 50 \%$ and $71 \%, 99 \%, 77 \%$, and $98 \%$ for stenoses $\geq 75 \%$, respectively. Table 2 lists the numbers of true positive, true negative, false positive, and false negative vessel segments for both observers. On patient level, the overall discriminatory power for the detection of stenoses was somewhat better when $\geq 50 \%$ stenosis was used as a positive test result instead of $\geq 75 \%$. Both observers detected an equal amount of stenoses on MS-CTA and DSA images. At the $\geq 50 \%$ threshold observer I detected 12 stenoses on MS-CTA and 11 on DSA, respectively. Observer II identified 10 stenoses on MS-CTA and 11 on DSA. At the $\geq 75 \%$ cut-off threshold these numbers were 7 and 7 stenoses and 6 and 7 stenoses on MS-CTA and DSA, respectively.

\section{Image quality}

According to the judgement of observer I and II, both imaging modalities offered images of diagnostic image quality. Observer I found 12/15 (80\%) images on DSA of excellent and $3 / 15(20 \%)$ of mediocre diagnostic quality. Observer II graded DSA image quality excellent in 14/15 (93\%) patients and mediocre in $1 / 15(7 \%)$. For the diagnostic quality of the MS-CTA images, observer I and II concluded excellent in $93 \%$ and $73 \%$ and mediocre in $7 \%$ and $27 \%$, respectively. The mean segment scores on patient level were: for observer I, MS-CTA, $1.99 \pm 0.12$; DSA, $1.87 \pm 0.34(P<0.001)$ and for observer II, MS-CTA, $1.88 \pm 0.33$; DSA, $1.99 \pm 0.12(P<0.001)$. The overall mean segment score on patient level for both observer I and II were: MS-CTA, $1.93 \pm$ 0.26 ; DSA, $1.93 \pm 0.26(P=0.85)$. 


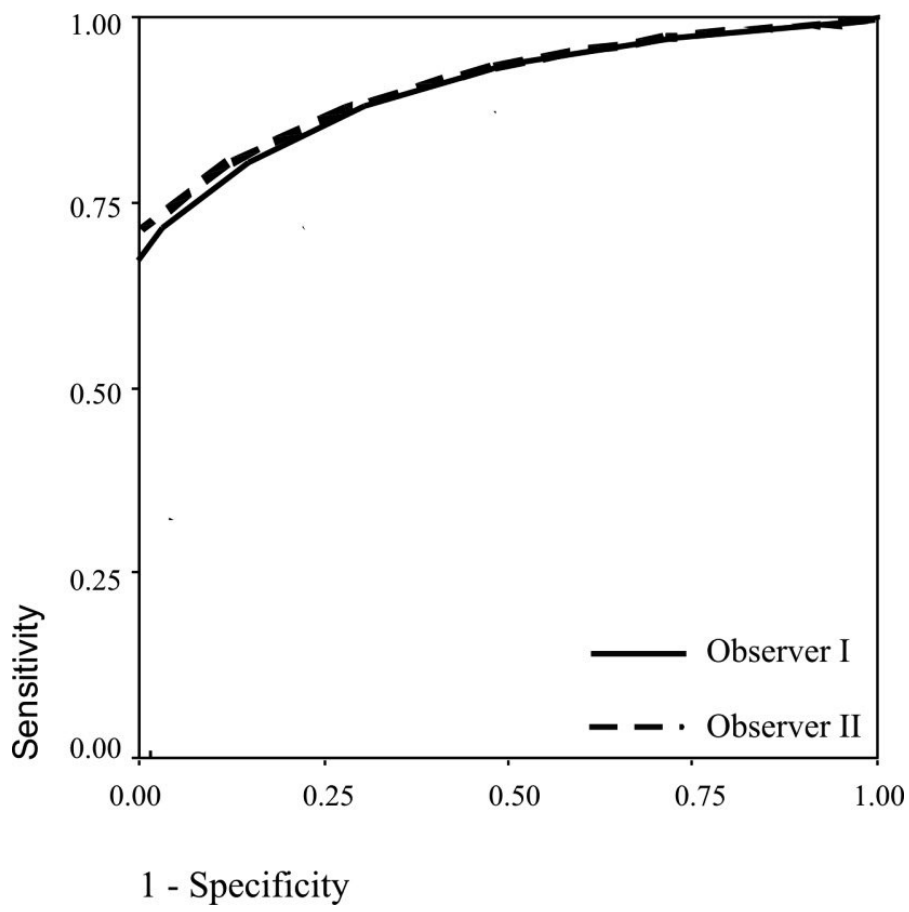

Figure 3. ROC graph showing sensitivity and specificity of $\geq 75 \%$ stenosis detection through MS-CTA with DSA as gold standard.

\begin{tabular}{llcccc}
\hline & & Sensitivity (\%) & Specificity (\%) & PPV (\%) & NPV (\%) \\
\hline Observer I & $\geq 50 \%$ & 82 & 98 & 75 & 98 \\
\multirow{3}{*}{ Observer II } & $\geq 75 \%$ & 71 & 98 & 71 & 98 \\
& $\geq 50 \%$ & 82 & 99 & 90 & 98 \\
& $\geq 75 \%$ & 71 & 99 & 83 & 98 \\
\hline
\end{tabular}

Table 1. Sensitivity, specificity, positive predictive value (PPV), and negative predictive value (NPV) of MS-CTA compared to DSA for the detection of stenoses $\geq 50 \%$ and $\geq 75 \%$ in arteriovenous fistulas for hemodialysis as detected by two independent observers. 


\begin{tabular}{|c|c|c|c|c|c|c|c|c|c|c|c|c|c|}
\hline & & & erv & & & & & & & bse & er & & \\
\hline & & & DS & & & & & & & & & & \\
\hline Stenosis & grade & 1 & 2 & 3 & 4 & 5 & Stenosis & grade & 1 & 2 & 3 & 4 & 5 \\
\hline & 1 & 120 & 0 & 0 & 1 & 0 & & 1 & 120 & 0 & 0 & 1 & 0 \\
\hline & 2 & 0 & 2 & 1 & 0 & 0 & & 2 & 0 & 4 & 1 & 0 & 0 \\
\hline MS-CTA & 3 & 0 & 2 & 2 & 1 & 0 & MS-CTA & 3 & 0 & 1 & 2 & 1 & 0 \\
\hline & 4 & 0 & 1 & 1 & 5 & 0 & & 4 & 0 & 0 & 1 & 5 & 0 \\
\hline & 5 & 0 & 0 & 0 & 0 & 0 & & 5 & 0 & 0 & 0 & 0 & 0 \\
\hline
\end{tabular}

Table 2. Stenosis detection of MS-CTA compared to DSA for both observers. (grade $1=0 \%-20$ $\%$ stenosis, grade $2=21 \%-49 \%$ stenosis, grade $3=50 \%-74 \%$ stenosis, grade $4=75 \%-99 \%$ stenosis, grade $5=$ occlusion).
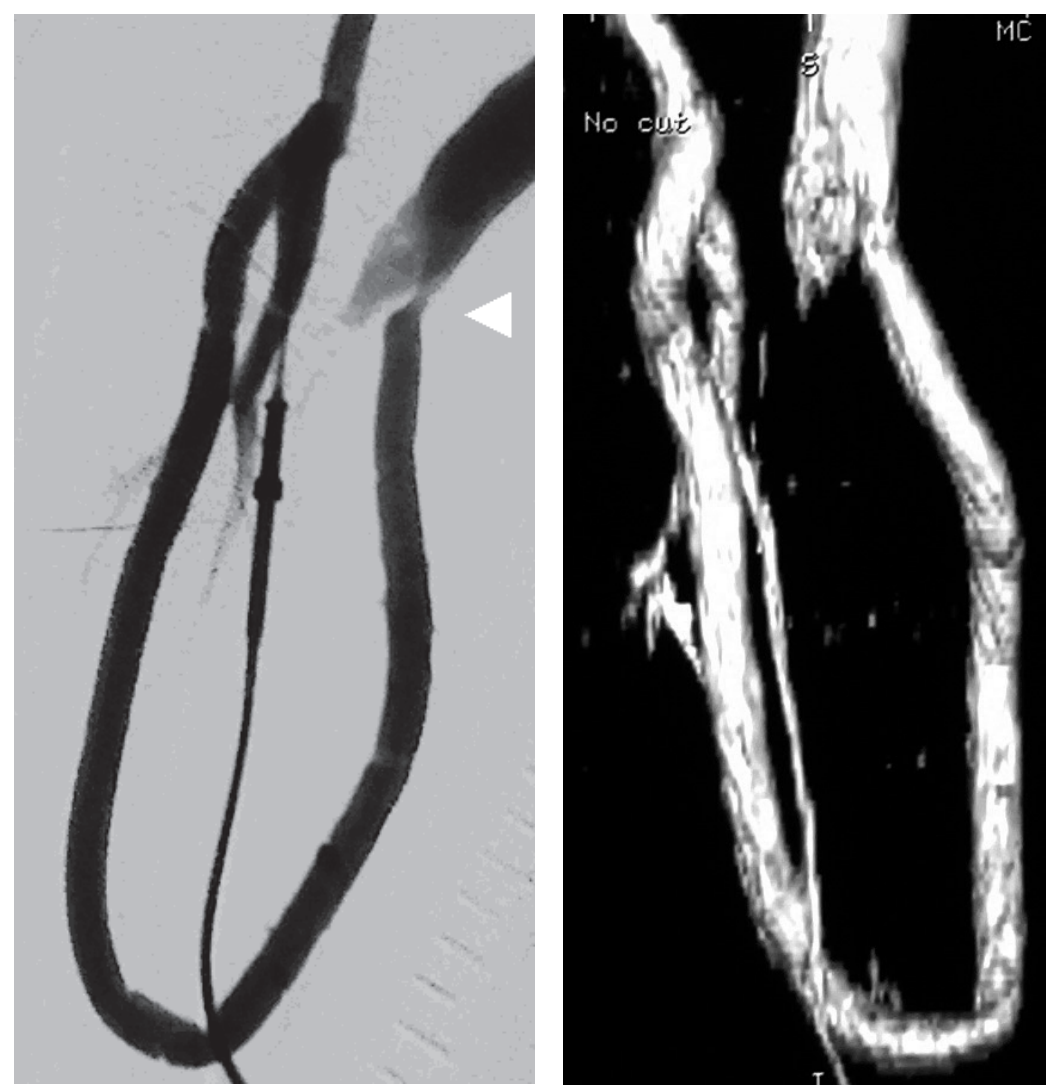

Figure 4a. Antero-posterior image obtained with DSA of a prosthetic PTFE AVF showed a grade 4 stenosis in the efferent vein (arrow head).

Figure $4 \boldsymbol{b}$. Semicoronal image obtained with MS-CTA of the same prosthetic PTFE AVF. However this stenosis is not visible on MS-CTA, and as such, the MS-CTA is false negative. 


\section{Agreement between MS-CTA and DSA for the detection of stenosis}

The linear weighted kappa value regarding the detection of hemodynamic significant stenoses, i.e., $\geq 50 \%$, was 0.75 and 0.86 for observer I and II, respectively, indicating good agreement of stenosis detection on MS-CTA and DSA.

\section{Interobserver agreement}

For the detection of hemodynamic significant stenoses, i.e., $\geq 50 \%$, the linear weighted kappa value was 0.70 and 1.0, for MS-CTA and DSA, respectively. This indicates excellent interobserver agreement on DSA and fairly good agreement on MS-CTA.
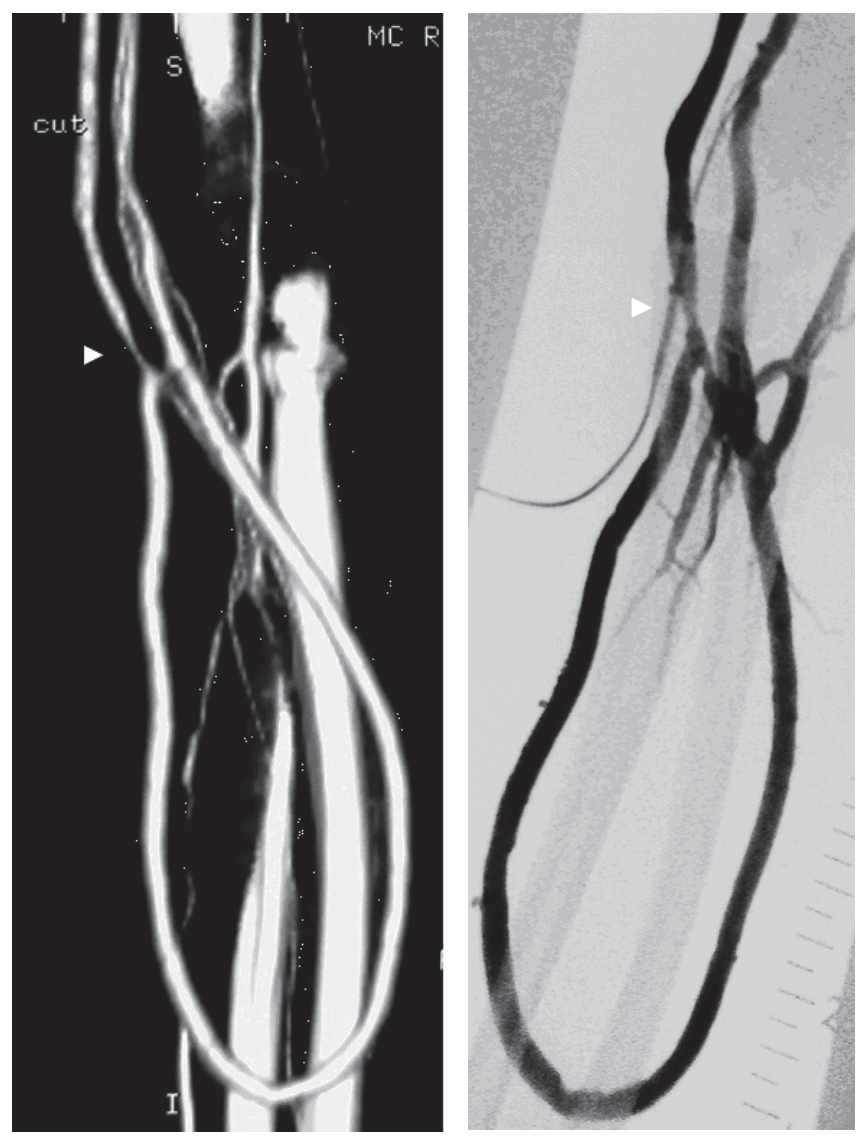

Figure 5a. Semicoronal image obtained with MS-CTA of a prosthetic PTFE graft displayed a grade 4 stenosis in the efferent vein (arrow head).

Figure $5 \boldsymbol{b}$ Antero-posterior image obtained with DSA of the same prosthetic PTFE graft also displayed the stenosis in the efferent vein (arrow head). However the stenosis is scored as a grade 3 stenosis, so the MS-CTA overestimated the stenosis. 


\section{Discussion}

With this study we have shown that spiral MS-CTA is a reliable and reproducible method for the detection of stenoses in hemodialysis AVF. No complications were noted during or after the examination. MS-CTA images of all AVF were considered by both observers to be of diagnostic quality. Unfortunately, in one patient, with a prosthetic loop AVF, DSA detected a stenosis that was not depicted with MS-CTA. This stenosis was located in the efferent vein (Figure 4). Because failure to detect a significant stenosis may lead to access thrombosis, the sensitivity of a diagnostic test should be as high as possible. On the other hand in a few patients MS-CTA overestimated the grade of stenosis (Figure 5).

The greatest limitation of this study lies in the small number of patients. However comparisons were made on a segment-to-segment basis, providing 136 segments to be analyzed and increasing the overall data sample. Other limitations may be the maximum span of 3 weeks between MS-CTA and DSA imaging. It must be considered that new stenoses could develop during this interval and may have accounted for differences between MS-CTA and DSA in the detection of stenoses. Also the CTtechnique used in this study may be considered as less accurate as compared to newer scanners. Instead of scanning at $2.5 \mathrm{~mm}$ collimation on a 4 detector scanner, most centers have nowadays scanners that can obtain collimated images at 0.5 to $1.25 \mathrm{~mm}$ and therefore the resolution is much better. Finally, the inclusion criteria for participating into the study were, extensive, and probably with more strict inclusion criteria, the accuracy and clinical utility of MS-CTA could be improved.

Lin et al. concluded in their study that MS-CTA nicely correlates to angiography for the evaluation of AVF. ${ }^{3}$ Cavagna et al. concluded that MS-CTA ensure panoramic and high-resolution angiographic-like depiction of vessels, providing excellent pre- and postoperative evaluation of patients with AVF malfunction. ${ }^{4}$ In a study by Ko et al., 43 patients underwent multi-detector CT angiography, and only 14 also underwent DSA within 3-5 days after multi-detector angiography. They found no significant difference in the detection and grading of stenoses at various segments. Therefore they concluded that multi-detector CT angiography is clinically feasible for evaluating the complete vascular tree of failing AVFs and in showing uncommon complications, including brachial aneurysm and central vein lesions. ${ }^{6}$

Nevertheless, the current MS-CTA technique has also limitations. Large coverage of the region of interest may hinder the resolution of the vasculature imaging. Therefore, we have focused on the region of interest at the AVF and adjacent arterial inflow and venous outflow vessels during scanning to obtain better image quality. With 
this technique, stenoses outside the imaging field in the central arterial and venous vessels may be missed. Another limitation of MS-CTA is the impossibility of performing corrective intervention immediately, should a hemodynamically significant stenosis be detected. However, Duijm et al. could achieve in all but one of the patients a DSA of the complete arterial inflow, followed by endovascular intervention of significant inflow stenoses, using a retrograde venous access puncture technique. ${ }^{11}$

MS-CTA may have several advantages compared to conventional DSA imaging: (a) through an intravenous contrast medium injection, the scans can be obtained in the arterial phase, sparing time and discomfort of arterial puncture in conventional angiography and shortening the examination time; (b) the data can be reconstructed to create angiographic projections through any plane and in 3D reconstructions. These reconstructions can help to estimate the degree of stenoses. In comparison to conventional DSA, MS-CTA examinations can offer information regarding not only the vessel lumen but also the vessel wall. ${ }^{12}$ MS-CTA examination is time-saving. In our experience, MS-CTA scans were performed in 8-10 min or less. Postscan image processing required only about 4-5 min with current computer capacity. However, at least 40-45 min were needed from access puncture to hemostasis in DSA. In addition, literature reports lower skin radiation dose of MS-CTA in comparison to DSA during abdominal aorta image studies (0.00224 vs $0.071 \mathrm{~Gy})^{13}$ and this may be another advantage of spiral MS-CTA. DSA may also exhibit complications like contrast extravasation, bleeding at the puncture site, and acute thrombosis of the vessel, all which can be avoided by MS-CTA.

Still there are several other imaging modalities available to detect the extent and severity of AVF stenoses. Color Doppler Ultrasonography (CDUS) is a readily available, inexpensive, and noninvasive method, and has no radiation exposure. However the quality of the images depends on the skill of the operator. ${ }^{14-16}$ Other drawbacks of CDUS are the inaccurate detection of central venous obstruction, overestimation of stenoses at the arterial anastomoses, and the absence of an angiographic map, which may be desired for surgery or percutaneous therapy. ${ }^{17}$

Another option to detect the extent and severity of AVF stenoses is MRA, which is not accompanied by radiation exposure and also offers the ability to acquire 3D data sets. Varying results have been published concerning the ability of MRA to depict and detect flow-limiting stenoses in AVF using time-of-flight (TOF), ${ }^{4,18-21}$ phase contrast $(P C)$, and contrast enhanced (CE) MRA $8,18,22-24$ techniques. In these studies, the use of TOF- and PC-MRA resulted in stenosis overestimation because flow voids caused by poststenotic intravoxel phase dispersion. ${ }^{4,18-21}$ With CE-MRA, better results have been obtained..$^{8,18,22-24}$ However, the presence of vascular metallic stents, especially 
those made of stainless steel, may be a limitation of MRA, as it is well known that these objects can hamper postinterventional MRA. ${ }^{25}$ In addition, about 10 percent of patients exhibit claustrophobia, which makes MRA investigation impossible.

In conclusion, MS-CTA is a minimally invasive procedure that can significantly influence patient care by avoiding potential complications. Moreover, MS-CTA can provide excellent visualization of forearm hemodialysis access AVF and has a moderate sensitivity, but high specificity for the detection of significant stenoses. 


\section{References}

1. Murphy GJ, White SA, Nicholson ML. Vascular access for haemodialysis. Br J Surg 2000;87:1300-1315.

2. NKF-DOQI clinical practice guidelines for vascular access. National Kidney FoundationDialysis Outcomes Quality Initiative. Am J Kidney Dis 1997;30:S150-S191.

3. Lin YP, Wu MH, Ng YY, Lee RC, Liou JK, Wank JH, et al. Spiral computed tomographic angiography - A new technique for evaluation of vascular access in hemodialysis patients. Am J Nephrol 1998;18:117-122.

4. Cavagna E, D'Andrea P, Schiavon F, Tarroni G. Failing hemodialysis arteriovenous fistula and percutaneous treatment: imaging with $\mathrm{CT}, \mathrm{MRI}$ and digital subtraction angiography. Cardiovasc Intervent Radiol 2000;23:262-265.

5. Wierzbicki P, Zagrodzka M, Prokopiuk M, Kade G, Maruszynski M, Wankowicz Z. Spiral computed tomography in evaluation of arteriovenous fistula for hemodialysis. Preliminary report. Pol Merkuriusz Lek 2002;13:368-372.

6. Ko SF, Huang CC, Ng SH, Lee TY, Hsieh MJ, Lee FY, et al. MDCT angiography for evaluation of the complete vascular tree of hemodialysis fistulas. AJR 2005;185:1268-1274.

7. Staple TW. Retrograde venography of subcutaneous arteriovenous fistulas created surgically for hemodialysis. Radiology 1973;106:223-224.

8. Planken RN, Tordoir JHM, Dammers R, de Haan MW, Oei TK, van der Sande FM, et al. Stenosis detection in forearm hemodialysis arteriovenous fistulae by multiphase contrast-enhanced magnetic resonance angiography: preliminary experience. J Magn Reson Imaging 2003;17:54-64.

9. Erkel van AR, Pattynama PM. Receiving operating characteristic (ROC) analysis: basic principles and applications in radiology. Eur J Radiol 1998;27:88-94.

10. Cohen J. Weighted kappa : nominal scale agreement with provision for scaled disagreement or partial credit. Psychol Bull 1968;70:213-230.

11. Duijm LEM, van der Rijt RHH, Cuypers PWM, Tielbeek A, Receveur KJ, Douwes-Draaijer $\mathrm{P}$, et al. Outpatient treatment of arterial inflow stenoses of dysfunctional hemodialysis access fistulas by retrograde venous access puncture and catheterization. J Vasc Surg 2008;47:591-598.

12. Galanski M, Prokop M, Chavan A, Schaefer CM, Jandeleit K, Nischelsky JE. Renal arterial stenosis: Spiral CT angiography. Radiology 1993; 189: 185-192.

13. Castello P, Gaa J. Spiral CT angiography of abdominal aortic aneurysms. Radiographics 1995;15:397-406.

14. Bay WH, Henry ML, Lazarus JM, Lew NL, Ling J, Lowric EG. Predicting hemodialysis access failure with color flow Doppler ultrasound. Am J Nephrol 1998;18:296-304.

15. Wiese P. Nonnast-Daniel B. Colour Doppler ultrasound in dialysis access. Nephrol Dial Transplant 2004;19:1956-1963.

16. Schwarz C, Mitterbauer C, Boczula M, Maca T, Funovics M, Heinze G, et al. Flow monitoring: performance characteristics of ultrasound dilution versus color Doppler ultrasound compared with fistulography. Am J Kidney Dis 2003;42:539-545.

17. Dumars MC, Thompson WE, Bluth El, Lindberg JS, Yosclevitz M, Merritt CRB. Management of suspected hemodialysis graft dysfunction: usefulness of diagnostic US. Radiology 2002;222:103-107.

18. Bos C, Smits JH, Zijlstra JJ, van der Mark WA, Blankestijn PJ, Bakker CJ, et al. MRA of hemodialysis access grafts and fistulae using selective contrast injection and flow interruption. Magn Reson Med 2001;45:557-561. 
19. Gehl HB, Bohndorf K, Glaziwa U, Handt S, Gunther RW. Imaging of hemodialysis fistulas: limitations of MR angiography. J Comput Assit Tomogr 1991;15:271-275.

20. Konermann M, Sanner B, Laufer U, Josephs W, Odenthal HJ, Horstmann E. Magnetic resonance angiography as a technique for the visualization of hemodialysis shunts. Nephron 1996;73:73-78.

21. Laissy JP, Menegazzo D, Debray MP, Loshkajian A, Viron B, Mignon F et al. Failing arteriovenous hemodialysis fistulas: assessment with magnetic resonance angiography. Invest Radiol 1999;34:218-224.

22. Froger CL, Duijm LEM, Liem YS, Tielbeek AV, Donkers-van Rossum AB, Douwes-Draaijer $\mathrm{P}$, et al. Stenosis detection with MR angiography and digital subtraction angiography in dysfunctional hemodialysis access fistulas and grafts. Radiology 2005;234:284-291.

23. Doelman C, Duijm LEM, Liem YS, Tielbeek AV, Donkers-van Rossum AB, Cuijpers PW, et al. Stenosis detection in failing hemodialysis access fistulas and grafts: Comparison of color doppler ultrasonography, contrast-enhanced magnetic resonance angiography, and digital substraction angiography. J Vasc Surg 2005;42:739-46.

24. Pinto C, Hickey R, Caroll TJ, Sato K, Dill K, Omary RA, et al. Time-resolved MR angiography with generalized autocalibrating partially parallel acquisition and time-resolved echosharing angiographic technique for hemodialysis arteriovenous fistulas and grafts. J Vasc Interv Radiol 2006;17:1003-1009.

25. Wang Y, Truong TN, Yen C, Bilecen D, Watts R, Trost DW, et al. Quantative evaluation of susceptibility and shielding effects of nitinol, platinum, cobalt-alloy, and stainless steel stents. Magn Reson Med 2003;49:972-976. 
General discussion, conclusions and future perspectives

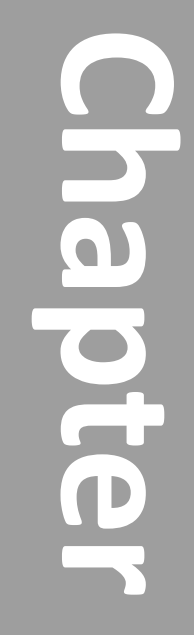


Chapter 7 
Chapter 1: Hemodialysis as renal replacement therapy and the role of the radialcephalic arteriovenous fistula for vascular access in patients with diseased vessels

Chronic renal disease (CRD) is increasing in incidence and prevalence on a worldwide basis. ${ }^{1}$ Large national studies of European populations report a prevalence of approximately $7-10 \% .^{2,3}$ CRD has multiple etiologies including arteriosclerosis, diabetes, hypertension, glomerulonefritis and cystic disease, leading to end-stage renal disease (ESRD). Hemodialysis is often used as renal replacement therapy for patients with ESRD. Ever since the first hemodialysis, the biggest issue has been creating and maintaining vascular access. This to facilitate connection to the artificial kidney for blood withdrawal and purification. Achieving long-term vascular access for hemodialysis is becoming a challenge because of an increase in elderly ESRD patients with various co-morbidities that are associated with poor and diseased vessels. Therefore it is difficult in these patient to create a successful vascular access. ${ }^{4-6}$ The radial-cephalic arteriovenous fistula (RCAVF) at the wrist and the brachial-cephalic arteriovenous fistula at the elbow are the primary and secondary access options for dialysis treatment. ${ }^{4,6,7}$ The brachial-basilic arteriovenous fistula is the tertiary option, when the above options are not possible or have failed. However, up to $31,5 \%$ of the RCAVFs thrombose directly after operation or do not function adequately due to failure of maturation. ${ }^{8,9}$ Also the RCAVF has a moderate patency rate at 1 year of follow up..$^{8,10-12}$ The primary patency of brachial-cephalic fistulas are comparable to that of RCAVFs. ${ }^{13}$ Maturation failure may be a disadvantage of the brachial-basilic arteriovenous fistula. The incidence of non-maturation has been reported within the range of $0 \%$ to $38 \% .{ }^{14}$ The most important disadvantage however is a considerably higher incidence of peripheral ischemia and cardiac failure due to high access flow. Non-maturation results in delay of initiation of dialysis treatment with the need for placement of central venous catheters with their related morbidity and mortality. In case of tiny or diseased arteries and/or veins, the risk on access failure is probably higher and an alternative vascular access has to be considered. Few publications report on the outcome or RCAVFs in patients with poor or doubtfull vessels and no information on the performance of alternative accesses in these patients is available. A recent study on the results of a questionnaire send to American and Canadian nephrologists, shows that the choice for autogenous arteriovenous fistula (AVF) in older patients and in those with multiple comorbidities or a previous failed fistula, is different from what guidelines do advise. American nephrologists selected arteriovenous grafs (AVG) as an alternative to the AVF, while Canadian nephrologists even primarily selected central vein catheters. Not only the nephrologists choose for 
catheter access in these patient group, but also the patients theirselves prefer catheter access above AVFs. ${ }^{15} \mathrm{~A}$ recent study illustrated in detail how advanced age might affect clinical judgement regarding choice of vascular access. ${ }^{16}$ This observational study compared fistula and patient survival in dialysis-dependent patients older or younger than 70 years of age. Cumulative fistula survival at 12 months was $68 \%$ in the younger patients, but only $39 \%$ in those over age 70 . Patient survival at 18 months was $75 \%$ in the younger patients, but only $50 \%$ in those over age 70 . Finally, among 23 elderly patients who died, only 35\% had ever had their fistula used for dialysis. On the basis of these observations, one could argue for placing a graft rather than a fistula in catheter-dependent hemodialysis patients over the age of 70 years.

Chapter 2: Results of radial-cephalic wrist arteriovenous fistula for hemodialysis: A meta-analysis

The RCAVF is considered the first choice for an autogenous AVF. Once established, it has the advantage of good long-term survival, and a low complication rate. However, the RCAVF has the disadvantage of primary failure, due to early thrombosis and failure to mature. Estimates of primary failure, primary patency and secondary patency vary considerably. An important source of that variability is a lack of precision in individual studies. For this meta-analysis, primary failure rates and primary and secondary patency data at one year of follow up from various publications considering RCAVFs for hemodialysis were aggregated, with the primary objective to improve the precision of the estimates of these parameters. In addition to improving the precision, a metaanalysis offers the opportunity to explore questions that could not be answered by the original studies by determining the effect of particular study characteristics on the overall results. In this analysis the effect of various study characteristics, including study year, gender and age were examined.

The analysis showed a pooled estimated primary failure rate of $15.3 \%$. In addition the pooled estimated primary and secondary patency rates of $62.5 \%$ and $66.0 \%$ respectively were calculated. Heterogeneity between studies was found in primary failure rates, primary patency and secondary patency. An important explanation might be the heterogeneity between studies in the definitions of primary failure and primary and secondary patency. Only a few authors provided an explicit definition of the patency criterion they have used. When criteria were specified, many different definitions were used. Nowadays higher percentages of primary failure are reported. The study showed that differences in primary failure, primary patency and secondary patency can not be declared by patient demographics, such as sex and age. Therefore 
other factors must be taking into account, such as vessel diameter and quality. In a report of surgically created AVFs, Reilly et al. found that vein size was a significant predictor of subsequent fistula survival, while sex was not. ${ }^{17} \mathrm{~A}$ more recent study also found that vessel size predicted fistula failure in the first 3 months after surgery. ${ }^{18}$ Huijbregts et al. showed that the probability of primary failure is strongly related to the center of access creation, suggesting an important role for the vascular surgeon's skills and decisions. ${ }^{19}$ Therefore, one may argue, for more attention, during the surgical training, for teaching in creating AVFs. An other factor which may influence primary failure is the use of antiplatelets agents in the post-operative period. ${ }^{20-22} \mathrm{~A}$ large study showed that the use of clopidogrel reduced the frequency of early thrombosis of new created AVFs. ${ }^{20}$ However, the beneficial effect of clopidogrel on thrombosis was not accompanied by increase in the proportion of fistulas that were suitable for dialysis. This discrepancy between the effect of clopidogrel on fistula patency and fistula suitability suggests that thrombosis may be a manifestation rather than a cause of maturation failure. Therefore, future work directed at determining the contributions to fistula maturation of underlying vascular function, vascular anatomy, and surgical technique may identify better targets for interventions to improve fistula outcomes.

\section{Chapter 3: Prospective evaluation of failure modes in autogenous radial-cephalic wrist access for hemodialysis}

Usually, RCAVF thrombosis and non-maturation depend on the quality and size of the vessels used for the AV anastomosis and the ability of vessel adaptation induced by the augmented bloodflow volumes. A preoperative assessment of upper extremity vessel characteristics seems therefore worthwile to define arteries and veins suitable for autogenous RCAVF creation. Certain duplex-derived parameters may predict the risk on failure or dysmaturation. In several studies, published in the nineties, the internal radial artery diameter has been used to predict the outcome of radialcephalic AVFs or to plan strategies for vascular access creation. ${ }^{18,23,24}$ Although, the importance of using well-sized radial arteries for creating RCAVFs is well emphasized in the literature, we could not estimate a significant impact of arterial diameters on fistula outcome. Probably, a small variation of arterial diameters in the patients studied, may be the explanation for this observation. In a more recent study there was no significant association between either radial artery diameter or dilated vein diameter and primary failure. However there was an association between radial artery diameter and primary patency. ${ }^{25}$ Cephalic vein diameters were significantly associated with non-maturation and this finding is well in line with the few data from 
the literature. ${ }^{26}$ From our data, we conclude that preoperative vessel evaluation can help in the decision to choose an autogenous vascular access which has a great chance on functioning. Still, in $14 \%$ of the patients the RCAVF failed, and one might argue if the accepted vessel diameters for RCAVF creation in this study were possibly too small.

The cross-sectional area and blood flow rate, as measured using duplex ultrasonography, are useful in predicting the outcome of vascular access for hemodialysis. ${ }^{18,27}$ This predictive value of postoperative flow measurement was also proven in the present study. Failed RCAVFs had lower bloodflows through the radial artery compared to succesfull fistulas one, seven and 42 days after operation.

Radial artery wall changes due to arterial disease are common in patients with ESRD and worse in patients with diabetes or renovascular disease. ${ }^{28} \mathrm{Ku}$ et al. reported that measurement of intima-media thickness (IMT) with ultrasound correlated significantly to histology. Furthermore, they found a significant correlation between IMT and AVF failure due to thrombosis or fistula failure at 1 year. ${ }^{29}$ These results show that pre-existing arterial disease is important for AVF outcome and this can also be assessed by ultrasonography.

In the current study, $64 \%$ of the patients showed an anatomical lesion at or near the AV anastomosis, amenable to radiological or surgical intervention. Similar observations were reported in 52 patients with non-maturating AVFs. ${ }^{30}$ All AVFs showed significant stenoses, half of which were located in the anastomotic area. Treatment by means of PTA and stent placement resulted in maturation in $97 \%$ of patients. In a more recent study 25 patients were included with failing distal access maturation due to forearm artery lesions. All underwent PTA of forearm arteries. After PTA 91\% accesses started to be used for hemodialysis without difficulties. ${ }^{31}$ Therefore, the authors concluded that the efficacy of PTA clearly influences surgical strategy and is a major argument in favor of attempting to create distal accesses in patients with mild distal artery lesions. This is also an argument in favour of attempting to create a distal access in patients with small vessels. On the other hand, Lee et al. observed in their study significantly inferior long-term AVF survival in patients requiring two or more interventions to achieve AVF maturation, as compared with those requiring zero or one intervention. Moreover, AVFs requiring two or more interventions to promote maturation also required more interventions to maintain long-term patency after dialysis use. ${ }^{32}$ Voormolen et al. showed, in a meta-analysis, that radiologic and surgical interventions in AVFs with nonmaturation have a substantial success rate. Secondary patency rates were high, and seem no worse compared with "normal" cohorts including AVFs that initially matured. ${ }^{33}$ Therefore, they suggested that patients 
experiencing AVF nonmaturation are eventually able to use their AVF for long-term dialysis just as effectively as patients in whom the AVF matured initially. Both studies agreed that extra effort in terms of interventions would be required to achieve maturation and to maintain patency. The meta-analysis showed that hemodynamic risk factors measured postoperatively stratify risk of nonmaturation most effectively. As a consequence, acquiring these risk factors early in the AVF maturation period to select patients in need of early treatment might facilitate minimization of additional maturation time.

\section{Chapter 4: Randomised controlled trial shows that patients with poor quality forearm vessels do benefit from implantation of a prosthetic graft for vascular access.}

The usefulness of a RCAVF depends on an efficient dilatation and arterialization of the forearm veins used for the creation of AV anastomosis, which makes repeated successful cannulations possible. RCAVFs that mature without any early complications may function for many years. However, up to 31,5\% of RCAVFs thrombose directly after operation or do not function adequately due to failure of maturation..$^{8-9}$ Nonfunctioning vascular access result in delay of initiation of dialysis treatment with additional morbidity. As a consequence of access abandonment more patients need a temporary central vein catheter placement with the risk of catheter related problems. ${ }^{34-38}$ Usually, AVF maturation depends on the quality and size of the vessels used for the AV anastomosis and the ability of vessel adaptation induced by the augmented bloodflow volumes. In case of tiny or diseased arteries and/or veins, the risk on access non-maturation is probably higher and an alternative vascular access may be considered. However, there are only few data on the outcome on RCAVFs in patients with poor or doubtfull vessels and also no information on the performance of alternative accesses in these patients is available. To adress this subject, we have performed a randomized multicenter study comparing RCAVF vs forearm prosthetic graft (PTFE) implantation in patients with poor (doubtfull) vessels. We found an one year primary patency of $33 \%$ in the RCAVF group compared to $44 \%$ in the prosthetic AVF group. Also, the secondary patency of $52 \%$ at one year in the RCAVF group was significantly lower compared to $79 \%$ in the PTFE graft group. Therefore, we conclude that patients with poor forearm vessels benefit from implantation of a prosthetic graft and this may a better option than a primary autogenous RCAVF. In addition, one may argue that primary selection of a PTFE AVF in elderly patients may be worthwhile, given the reduced life expectancy of these patients ( $50 \%$ mortality at 2 years). ${ }^{39}$ 
PTFE has the advantage of easy handling, is always available, can be inserted under local or regional anaesthesia in a wide variety of configurations depending on the available vascular anatomy and, if necessary, can be needled immediately for hemodialysis. Most studies show a superiority of autogenous fistulas to PTFE graft in terms of primary and secondary patency. ${ }^{26,40,41}$ There are only a few studies which report no differences in patency at one year. ${ }^{42,43} \mathrm{~A}$ possible explanation for similar secondary patency rates is the introduction of graft surveillance and refinements in both percutaneous radiological techniques and surgical revision. Despite this similarity in patencies, PTFE grafts are still associated with a high complication rate. ${ }^{26,40,41}$ This could not be confirmed in this study, taken into account that RCAVFs developed an almost similar total number of 102 vs 122 complications in the prosthetic AVFs. The number of thrombotic occlusions was significantly higher in grafts, while non-maturation and cannulation difficulties occurred in RCAVFs in particular. On the other hand more interventions were needed for graft salvage (79 vs 43 interventions). In particular, graft stenosis and thrombosis were responsible for most of these interventions. Progressive stenotic lesions, due to intimal hyperplasia at the graft-vein anastomosis, lead to bloodflow decrease and ultimately graft occlusion. Therefore early detection and correction of hemodynamically significant stenosis, in both autogenous and prosthetic AVFs, with PTA or surgical revision reduces the rate of AVF thrombosis. ${ }^{44-48}$ However, a systematic review suggests that also serial surveillance of asymptomatic arteriovenous hemodialysis access for the detection and treatment of stenosis may reduce the risk of thrombosis and prolong access survival more than usual clinical monitoring, but these comparisons were not statistically significant. ${ }^{49}$ Therefore the authors stated that large multicenter clinical trials of surveillance vs clinical monitoring appear necessary to establish whether surveillance is cost effective in patients with AV access for hemodialysis. However, in a simultaneously published review, the authors concluded that there was no evidence that screening with access blood flow measurements or Doppler ultrasound is of benefit to patients with grafts. However, access blood flow screening may prevent access thrombosis in AVFs, but may not reduce the risk of access loss or extent of resource use. Also they support the idea of further evaluation in a largescale randomized trial. ${ }^{50}$ 


\section{Chapter 5: Current imaging techniques for stenosis detection in hemodialysis vascular access}

When a hemodynamically significant stenosis is suspected, access imaging should be performed as soon as possible, because these stenosis jeopardize flow and patency. ${ }^{51}$ Recently, duplex ultrasonography (DUS) was suggested as the initial imaging modality of dysfunctional fistulae..$^{52}$ DUS is a readily available, inexpensive, and noninvasive method, and has no radiation exposure. However the quality of the images depends on the skill of the operator..$^{53-55}$ Once a stenosis is detected, digital subtraction angiography (DSA) has to be performed to depict the complete access to detect all significant stenoses eligible for PTA. When DSA is inconclusive contrast enhanced magnetic resonance angiography (CE-MRA) should be considered. CEMRA is also not accompanied by radiation exposure and offers the ability to aquire three-dimensional (3D) data sets, wich may solve the potential problem of vessel overlap. ${ }^{56}$ Several subsequent studies have been reported that compare DUS, CEMRA and DSA to detect flow limiting stenoses in patients at risk for vascular access thrombosis. ${ }^{52,57-59}$ DUS proved to be an initial imaging modality of dysfunctional AVFs, but complete access should be depicted at DSA, to detect all significant stenoses eligible for interventions. CE-MRA should be considered only if DSA is inconclusive. ${ }^{52}$ However, CE-MRA has limited clinical value as result of current inability to perform MR-guided access interventions after stenosis detection. ${ }^{57}$ On the other hand, Cavagna et al. concluded that the first procedure in the investigation of patients with failing hemodialysis AVF may involve obtaining a MS-CTA or CE-MRA to define the location and extent of disease segments as well as to generate a "road map" for therapy planning. Information regarding the degree of vascular impairment may help to stratify patients into those who can have PTA versus those who require an operative procedure. In their opinion DSA can be reserved for patients who are candidates for percutaneous intervention such as PTA and stenting. ${ }^{59}$

Multi-slice computed tomographic angiography (MS-CTA) is a relatively new minimal invasive technique for stenosis detection in hemodialysis access. MS-CTA offers also the ability to acquire 3D data sets, and is time-saving because MS-CTA scans can be performed in 8-10 min or less. However until now, the experience with MS-CTA for imaging of stenoses in vascular hemodialysis access is limited. ${ }^{59-62}$ Therefore the study was performed which is reported in chapter 6 . 


\section{Chapter 6: Multi-slice computed tomographic angiography can provide good visualisation of forearm hemodialysis arteriovenous fistulas}

This chapter describes a study in which the value of MS-CTA to detect flow-limiting stenoses in AVFs was assessed with DSA as the gold standard of reference. The results demonstrate that MS-CTA has a high specificity for detection of stenosis. Also, MS-CTA is a minimally invasive procedure and therefore can significantly influence patient care by avoiding potential complications.

Since the results in chapter 6 have been published in 2008, several subsequent studies have been reported that compare conventional DSA and MS-CTA to detect flow-limiting stenoses in patients at risk for vascular access thrombosis. ${ }^{63-64} \mathrm{MS}$ CTA provides excellent correlation in vascular stenosis as compared with DSA in hemodialysis access. ${ }^{64}$ Therefore, MS-CTA may offer a reliable solution to evaluate dysfunctional hemodialysis AVFs including the complete arterial inflow. However, until more data are available about patient radiation dose, its clinical value remains limited to situations when DSA with subsequent therapy is difficult or impossible, when imaging is needed before surgery and percutaneous intervention is not warranted, or when a nondiagnostic vascular segment is present on DSA. ${ }^{63}$ These two recent published studies both reports a high sensitivity of $90.2 \%$ and $100 \%$, respectively. This is much higher then the moderate sensitivity of $82 \%$, revealed in chapter 6 . The possible explanation for this discrepancy is the fact that these recent studies used a 64 multidetector row computed tomographic (MDCT) scanner instead of a 4 MDCT scanner, which was used in the study reported in chapter 6 . As with any screening test, a high sensitivity is desirable. In case of hemodialyisis vascular access, the failure to identify a significant stenosis may lead to hemodialysis fistula thrombosis.

To obtain optimal vascular enhancement, comprehensive adjustment of the injection flow rate and precise timing of scanning are essential. ${ }^{60,65}$ For single-detector CTA, a large volume of contrast material and a high flow rate are required to maintain high and uniform opacification of vessels. ${ }^{60,65}$ With the help of an automated tracking system of contrast enhancement and a predefined trigger threshold at the appropriately selected region of interest, ${ }^{66,67}$ high quality MS-CTA images can be obtained. In addition, the total amount of contrast material can be reduced to less than $100 \mathrm{~mL}$. MS-CTA examinations can be accomplished quickly (8-10 min), and postproccessing usually takes about $5 \mathrm{~min}$. MS-CTA shows good to excellent image quality scores for all segments of the vascular tree for both autogenous and prosthetic AVFs, wich results in highly reliable evaluations for treatment planning. 


\section{Conclusions of this thesis}

1. Autogenous radial-cephalic arteriovenous fistulas have a high primary failure rate and moderate patency rate at one year of follow up.

2. Primary nonfunctioning radial-cephalic arteriovenous fistulas show low postoperative bloodflows. Endovascular and surgical intervention result in a considerable salvage rate of radial-cephalic arteriovenous fistulas.

3. Patients with poor forearm vessels do benefit from implantation of a forearm prosthetic graft in terms of lower primary failure and better one year patency rates compared to radial-cephalic arteriovenous fistulas.

4. Duplex ultrasound is the initial imaging modality of stenosis detection in dysfunctional hemodialysis vascular access. The complete vascular tree can be depicted with digital subtraction angiography to detect all significant stenoses eligible for intervention, which can be performed in the same session.

5. Multi-slice computed tomographic angiography can provide good visualization of forearm hemodialysis access arteriovenous fistulas and has moderate sensitivity, but high specificity for the detection of flow-limiting stenoses.

\section{Future perspectives}

Recent guidelines have strongly encouraged nephrologists, vascular access surgeons, and dialysis units to make valiant efforts to increase fistula use in hemodialysis population. Unfortunately, the rigid "all autogenous" recommendations are not based on solid, current, evidence-based data. This policy may be harmful to some hemodialysis patients by subjecting them to prolonged catheter dependence, while they are waiting on maturation of their AVF. Once they are successfully cannulated for dialysis, AVFs last longer than grafts, require fewer interventions to maintain long term patency for dialysis. However, autogenous fistulas have a much higher primary failure rate than grafts, require more interventions to achieve maturation, and entail longer central vein catheter dependence, thereby leading to more catheterrelated complications. Given the tradeoffs between fistulas and grafts, there is equipoise about their relative merits in patients with moderate to high risk of fistula nonmaturation. The time is right for definitive, large, multicenter randomized clinical trials to compare fistulas and grafts in various subsets of chronic kidney disease patients. Until the results of such clinical trials are known, the optimal vascular access for a given patients should be determined by the nephrologist and access surgeon 
by taking into account (1) whether dialysis has been initiated, (2) the patient's life expectancy, (3) whether the patient has had a previous failed vascular access, and (4) the likelihood of fistula nonmaturation. Careful clinical judgment should optimize vascular access outcomes and minimize prolonged catheter dependence among hemodialysis patients. 


\section{References}

1. Kidney Disease Outcome Quality Initiative. Clinical practice guidelines for chronic kidney disease: evaluation, classification and stratification. Am J Kidney Dis 2002;39(Suppl 2):S1-246.

2. Hillege HL, Janssen WM, Bak AA, Diercks GF, Grobbee DE, Crijns HF, et al. Microalbuminuria is common, also in a non-diabetic nonhypertensive population, and an independent indicator of cardiovascular risk factors and cardiovascular morbidity. $J$ Intern Med 2001;249:519-526.

3. Hallan SI, Coresh J, Astor BC, Asberg A, Powe NR, Ramundstad S, et al. International comparison of the relationship of chronic kidney disease prevalence and ESRD risk. J Am Soc Nephrol 2006;17:2275-2284.

4. Tordoir JH, Mickley V. European guidelines for vascular access: clinical algorithms on vascular access for haemodialysis. Edtna Erca J 2003;29:131-136.

5. III. NKF-K/DOQI Clinical Practice Guidelines for Vascular Access: update 2000. Am J Kidney Dis 2001;37:S137-181.

6. Clinical practice guidelines for vascular access. Am J Kidney Dis 2006;48 Suppl 1:S176246.

7. Tordoir JH, Canaud B, Haage P, Konner K, Basci A, Fouque D, et al. EBPG on Vascular Access. Nephrol Dial Transplant. 2007;22 Supl:ii88-117.

8. Dixon BS, Novak L, Fangman J. Hemodialysis vascular access survival: upper-arm native arteriovenous fistula. Am J Kidney Dis 2002;39:92-101.

9. Zeebregts C, van den Dungen J, Bolt A, Franssen C, Verhoeven E, van Schilfgaarde R. Factors predictive of failure of Brescia-Cimino arteriovenous fistulas. Eur J Surg 2002;168:29-36.

10. Wetzig GA, Gough IR, Furnival CM. One hundred cases of arteriovenous fistula for haemodialysis access: the effect of cigarette smoking on patency. Aust $\mathrm{N} Z \mathrm{~J}$ Surg 1985;55:551-554.

11. Golledge J, Smith CJ, Farrington K, Thompson HH. Outcome of primary radiocephalic fistula for haemodialysis. Br J Surg 1999;86:211-216.

12. Burger H, Kluchert BA, Kootstra G, Kitslaar PJ, Ubbink D TH. Survival of arteriovenous fistulas and shunts for haemodialysis. Eur J Surg 1995;161:327-334.

13. Zeebregts CJ, Tielliu IF, Hulsebos RG, de Bruin C, Verhoeven EL, Huisman RM, et al. Determinants of failure of bracho-cephalic elbow fistulas for haemodialysis. Eur J Vas Endovasc Surg 2005;30:209-214.

14. Dix FP, Khan $\mathrm{Y}, \mathrm{Al}$-Khaffaf $\mathrm{H}$. The brachial artery-basilic vein arterio-venous fistula in vascular access for haemodialysis--a review paper. Eur J Vasc Endovasc Surg 2005;31:7079.

15. Xi W, MacNab J, Lok CE, Lee TC, Maya ID, Mokrzycki MH, et al. Who should be referred for a fistula? A survey of nephrologists. Nephrol Dial Transplant 2010;25:2644-2651.

16. Richardson Al, Leake A, Schmieder GC, Biuckians A, Stokes GK, Panneton JM, et al. Should fistulas really be first in the elderly patient? J Vasc Access 2009;10:199-202.

17. Reilly DT, Wood RFM, Bell PRF. Prospective study of dialysis fistulas: problem patients and their treatment. Br J Surg 1982;69:549-553.

18. Wong V, Ward R, Taylor J, Selvakumar S, How TV, Bakran A. Factors associated with early failure of arteriovenous fistulae for haemodialysis access. Eur J Endovasc Surg 1996;12:207-213. 
19. Huijbregts HJ, Bots ML, Moll FL, Blankestijn PJ. Hospital specific aspects predominantly determine primary failure of hemodialysis arteriovenous fistulas. J Vasc Surg 2007;45:962-967.

20. Dember LM, Beck GJ, Allon M, Delmez JA, Dixon BS, Greenberg A, et al. Effect of clopidogrel on early failure of arteriovenous fistulas for hemodialysis: A randomized controlled trial. JAMA 2008;299:2164-2171.

21. Hasegawa T, Elder SJ, Bragg-Gresham JL, Pisoni RL, Yamazaki S, Akizawa T, Jadoul M, et al. Consistent aspirin use associated with improved arteriovenous fistula survival among incident hemodialysis patients in the dialysis outcome and practice patterns study. Clin J Am Soc Nephrol 2008;3:1373-1378.

22. Dixon BS, Beck GJ, Vazques MA, Greenberg A, Delmez JA, Allon M, et al. Effect of dipyridamole plus aspirin on hemodialysis graft patency. N Eng J Med 2009;360:21912201.

23. Lemson MS, Leunissen KM, Tordoir JH. Does preoperative duplex examination improve patency rates of BresciaCimino fistulas? Nephrol Dial Transplant 1998;13:13601361.

24. Malovrh M. Non-invasive evaluation of vessels by duplex sonography prior to construction of arteriovenous fistulas for haemodialysis. Nephrol Dial Transplant 1998;13:125-129.

25. Korten E, Toonder IM, Schrama YC, Hop WCJ, van der Ham AC, Wittens CHA. Dialysis fistulae patency and preoperative diameter ultrasound measurements. Eur J Vasc Endovasc Surg 2007;33:467-471.

26. Silva MB Jr, Hobson RW 2nd, Pappas PJ, Jamil Z, Araki CT, Goldberg MC, et.al. A strategy for increasing use of autogenous hemodialysis access procedures: impact of preoperative noninvasive evaluation. J Vasc Surg 1998;27:302307.

27. Lin SL, Chen HS, Huang CH, Yen TS. Predicting the outcome of hemodialysis arteriovenous fistulae using duplex ultrasonography. J Formos Med Assoc 1997;96:864-868.

28. Malovrh M. Native arteriovenous fistula: preoperative evaluation. Am J Kidney Dis 2002;39:125-129.

29. Ku YM, Kim YO, Kim JI, Choi YJ, Yoon SA, Kim YS, et al. Ultrasonographic measurements of intima-media thickness or radial artery in pre-dialysis uraemic patients: comparison with histological examinations. Nephrol Dial Transplant 2006;21:715-720.

30. Turmel-Rodrigues L, Mouton A, Birmele B, Billaux L, Ammar N, Grezand O, et.al. Salvage of immature forearm fistulas for haemodialysis by interventional radiology. Nephrol Dial Transplant 2001;16:2365-2371.

31. Raynaud A, Novelli L, Bourquelot P, Stolba J, Beyssen B, Franco G. Low-flow maturation failure of distal accesses: Treatment by angioplasty of forearm arteries. J Vasc Surg 2009;49:995-999.

32. Lee $T$, Ullah A, Allon M, Succop P, El-Khatib M, Munda R, et al. Decreased cumulative access survival in arteriovenous fistulas requiring interventions to promote maturation. Clin J Am Soc Nephrol 2011;6:575-581.

33. Voormolen EHJ, Jahrome AK, Bartels LW, Moll FL, Mali WP, Blankestijn PJ. Nonmaturation of arm arteriovenous fistulas for hemodialysis access: A systematic review of risk factors and results of early treatment. J Vasc Surg 2009;49:1325-1336.

34. McLaughlin K, Jones B, Mactier R, Porteus C. Long-term vascular access for hemodialysis using silicon dual-lumen catheters with guidewire replacement of catheters for technique salvage. Am J Kidney Dis 1997;29:553-559.

35. McDowell DE, Moss AH, Vasilakis C, Bell R, Pillai L. Percutaneously placed dual-lumen silicone catheters for long-term hemodialysis. Am Surg 1993;59:569-573. 
36. Moss AH, McLaughlin MM, Lempert KD, Holley JL. Use of a silicone catheter with a Dacron cuff for dialysis short-term vascular access. Am J Kidney Dis 1988;12:492-498.

37. Dryden MS, Samson A, Ludlam HA, Wing AJ, Phillips I. Infective complications associated with the use of the Quinton 'Permacath' for long-term central vascular access in haemodialysis. J Hosp Infect 1991;19:257-262.

38. Grote J, Lufft V, Nikutta P, van der Lieth H, Bahlmann J, Daniel WG. Transesophageal echocardiographic assessmant of superior vena cava thrombosis in patients with longterm central venous hemodialysis catheters. Clin Nephrol 1994;42:183-188.

39. Culp K, Taylor L, Hulme PA. Geriatric hemodialysis patients: a comparative study of vascular access. J Am Nephrol Nurses Assoc 1996;23:583-590.

40. Miller A, Holzenbein TJ, Gottlieb MN, Sacks BA, Lavin PT, Goodman WS, et al. Strategies to increase the use of autogenous arteriovenous fistula in end-stage renal disease. Ann Vasc Surg 1997;11:397-405.

41. Gibson KD, Caps MT, Kohler TR, Hatsukami TS, Gillen DL, Aldassy M, et al. Assessment of a policy to reduce placement of prosthetic hemodialysis access. Kidney Int 2001;59:2335-2345.

42. Kherlakian GM, Roedersheimer LR, Arbaugh JJ, Newark KJ, King LR. Comparison of autogenous fistula versus expanded polytetrafluorethylene graft fistula for angioaccess in hemodialysis. Am J Surg 1986;152:238-243.

43. Palder SB, Kirkman RL, Whittemore AD, Hakim RM, Lazarus JM, Tilney NL. Vascular access for hemodialysis. Patency rates and results of revision. Ann Surg 1985;202:235239.

44. Safa AA, Valji K, Roberts AC, Ziegeler TW, Hye RJ, Oglevie SB. Detection and treatment of dysfunctional hemodailysis acess grafts: effect of a surveillance program on graft patency and the incidence of thrombosis. Radiology 1996;199:653-657.

45. Burger H, Zijlstra JJ, Kluchert SA, Scholten AP, Kootstra G. Percutaneous transluminal angioplasty improves longevity in fistulae and shunts for haemodialysis. Nephrol Dial Transplant 1990;5:608-611.

46. Schwab SJ, Raymond JR, Saeed M, Newman DE, Dennis PA, Bollinger RR. Prevention of haemodialysis fistula thrombosis. Early detection of fistula stenoses. Kidney Int 1989; 36:707-711.

47. Turmel-Rodriques L, Pengloan J, Blanchier D, Abaza M, Birmele B, Haillot O, et al. Insufficient dialysis shunts: improved long-term patency rates with close hemodynamic monitoring, repeated percutaneous balloon angioplasty, and stent placement. Radiology 1993;187:273-278.

48. GlanzS, Gordon DH, Butt KMH, Hong J, Lipkowitz GS. The role of percutaneous angioplasty in the management of chronic hemodialysis fistulas. Ann Surg 1987;206:777-781.

49. Casey ET, Murad MH, Rizvi AZ, Sidawy AN, McGrath MM, Elamin MB, et al. Surveillance of arteriovenous hemodialysis access: A sytematic review and meta-analysis. J Vasc Surg 2008;48:48S-54S.

50. Tonelli $\mathrm{M}$, James $\mathrm{M}$, Wiebe $\mathrm{N}$, Jindal $\mathrm{K}$, Hemmelgarn $\mathrm{B}$. Ultrasound monitoring to detect access stenosis in hemodialysis patients: a systematic review. Am J Kidney Dis 2008;51:630-640.

51. Murphy GJ, White SA, Nicholson ML. Vascular access for haemodialysis. Br J Surg 2000;87:1300-1315.

52. Doelman C, Duijm LEM, Liem YS, Tielbeek AV, Donkers-van Rossum AB, Cuypers PW, et al. Stenosis detection in failing hemodialyis access fistulas and grafts: Comparison of color Doppler ultrasonography, contrast-enhanced magnetic resonance angiography, and digital subtraction angiography. J Vasc Surg 2005;42:739-746. 
53. Bay WH, Henry ML, Lazarus JM, Lew NL, Ling J, Lowric EG. Predicting hemodialysis access failure with color flow Doppler ultrasound. Am J Nephrol 1998;18:296-304.

54. Wiese P. Nonnast-Daniel B. Colour Doppler ultrasound in dialysis access. Nephrol Dial Transplant 2004;19:1956-1963.

55. Schwarz C, Mitterbauer C, Boczula M, Macca T, Funovics M, Heinze G, et al. Flow monitoring: performance characteristics of ultrasound dilution versus color Doppler ultrasound compared with fistulography. Am J Kidney Dis 2003;42:539-545.

56. Planken RN, Tordoir JHM, Dammers R, de Haan MW, Oei TK, van de Sande FM, et al. Stenosis detection in forearm hemodialysis arteriovenous fistulae by multiphase contrast-enhanced magnetic resonance angiography: preliminary experience. J Magn Reson Imaging 2003;17:54-64.

57. Froger CL, Duijm LEM, Liem YS, Tielbeek AV, Donkers-van Rossum AB, Douwes-Draaijer $P$, et al. Stenosis detection with MR angiography and digital subtraction angiography in dysfunctional hemodialysis access fistulas and grafts. Radiology 2005;234:284-291.

58. Han KM, Duijm LE, Thelissen GR, Cuypers PW, Douwes-Draaijer P, Tielbeek AV, et al. Failing hemodialysis access grafts: evaluation of complete vascular tree with 3D contrast-enhanced MR angiography with high spatial resolution: initial results in 10 patients. Radiology 2003;227:601-605.

59. Cavagna E, D'Andrea P, Schiavon F, Tarroni G. Failing hemodialysis arteriovenous fistula and percutaneous treatment: imaging with $\mathrm{CT}, \mathrm{MRI}$ and digital subtraction angiography. Cardiovasc Intervent Radiol 2000;23:262-265.

60. Lin YP, Wu MH, Ng YY, Lee RC, Liou JK, Lee RC, Liou JK, Yang WC, et al. Spiral computed tomographic angiography - A new technique for evaluation of vascular access in hemodialysis patients. Am J Nephrol 1998;18:117-122.

61. Wierzbicki P, Zagrodzka M, Prokopiuk M, Kade G, Maruszynski M, Wankowicz Z. Spiral computed tomography in evaluation of arteriovenous fistula for hemodialysis. Preliminary report. Pol Merkuriusz Lek 2002;13:368-372.

62. Ko SF, Huang CC, Ng SH, Lee TY, Hsieh MJ, Lee FY, et al. MDCT angiography for evaluation of the complete vascular tree of hemodialysis fistulas. AJR 2005;185:1268-1274.

63. Heye S, Maleux G, Claes K, Kuypers D, Oyen R. Stenosis detection in native hemodialysis fistulas with MDCT angiography. AJR 2009;192:1079-1084.

64. Wasinrat J, Siriapisith T, Thamtorawat S, Tongdee T. 64-slice MDCT angiography of upper extrimity in assessment of native hemodialysis access. Vasc Endovasc Surg 2011;45:69-77.

65. Rubin GD, Shiau MC, Leung AN, Kee ST, Logan LJ, Sofilos MC. Aorta and iliac arteries: single versus multiple detector row helical CT angiography. Radiodiology 2000;215:670676.

66. Kircher J, Kirkuth R, Laufer U, Noack M, Liermann D. Optimized enhancement in helical CT: experienes with a real-time bolus tracking system in 628 patients. Clin Radiol 2000;55:368-373.

67. Sheiman RG, Raptopoulus V, Caruso P, Vrachliotis T, Pearlman J. Comparison of tailored and empiric scan delays for CT angiography of the abdomen. AJR 1996;167:725-729. 
Summary

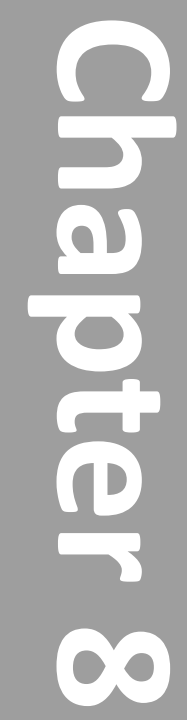


Chapter 8 
In chronic renal disease (CRD) there are structural abnormalities of the kidney resulting in decreased kidney function and leading to end-stage renal disease (ESRD). ESRD patients require renal transplantation or are permanently dependent upon renal replacement therapy (peritoneal dialysis or hemodialysis) in order to avoid life threatening uremia. In hemodialysis waste products from the patients blood are removed by an artificial kidney. Blood will be withdrawn from the body through an arterial tube and transferred to the dialysis apparatus and afterwards returned to the body through a venous tube. Therefore a well functioning vascular access is necessary for successful hemodialysis treatment.

Current guidelines recommend the use of the autogenous radial-cephalic arteriovenous fistula (RCAVF) as first choice hemodialysis access because of a low complication incidence and favourable patency rates. However in case of tiny or diseased bloodvessels, the risk on access failure is high and an alternative vascular access may be considered.

To improve the precision of the estimates of primary failure rates and primary and secondary one year patencies of RCAVF a meta-analysis was performed in chapter 2. A medline search was performed of the English language medical literature. This electronic database search was supplemented by manual search of bibliographic reference lists in review articles and original articles. This meta-analysis showed a high pooled estimated primary failure rate of $15.3 \%$ and moderate pooled estimated primary and secondary patency rates of $62.5 \%$ and $66.0 \%$ respectively at 1 year of follow up.

Although RCAVFs are the primary and best option for hemodialysis vascular access, 10 to $24 \%$ of the RCAVFs fail directly due to thrombosis and non-maturation. In chapter 3 the failure modes of RCAVFs and the impact of treatment on fistula outcome was investigated in 43 patients. Thrombosis and non-maturation occurred in respectively $14(33 \%)$ and $3(7 \%)$ patients. Twelve interventions ( 6 by percutaneous transluminal angioplasty (PTA) and 6 by surgical revision) were needed, resulting in salvage of 8 RCAVFs (47\%). All patients had a complete duplex follow up to 42 days. In non-maturating RCAVFs the mean radial artery flow remained significantly lower compared to the functioning RCAVFs at 1, 7 and 42 days (440 vs $754 \mathrm{cc} / \mathrm{min}, 524$ vs $799 \mathrm{cc} / \mathrm{min}$ and $532 \mathrm{vs} 946 \mathrm{cc} / \mathrm{min}$ ). A total of 34 RCAVFs (79\%) became functional for hemodialysis access. Therefore, an aggressive interventional approach towards nonfunctional RCAVFs is worthwhile and leads to a considerable salvage rate. 
In chapter 4 the results are described of a randomized multicenter study comparing RCAVF with prosthetic (PTFE) graft implantation in patients with poor vessels. A total of 383 patients needing primary vascular access for hemodialysis entered this study. According to defined vessel criteria from preoperative duplex scanning, 140 patients were allocated to primary creation of a RCAVF and 61 patients to primary prosthetic graft implantation. The remaining 182 patients were randomized to receive either a RCAVF (92) or forearm prosthetic graft implant (90). Follow-up was performed during a period of 12 months. Fifty-nine percent of the RCAVFs were functional for dialysis treatment after 6 weeks, resulting in a primary failure rate of $41 \%$. However, 98\% of prosthetic graft AVFs were functional for dialysis treatment after 6 weeks, resulting in a primary failure rate of $2 \%$. Patency was defined as functional patency with adequate dialysis. Primary and assisted-primary one-year patencies were $33 \%$ $( \pm 5.3 \%)$ vs $44 \%( \pm 6.2 \%)(P=.03)$ and $48 \%( \pm 5.5 \%)$ vs $63 \%( \pm 5.9 \%)(P=.035)$ for RCAVF and prosthetic AVF, respectively. Secondary patencies were $52 \%( \pm 5.5 \%)$ vs $79 \%( \pm 5.1 \%)(P=.0001)$ for RCAVF and prosthetic AVF, respectively. Patients with prosthetic AVFs developed more complications than patients with RCAVFs (1.45/py vs $1.19 /$ py). Also more interventions were needed for access salvage in the patients with prosthetic graft implants than in patients with RCAVFs (0.94/py vs $0.50 /$ py). However, taking the patency rates into account, patients with poor forearm vessels do benefit from implantation of a prosthetic graft for vascular access.

In a review in chapter $\mathbf{5}$, the current imaging modalities for stenosis detection in hemodialysis vascular access are discussed. Due to the facts that duplex ultrasonography (DUS) is readily available, inexpensive, noninvasive, and has no radiation exposure, it is suggested as the initial imaging modality of stenosis detection in hemodialysis vascular access. However, digital subtraction angiography (DSA) can depict the complete vascular access to detect all significant stenoses, which can be treated in the same session. When DSA is inconclusive or in complex vascular accesses, magnetic resonance angiography (MRA) or multi-slice computed tomographic angiography (MS-CTA) can be performed. Both relatively new imaging modalities are useful, safe and practical.

In chapter 6 the results are shown of a prospective study in which the accuracy of MS-CTA for the detection and grading of stenoses in AVF for hemodialysis was assessed. DSA was used as the gold standard of reference. Dysfunctioning forearm AVFs were evaluated by both DSA and MS-CTA and were read in a prospective, blinded manner by two radiologists experienced in vascular imaging. MS-CTA is a minimally invasive procedure that can significantly influence patient care by avoiding potential complications. Although MS-CTA has a moderate sensitivity (82\% for 
stenoses $\geq 50 \%$ ), it has a high specificity ( $98 \%$ for stenoses $\geq 50 \%$ ) for the detection of flow-limiting stenoses in vascular accesses. Therefore MS-CTA can provide good visualization of stenoses in forearm hemodialysis access AVFs.

In Chapter 7, the general discussion, the results of this thesis are discussed and placed in a broader context. Also the most important conclusions of this thesis are mentioned. Finally, a recommendation is made for, future, large randomized multicenter trials to compare fistulas and grafts in various subsets of CRD patients. 

Nederlandse samenvatting

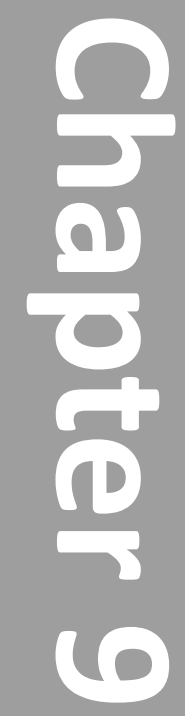


Chapter 9 
Bij chronisch nierinsufficiëntie zijn er afwijkingen in de nier, welke leiden tot verminderde nierfunctie en uiteindelijk tot eindstadium nierfalen. Patiënten met eindstadium nierfalen moeten een niertransplantatie ondergaan of zijn permanent afhankelijk van nierfunctie-vervangende therapie zoals peritoneaal dialyse (buikspoeling) of hemodialyse, dit om een levensbedreigende uremie te voorkomen. Bij hemodialyse worden afvalstoffen uit het bloed van de patiënt verwijderd door een kunstnier. Bloed wordt uit het lichaam van de patiënt gehaald via een slang aangesloten op een bloedvat en getransporteerd naar het dialyse apparaat en vervolgens weer teruggepompt naar het lichaam via een tweede slang. Een goed functionerende vaattoegang is daarom noodzakelijk voor een succesvolle hemodialyse behandeling. Een vaattoegang kan worden gecreëerd door een verbinding te maken tussen een slagader en een ader, ook wel een arterioveneuze fistel (AVF) genaamd.

Huidige richtlijnen adviseren het gebruik van de pols radio-cephale arterioveneuze fistel (RCAVF) als eerste optie voor een hemodialyse toegang, omdat deze weinig complicaties geeft en een goede levensduur heeft. Hierbij wordt ter plaatse van de pols een ader aan een slagader gehecht, zodat deze ader na de operatie gaat verwijden en zo goed aanprikbaar wordt voor dialyse. Echter als de patiënt kleine vaten of vaten van slechte kwaliteit heeft, neemt het risico op mislukken van de fistel toe en zal een alternatieve vaattoegang overwogen moeten worden. Als alternatief kan een kunststof bloedvat onderhuids ingehecht worden tussen een slagader en een ader, ook wel een arterioveneuze graft (AVG) genaamd.

Om een nauwkeurige schatting te maken van het vroeg falen percentage en de primaire en secundaire levensduur na 1 jaar van de RCAVF, hebben we een metaanalyse verricht in hoofdstuk 2. Een Medline zoekactie is verricht van de in het Engels geschreven medische literatuur. Deze elektronische database zoekactie werd aangevuld met handmatig doorzoeken van referentielijsten van review artikelen en originele artikelen. Deze meta-analyse liet een hoge schatting zien van het primair falen van 15,3\% en een lage schatting van de primaire en secundaire levensduur na 1 jaar van respectievelijk $62,5 \%$ en $66 \%$.

Ondanks dat de RCAVF de eerste en beste optie is voor een hemodialyse vaattoegang, faalt 10 tot $24 \%$ als gevolg van trombose of het niet rijpen (uitzetten van de bloedvaten) van de AVF. In hoofdstuk 3 worden de oorzaken van het falen van de RCAVF onderzocht en wordt er gekeken naar de resultaten van behandeling bij 43 patiënten. Trombose en het niet rijpen van de fistel kwam in respectievelijk 14 (33\%) en 3 (7\%) patiënten voor. Twaalf ingrepen ( 6 dotter en 6 chirurgische behandelingen) waren 
nodig om uiteindelijk nog 8 RCAVF "te redden" (47\%). Alle patiënten ondergingen een complete follow-up met ultrageluidonderzoek. In niet ontwikkelende RCAVFs bleef de gemiddelde bloedvolumestroom van de pols slagader op dag 1, 7 en 42, significant lager vergeleken met de goed ontwikkelde RCAVFs (440 vs $754 \mathrm{ml} / \mathrm{min}$, $524 \mathrm{vs} 799 \mathrm{ml} / \mathrm{min}$ en 532 vs $946 \mathrm{ml} / \mathrm{min}$ ). Totaal gingen er 34 RCAVFs (79\%) goed functioneren als dialyse vaattoegang. Daarom is een agressieve benadering middels een behandeling voor niet functionerende RCAVFs nuttig, want dit leidt tot een aanzienlijke toename van goed functionerende RCAVFs.

In hoofdstuk 4 worden de resultaten beschreven van een gerandomiseerde multicenter studie, waarbij de RCAVF wordt vergeleken met de kunststof AVG in de onderarm bij patiënten met slechte vaten. Een totaal van 383 patiënten, die voor de eerste keer een vaattoegang voor dialyse moesten krijgen, deden mee aan deze studie. Volgens de vooraf bepaalde preoperatieve ultrageluid criteria, kregen 140 patiënten primair een RCAVF, en 61 patiënten kregen primair een kunststof AVG in de onderarm. De overige 182 patiënten werden gerandomiseerd, waarbij 92 patiënten een RCAVF en 90 patiënten een kunststof AVG kregen in de onderarm. De patiënten werden 12 maanden gevolgd. Negenenvijftig procent van de RCAVFs was functioneel voor dialyse na 6 weken, resulterend in een primair faalkans van 41\%. Echter $98 \%$ van de kunststof AVG was functioneel voor dialyse na 6 weken, resulterend in een primair faalkans van $2 \%$.

De levensduur (patency) van de dialyse toegang is gedefinieerd als functionele levensduur met de mogelijkheid tot adequate dialyse. De primaire levensduur zegt iets over het interval tussen het aanleggen van de toegang en de eerste ingreep of het uiteindelijk falen van de toegang. De geassisteerde-primaire levensduur zegt iets over het interval tussen aanleggen van de toegang en uiteindelijk falen van de toegang, inclusief behandelingen om de vaattoegang open te houden. Secundaire levensduur zegt iets over het interval tussen aanleggen en uiteindelijk falen van de toegang, inclusief ingrepen voor de behandeling van trombose of vernauwingen.

De primaire en geassisteerde-primaire levensduur na 1 jaar waren voor RCAVF en kunststof AVG respectievelijk 33\% ( $\pm 5.3 \%)$ vs $44 \%$ ( $\pm 6.2 \%)(P=.03)$ en $48 \%( \pm 5.5 \%)$ vs $63 \%( \pm 5.9 \%)(P=.035)$. De secundaire levensduur was voor RCAVF en kunststof AVG respectievelijk 52\% ( $\pm 5.5 \%)$ vs $79 \%$ ( $\pm 5.1 \%)(P=.0001)$. Patiënten met kunststof AVG hadden meer complicaties dan patiënten met RCAVFs (1.45 complicaties per patiënt per jaar vs 1.19 complicaties per patiënt per jaar). Ook waren er meer interventies nodig om de toegang functioneel te houden bij patiënten met een kunststof AVG dan bij patiënten met een RCAVF (0.94 interventies per patiënt per 
jaar vs 0.50 interventies per patiënt per jaar). Echter als men naar de levensduur kijkt, dan zouden patiënten met slechte vaten voordeel hebben bij het plaatsen van een kunststof AVG als vaattoegang voor dialyse.

In een overzicht in hoofdstuk 5 worden de huidige afbeeldingtechnieken voor de opsporing van vernauwingen in dialyse vaattoegangen besproken. Gezien het feit dat ultrageluidonderzoek snel voor handen is, goedkoop is, niet invasief is en geen bloodstelling aan straling geeft, is dit de voorkeurs afbeeldingtechniek voor de opsporing van vernauwingen in dialyse vaattoegangen. Echter digitale subtractie angiografie (DSA) (= vaatfoto met contrastinspuiting) kan de gehele vaattoegang afbeelden voor de opsporing van een significante vernauwing, welke dan in dezelfde sessie, eventueel met dotteren, kan worden behandeld. Wanneer DSA inconclusief is of wanneer er sprake is van een complexe vaattoegang, dan kan er een magnetische resonantie angiografie (MRA) of een computer tomografische angiografie (CTA) worden gemaakt. Beide relatief nieuwe afbeeldingstechnieken zijn bruikbaar, veilig en praktisch.

In hoofdstuk 6 worden de resultaten van een prospectieve studie naar de nauwkeurigheid van de CTA voor de opsporing en gradering van vernauwingen in vaattoegangen voor dialyse gepresenteerd. DSA werd gebruikt als de gouden standaard. Niet goed functionerende dialyse vaattoegangen werden onderzocht met zowel DSA als CTA, en werden prospectief en geblindeerd beoordeeld door twee ervaren radiologen op vasculair gebied. CTA is een minimaal invasief onderzoek, waardoor potentiële complicaties kunnen worden voorkomen. Ondanks dat CTA een matige sensitiviteit heeft ( $82 \%$ voor vernauwingen $\geq 50 \%$ ), heeft CTA wel een hoge specificiteit ( $98 \%$ voor vernauwingen $\geq 50 \%$ ) voor de opsporing van vernauwingen in vaattoegangen voor dialyse. Daarom kan worden geconcludeerd dat CTA goede visualisatie kan geven van vernauwingen in onderarm dialyse vaattoegangen.

In hoofdstuk 7, worden de resultaten van dit proefschrift besproken en in een bredere context geplaatst. Ook worden de belangrijkste conclusies van dit proefschrift genoemd. Als laatste wordt er een aanbeveling gedaan om in de toekomst grote gerandomiseerde multicenter onderzoeken te verrichten waarbij AVFs en AVGs worden vergeleken in verschillende groepen patiënten met chronische nierinsufficiëntie. 



\section{Dankwoord}

\section{Curriculum vitae}

List of publications

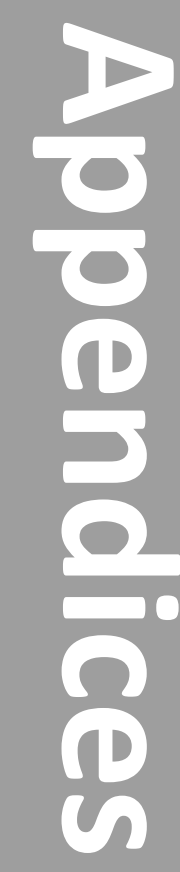


Appendices 


\section{Dankwoord}

Het is zover; mijn proefschrift is klaar!

Veel mensen hebben bijgedragen aan de totstandkoming van dit proefschrift. Zonder iemand te kort te doen, zijn er een aantal mensen die ik persoonlijk wil bedanken.

Prof. dr. P.J.E.H.M. Kitslaar, promotor, beste professor, hartelijk dank voor uw geduld maar vooral ook voor uw kritische en opbouwende commentaar, met name in de eind fase, welke hebben geresulteerd in het afronden van dit proefschrift.

Dr. J.H.M. Toirdoir, co-promotor, beste Jan, zonder jou onvermoeibare hulp en aanmoediging was mijn proefschrift nooit geworden zoals het nu is. Elk manuscript, ongeacht de hoeveelste versie, werd telkens weer met zeer veel bruikbaar commentaar voorzien. Mijn respect is groot voor jouw tomeloze energie en passie voor het onderzoek naar vaattoegangen voor hemodialyse.

Dr. T.I. Yo, co-promotor, u hebt mij, nadat ik mijn coschap chirurgie in het voormalige Clara Ziekenhuis had gelopen, aangenomen als AGNIO en zo raakte ik ook betrokken bij de COP-trial. Later besloot $u$, nadat Ine stopte met de COP-trial, dat ik het onderzoek mocht doen. Hartelijk dank voor uw begeleiding en aanmoedigingen al die jaren. Uitspraken als "de finish is in zicht" en "alleen nog een kaftje erom en een nietje erin" werkte zeer stimuleerd om het proefschrift te voltooien.

Ine Burgmans. Jij hebt de COP-trial goed op poten gezet. Door drukte besloot jij om de COP-trial aan mij over te dragen, daarom heb ik ook een deel van dit proefschrift aan jou te danken.

Leden van de beoordelingscommissie, Prof. dr. M.W. de Haan, Prof. dr. M. Post, Dr. F.M. van der Sande, Dr. A.A.E.A. de Smet, beste André, hartelijk dank voor de snelle en kundige beoordeling.

Leden van de promotiecommissie, Prof. dr. R.R.W.J. van der Hulst, Prof. dr. M. van Kleef, Dr. M.M. van Loon, hartelijk dank voor uw deelname. 
Deze studie was nooit tot stand gekomen zonder de medewerking van patiënten. Immers zonder patiënten geen klinisch onderzoek! Daarom hartelijk dank aan alle patiënten die mee hebben gedaan aan de COP-trial.

De overige deelnemende vaatchirurgen, Dr. W.M. Fritschy, Dr. H.G.W. de Groot en Dr. H. Burger. Hartelijk dank voor in het includeren van de vele patiënten. Het heeft een geweldige hoeveelheid data opgeleverd.

Dr. D. Vroegindeweij en G.P. Serafino, beste Gian Piero, hartelijk dank voor jullie zeer waardevolle bijdrage aan het radiologische deel van dit proefschrift.

Dr. W.C.J. Hop en Prof. dr. T. Stijnen, veel dank voor de hulp en de uitleg van de soms voor mij zeer moeilijk te begrijpen statistiek.

Van zeer groot belang voor het slagen van deze studie waren de medewerkers van de verschillende dialyse afdelingen, vaatlaboratoria en chirurgische poli's van het huidige Maasstad Ziekenhuis in Rotterdam, het azM in Maastricht, Isala Klinieken in Zwolle en Albert Schweitzer Ziekenhuis in Dordrecht. Van al deze medewerkers ben ik in het bijzonder veel dank verschuldigd aan Hanneke, Jane, Marga en Louise uit het Maasstad Ziekenhuis. Veel dank voor het verrichten van alle metingen en verzamelen van de enorme berg gegevens!

Collega onderzoekers, Xavier Keuter, Nils Planken, Ruben Dammers, veel dank voor de gezelligheid bij de congressen die we samen hebben bezocht en voor de ondersteuning bij dit onderzoek.

Maatschap Chirurgie van het voormalige Clara Ziekenhuis, en later Maasstad Ziekenhuis, heel veel dank voor de geweldige chirurgische vooropleiding. Jullie hebben mijn een zeer waardevolle basis gegeven, waarvan ik nu nog elke dag profijt heb!

Stafleden Plastische Chirurgie VUmc, dank voor de plastisch chirurgische vervolgopleiding, en de ruimte die ik kreeg om aan dit proefschrift te werken.

Collega assistenten Chirurgie en later Plastische Chirurgie, dank voor de collegialiteit tijdens onze opleiding en voor de gezelligheid tijdens wintersportreisjes en feestjes. 
Mijn maten, Hans-Peter Zweep en Arjen van Turnhout, beste H-P, beste Arjen, sinds kort vormen wij een team, echter voelt het of we al jaren samenwerken. Ik dank jullie daarvoor en hoop dat we samen een mooie toekomst tegemoet gaan.

Nellie, Annette, Elles, Nathalie en Marion, zonder polimedewerksters en secetaresse geen afdeling plastische chirurgie. Hartelijk dank voor jullie medewerking en ondersteuning.

Mijn paranimfen, Elian Uitterlinden en Sander Beekmans. Beste Elian, vanaf dag één zaten wij samen in de collegebanken in Rotterdam, en daar ontstond ook direct onze vriendschap. We hebben samen veel gevierd, met als hoogte punten jou promotie enkele jaren geleden en nu mijn promotie. Dank dat je er ook nu weer bij bent om me tijdens de promotie bij te staan. Beste Beekie, toen ik naar de plastisch chirurgie in het VUmc in Amsterdam ging, werd jij mijn collega en hebben wij samen onze opleiding doorlopen. Ons motto toen was, en nog steeds is "een dag niet gelachen is een dag niet geleefd". Hartelijk dank dat je me tijdens mijn promotie als paranimf bij wil staan.

Mijn schoonfamilie, Ria, Monique, Ivor, Myrthe en Fenne. Dank voor jullie interesse en gezelligheid. Jammer dat Michel dit niet meer mee kan maken, hij zal zeker trots zijn geweest.

Mijn broertje, schoonzus en kindereren. Lieve Chris, Sharon, Nina en Stan, bedankt voor jullie belangstelling en ondersteuning.

Lieve Pa en $\mathrm{Ma}$, na een jeugd zonder zorgen, hebben jullie mij altijd ondersteund op welk gebied dan ook. Eerst in de triathlon; geen wedstrijd was te ver, jullie gingen altijd mee. Later in mijn studie, niets was teveel jullie stonden altijd voor me klaar. Pa van $u$ heb ik geleerd om altijd een stap extra te zetten en altijd iets te hebben om naar te streven. Ook van het technisch inzicht wat u mij heeft bijgebracht tijdens het samen klussen, heb ik nog elke dag profijt. Ma van jou heb ik geleerd altijd opgeruimd te zijn en wat je doet ook goed te doen. Jullie hebben er voor gezorgd dat ik zover ben gekomen. 
Lieve Marieke, jij bent mijn allessie! Ook in sombere tijden bleef jij altijd de spil van ons gezin, en gaf jij mij alle ruimte om dit proefschrift af te ronden. Daar ben ik je ongelooflijk dankbaar voor. Je bent een fantastische vrouw en ik heb ontzettend veel zin in de toekomst met jou!

Lieve Pepijn, Pieter en Fientje. Het is niet in woorden uit te drukken hoeveel ik van jullie hou en hoe trots ik op jullie ben. Daar kan geen proefschrift tegen op. 


\section{Curriculum vitae}

Patrick Petrus Gijsbertus Maria Rooijens was born May 27, 1975 in Goirle in The Netherlands. He attended Rijksscholengemeenschap "Koning Willem II" in Tilburg, where he graduated from in 1994. Immediately thereafter he studied medicine at the Erasmus University in Rotterdam. After receiving his medical degree in 2000, he became a research assistant at the Department of Anatomy of the Erasmus University Rotterdam. During this period he collaborated, under supervision of Dr. G.J. Kleinrensink, with the Department of General Surgery (Prof. dr. H.W. Tilanus) to study the vascularization of the gastric tube. Thereafter, he worked for two years as a surgical resident in Medical Center Rijnmond-Zuid in Rotterdam (Prof. dr. J.F. Lange). During his clinical work he became involved with the research described in this thesis under supervision of dr. T.I. Yo and dr. J.H.M. Tordoir. In this same hospital he started in 2002 his surgical training. In 2004 he went to the Department of Plastic, Reconstructive and Hand Surgery at the VU medical center in Amsterdam (Prof. dr. M.J.P.F. Ritt) to perform his training in plastic surgery. In this period he was treasurer of JVPC (the association of residents in plastic surgery).

After he successfully finished his residency in 2008, he founded the Department of Plastic, Reconstructive and Hand Surgery in the hospitals MC Zuiderzee in Lelystad and MC Emmeloord. Since April 2012 he is working at the Department of Plastic, Reconstructive and Hand Surgery in Tergooiziekenhuizen in Hilversum. Patrick is living together with Marieke and has two sons, Pepijn and Pieter, and a little daughter Fientje. 
Appendices 


\section{List of publications}

Learning effect in isokinetic testing of ankle invertors and evertors. E.H.R. van Cingel, G.J. Kleinrensink, P.P.G.M. Rooijens, E.J. Uitterlinden, G. Aufdemkampe, R.Stoeckart. Isokinetics and Exercise Science 2001;9:171-177.

The preperitoneal tissue-dilemma in totally extraperitoneal (TEP) laparoscopic hernia repair: an anatomo-surgical study. J.F. Lange. P.P.G.M. Rooijens, S. Koppert, G.J. Kleinrensink. Surgical Endoscopy 2002; 16:927-930.

Prospective evalution of failure modes in autogenous radialcephalic wrist access for hemodialysis. J.H.M. Tordoir, P.P.G.M. Rooijens, R. Damers, F.M. van der Sande, M.W. de Haan, T.I. Yo. Nephrol Dial Transplant 2003;18:378-383.

The significance of angiogenesis in malignant phaeochromocytomas. P.P.G.M. Rooijens, R.R. de Krijger, H.J. Bonjer, F. van der Ham, A.L. Nigg, H.A. Bruining, S.W.J. Lamberts, E. van der Harst. Endocrine Pathology, 2004;15:39-45.

Radiocephalic wrist arteriovenous fistula for hemodialysis: meta-analysis indicates a high primary failure rate. P.P.G.M. Rooijens, J.H.M. Tordoir, T. Stijnen, J.P.J. Burgmans, A.A.E.A. Smet de, T.I. Yo. Eur J Vasc Endovasc Surg, 2004;28:583-589.

Autogenous radial-cephalic or prosthetic brachial-antecubital forearm loop AVF in patients with compromised vessels? A randomized multicenter study of the patency of primary hemodialysis access. P.P.G.M. Rooijens, J.P.J. Burgmans, T.I. Yo, W.C.J. Hop, A.E.A.A. Smet de, M.A. Dorpel van de, W.M. Fritschy, H.G.W. Groot de, H. Burger, J.H.M. Tordoir. J Vasc Surg, 2005; 42:481-487.

Repeated ankle sprains and delayed neuromuscular response: Acceleration time parameters. E.H.R. van Cingel G.J. Kleinrensink, E.J. Uitterlinden, P.P.G.M. Rooijens, P.G.H. Mulder, G. Aufdemkampe, R. Stoeckart. J Orthop Sports Phys Ther 2006; 2:7279.

Combined use of ultrasonic-assisted liposuction and limited incision platysmaplasty for treatment of the aging neck. P.P.G.M. Rooijens, H.-P. Zweep, W.H. Beekman. Aesthetic Plastic Surgery, 2008; 32:790-794. 
Multi-slice computed tomographic angiography for stenosis detection in forearm hemodialysis arteriovenous fistulas. P.P.G.M. Rooijens, G.P. Serafino, D. Vroegindeweij, R. Dammers, T.I.Yo, A.A.E.A. de Smet, J.H.M. Tordoir. J Vasc Access 2008;9:278-284.

Vascular anatomy of the stomach related to gastric tube construction. M. Buunen, P.P.G.M. Rooijens, H.J. Smaal, G.J. Kleinrensink, E. van der Harst, H.W. Tilanus, J.F. Lange. Dis Esophagus 2008;21:272-274. 